University of Louisville

ThinkIR: The University of Louisville's Institutional Repository

Electronic Theses and Dissertations

$12-2007$

\title{
Effects of direct ATP delivery to ischemic skeletal muscle.
}

Federico V. Grossi 1974-

University of Louisville

Follow this and additional works at: https://ir.library.louisville.edu/etd

\section{Recommended Citation}

Grossi, Federico V. 1974-, "Effects of direct ATP delivery to ischemic skeletal muscle." (2007). Electronic Theses and Dissertations. Paper 539.

https://doi.org/10.18297/etd/539

This Doctoral Dissertation is brought to you for free and open access by ThinkIR: The University of Louisville's Institutional Repository. It has been accepted for inclusion in Electronic Theses and Dissertations by an authorized administrator of ThinkIR: The University of Louisville's Institutional Repository. This title appears here courtesy of the author, who has retained all other copyrights. For more information, please contact thinkir@louisville.edu. 


\title{
EFFECTS OF DIRECT ATP DELIVERY TO ISCHEMIC SKELETAL MUSCLE
}

By

Federico V Grossi, M.D.

Universidad Nacional de Córdoba

at Córdoba, Argentina, 2000

\author{
A Dissertation \\ Submitted to the Faculty of the \\ Graduate School of the University of Louisville
}

Department of Physiology and Biophysics

University of Louisville

Louisville, Kentucky

December 2007 


\title{
EFFECTS OF DIRECT ATP DELIVERY TO ISCHEMIC SKELETAL MUSCLE
}

\author{
By \\ Federico V. Grossi, M.D. \\ Universidad Nacional de Córdoba \\ at Córdoba, Argentina, 2000
}

A Dissertation Approved on

October 3, 2007

By the Following Dissertation Committee

Dissertation Director 


\section{ABSTRACT}

\section{EFFECTS OF DIRECT ATP DELIVERY TO ISCHEMIC SKELETAL MUSCLE}

\section{Frederico V. Grossi}

\section{October 3, 2007}

The purpose of this dissertation was to demonstrate that a new method of direct intracellular energy delivery was effective in maintaining viability of in vitro Human Umbilical Vein Endothelial Cells (HUVECs) when exposed to chemical ischemia for prolonged periods of time and in preventing in vivo ischemia reperfusion injury in a composite tissue transplantation model. Ischemia and reperfusion injury is a well recognized phenomenon that occurs in situations like organ transplantation, shock, cardiac surgery, etc, where tissues are temporarily deprived of nutrients and oxygen for energy production. When exposed to short periods of ischemia, cells utilize their stored energy to survive. If ischemia is extended beyond certain limits, cellular energy stores become depleted leading to metabolic and structural changes. One of the effects of this lack of energy is the malfunctioning of the membrane adenosine triphosphate (ATP)-dependent ionic pumps which are ultimately responsible for maintaining cellular volume, intracellular $\mathrm{pH}$ and ionic homeostasis. Thus it is hypotesized that the negative effects of energy depletion on cellular homeostasis could be overcome by delivering energy directly into the cell. 
This method of direct energy delivery into cells is based on fusogenic lipid vesicles (FLVs) composed of lipids very similar to those that form the cellular membrane. These vesicles are very small and when put in contact with cell membranes, rapidly fuse to the cell membrane delivering their content into the cell interior. Making use of this phenomenon, the vesicles are loaded with ATP magnesium chloride (Mg-ATP) that is delivered directly into the cell, providing it with a readily usable form of energy. We hypothesized that, under chemical hypoxia, endothelial cell viability could be preserved and the $\mathrm{Na}+\mathrm{K}+-\mathrm{ATPase}$ pump activity could be maintained by delivering Mg-ATP directly into the cells. Further, we hypothesized that ischemia reperfusion injury due to tissue transplantation could be reduced by perfusing tissues ex vivo before reimplantation with a solution containing Mg-ATP-loaded FLVs.

The first two hypotheses were tested in the following manner. First, we determined the optimal concentration of Mg-ATP that the FLVs needed to be loaded with to maintain the viability of HUVECs exposed to 4 hours of chemical hypoxia. Second, we tested if the $\mathrm{Na}+\mathrm{K}+$ ATPase pump activity could be maintained by delivering Mg-ATP to HUVECs exposed to chemical hypoxia. The results of these experiments demonstrated that direct delivery of Mg-ATP using FLVs was effective in maintaining cell viability and $\mathrm{Na}+\mathrm{K}+\mathrm{ATPase}$ pump activity in cells exposed to chemical hypoxia.

The third hypothesis was tested using a rat hind limb transplantation model. Hind limbs were harvested and perfused ex vivo with a preservation solution containing Mg-ATP-loaded FLVs. After 13 or 21 hours of ischemia limbs, were 
transplanted to the recipient. Limbs perfused with the Mg-ATP FLV solution had a greater survival rate than limbs perfused with control solutions.

The application of this method of direct cellular energy delivery could have great implications in clinical situations where tissues are exposed to long periods of ischemia such as transplants or limb amputations. Further investigation is needed to optimize this preservation solution to allow its use as routine therapy is these situations. 


\section{DEDICATION}

To my parents, Jorge Pedro and Carmen, for their encouragement, support and unconditional love.

To Maria Jose, the love of my life, and her children Camila and Lucas for letting me be part of their life, for their love and support and for their patience during the preparation of this dissertation. 


\section{TABLE OF CONTENTS}

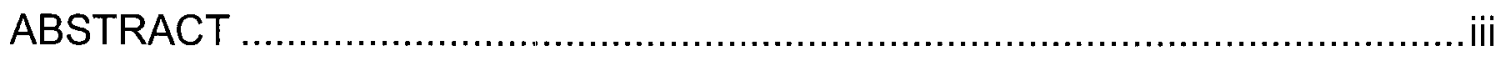

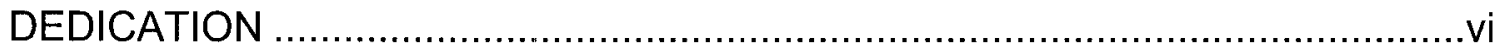

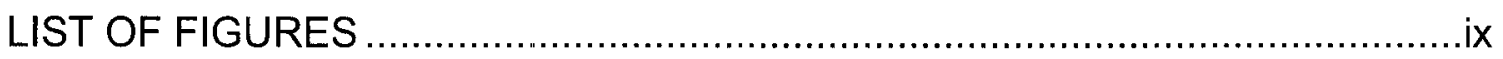

LIST OF TABLES

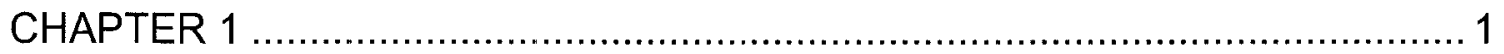

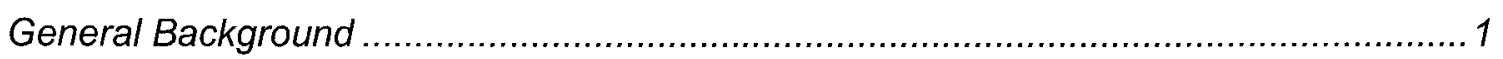

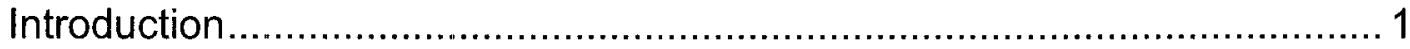

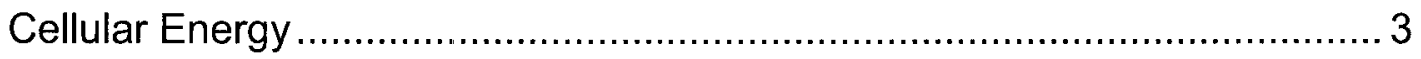

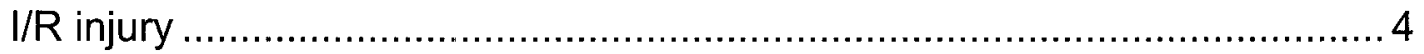

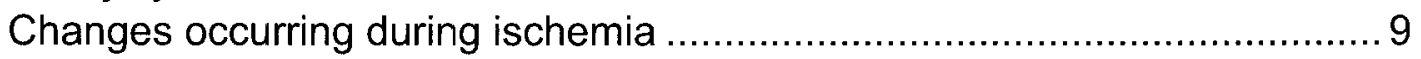

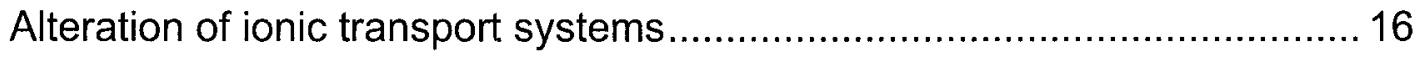

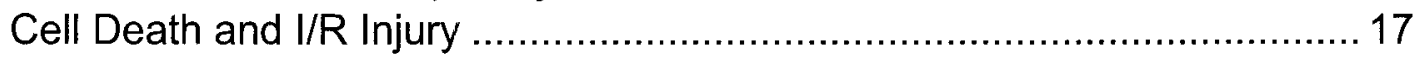

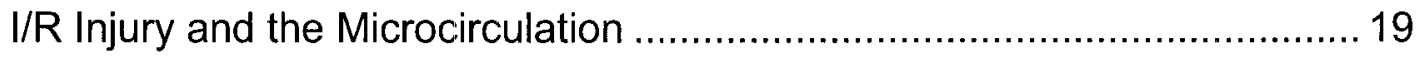

Pathophysiology of I/R injury in Skeletal Muscle .................................... 23

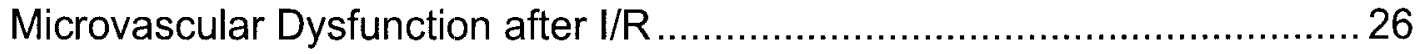

Exogenous ATP as an Energy Source .................................................... 28

Multilammellar Vesicles (Liposomes) as Drug Delivery Vehicles ................ 29

Small Fusogenic Lipid Vesicles (FLVs) as Drug Delivery Vehicles ............. 34

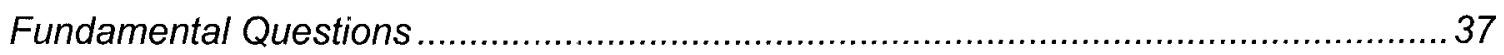

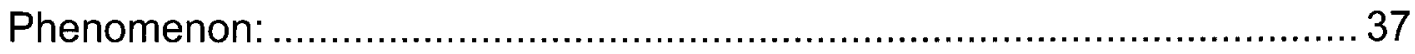

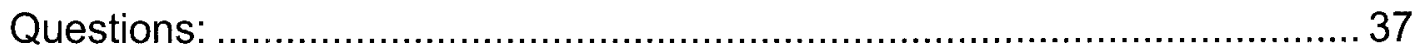

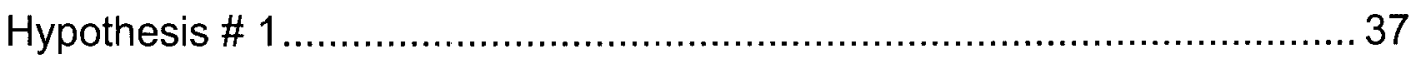

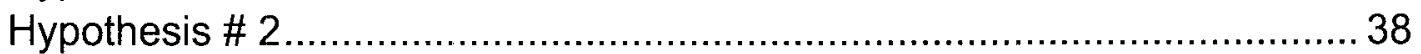

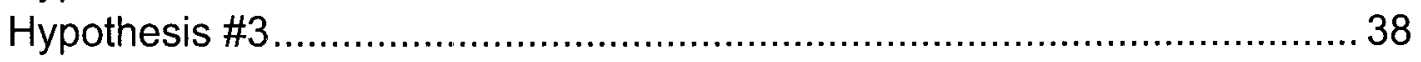

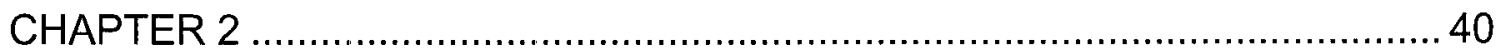

Delivery of Exogenous Mg-ATP preserves $\mathrm{Na}^{+}, \mathrm{K}^{+}$-ATPase Pump Function During

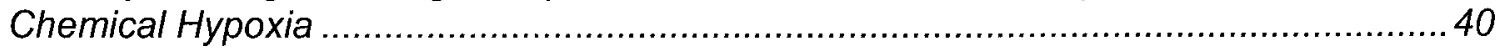

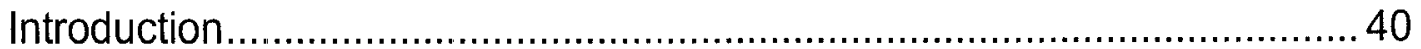

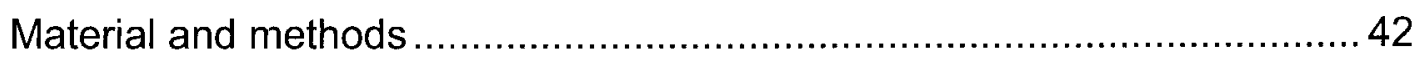

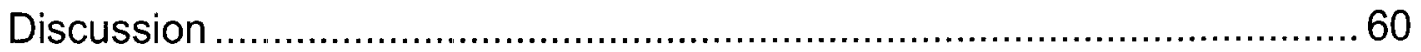


CHAPTER 3

Preservation of skeletal muscle at room temperature using a direct intracellular Mg-ATP

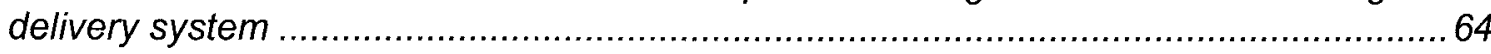

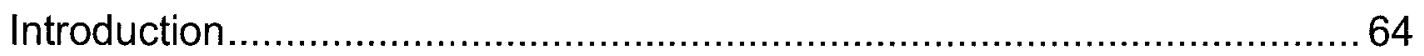

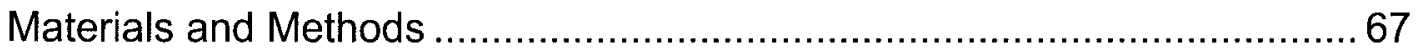

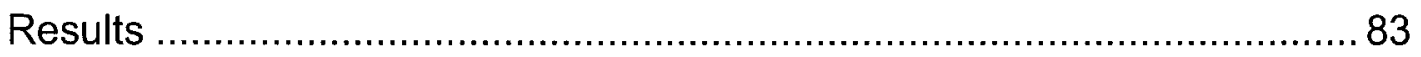

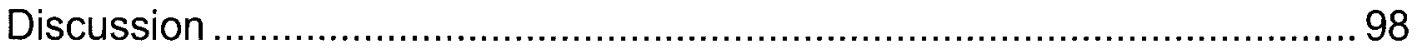

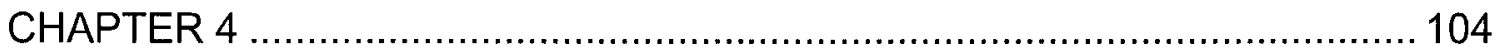

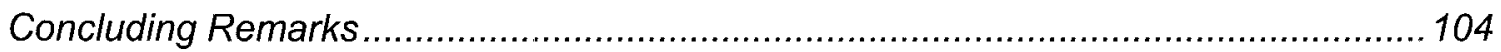

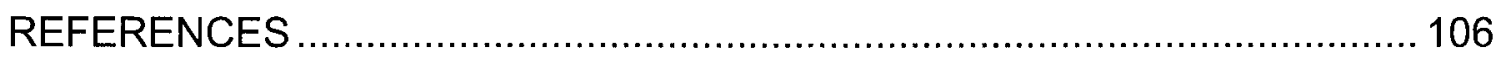

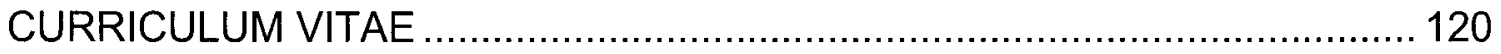




\section{LIST OF FIGURES}

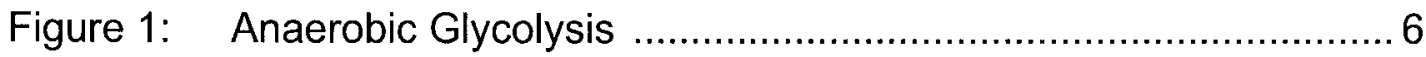

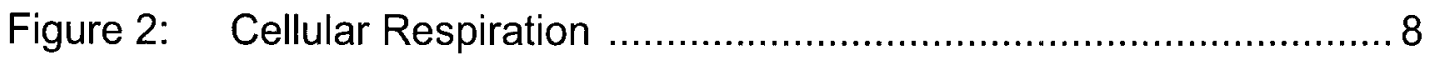

Figure 3: The sequence of events occurring during ischemia and reperfusion

Figure 4: ATP turnover of cells as a function of time exposure to anoxia or hypothermia

Figure 5: Apoptotic and necrotic pathways after oxidative stress of mitochondria

Figure 6: Sources and fate of superoxide radicals ................................ 25

Figure 7: Liposomes interact with cells .............................................. 32

Figure 8: Different types of lipid vesicles .............................................. 36

Figure 9: Percent viability of HUVECs in response to increasing doses of KCN for 4 hours

Figure 10: Percent viability of HUVECs after 4 hours of KCN treatment ...... 55

Figure 11: Percent viability of HUVECs incubated with Krebs, free MgATP, vesicles only and Mg-ATP-vesicles and subjected to 4 hours of $\mathrm{KCN}$ treatment

Figure 12: Results of $86 \mathrm{Rb}$ uptake experiments in HUVECs incubated in Krebs, free Mg-ATP and Mg-ATP-vesicles (10mM) and subjected to $4 \mathrm{~h}$ of $\mathrm{KCN}$

Figure 13: Limb isolation procedure .................................................. 74

Figure 14: Aseptic glass chamber used to protect the limbs from contamination during incubation and the perfusion system set up

Figure 15: Anastomosis of vessels and limb reperfusion after clamp release

Figure 16: Clinical and pathological features of transplanted limbs preserved for 13 hours at $23^{\circ} \mathrm{C}$

Figure 17: Kaplan-Meier survival curves of transplanted limbs preserved for 13 hours and 21 hours 


\section{LIST OF TABLES}

Table 1: Summary of the multiple cellular metabolic and structural changes that occur during ischemia or Hypoxia

Table 2. Composition of experimental solution used in the study ................70

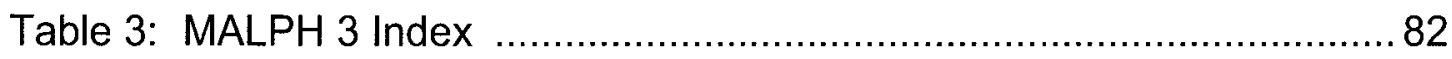

Table 4: MALPH-3 scores for Soleus (SOL) and Extersor Digitorius Longus (EDL) muscles ......................................................... 90

Table 5: Combined MALPH-3 scores for each treatment group ................. 92

Table 6: Cross-tabulation showing the percentage of cell infiltration for all the solutions tested

Table 7: Cross-tabulation showing the percentage of endothelium aberration for all the solutions tested 


\section{CHAPTER 1}

\section{GENERAL BACKGROUND}

\section{Introduction}

Composite tissue transplantation entails the complete detachment of large segments of tissue of varied histological types (bone, skin, muscle and nerve) from a donor subject with the subsequent transfer and revascularization to the recipient. As with other types of transplantation, ischemia and reperfusion $(I / R)$ injury is a dominant factor limiting tissue survival. Besides organ transplantation, I/R injury is recognized as a serious problem that occurs in a variety of medical procedures including, cardiovascular surgery, vascular bypass surgery and reconstructive surgery. ${ }^{5}$

Ischemia and reperfusion injury is a two step process. ${ }^{5}$ First, during ischemia, tissues become short of oxygen and nutrients and the lack of blood flow leads to accumulation of metabolic waste products. ${ }^{3}$ Second, upon reperfusion, a cascade of events is triggered including the production of oxygen radicals and inflammatiory mediators leading to endothelial dysfunction and apoptosis. ${ }^{4-7}$

Central to I/R injury and associated tissue damage in these procedures is the lack of delivery of substrates for energy production to the affected cells during the 
ischemic period. Cells are unable to produce energy in the form of adenosine triphosphate (ATP) resulting in adverse metabolic and structural changes. ATP is the main intracellular energy source and is constantly synthesized and metabolized in the body to maintain life. Virtually all cell processes are driven by the energy released when ATP is hydrolysed to form adenosine diphosphate (ADP) and inorganic phosphate. For most cells, the majority of ATP is generated in the mitochondria. The balance between energy consuming and energy producing reactions in a cell is carefully maintained, and the central metabolic ATP is kept at an almost constant level in spite of a very short turnover time. Cells do not use food nutrients as their energy supply. They almost exclusively use ATP, which is the essential link between energy production and energy utilization. ${ }^{8-10}$

To overcome the lack of cellular energy during ischemia, direct intravascular infusion of ATP to the ischemic tissues might be a rational approach. However, sufficient intracellular concentrations of ATP cannot be achieved because ATP does not diffuse across the cell membrane. Furthermore, ATP has a short half life of less than 5 min.

In Dr. Ehringer's laboratory, a highly efficient fusogenic lipid vesicle (FLV) that delivers its content into cells by fusing with the cell membrane was developed. By loading these FLVs with adenosine triphosphate magnesium chloride (Mg-ATP), exogenous energy (in the form of Mg-ATP) can be delivered into cells. This dissertation investigates the feasibility of protecting cells and composite tissues (skin, muscle, bone and nerve) from I/R injury by delivering exogenous Mg-ATP using FLVs infused intravascularly. 


\section{Cellular Energy}

ATP is the main intracellular energy source and is constantly synthesized and metabolized in the body to maintain life. Synthesis of proteins, fats and carbohydrates necessary for cell integrity, normal activity and function are dependent on ATP availability. All these cell processes are driven by the energy released when ATP is hydrolyzed. The majority of ATP is generated in the mitochondria. The balance between energy consuming and energy producing reactions in a cell is carefully maintained, and the central metabolic ATP is kept at an almost constant level in spite of a very short turnover time ${ }^{11}$. ATP is a purine nucleotide containing two high-energy phosphate bonds. When these bonds are hydrolyzed, free energy is liberated ${ }^{12-14}$. The synthesis of ATP by the respiring mitochondria requires inorganic phosphate, magnesium, substrate (usually glucose), ADP and the presence of oxygen ${ }^{15}$. Eukaryotic cells, with the help of mitochondria, can use oxygen as the terminal electron acceptor during oxidative phosphorylation. The participation of oxygen in the energy transformation process allows large amounts of free energy to be liberated during metabolism. This can be demonstrated most simply by comparing the yield of ATP from oxidation of glucose under anaerobic versus aerobic conditions. Anaerobic glycolysis to lactate (Figure 1) produces 2 moles of ATP per mole of glucose whereas aerobic glycolysis to carbon dioxide and water though the Krebs cycle and oxidative phosphorylation delivers 36-38 moles of ATP ${ }^{16,17}$ (Figure 2). Therefore, adequate supply of oxygen enhances ATP yield by 18-19 fold. The importance of oxygen for ATP production in humans has been confirmed in vivo. In patients with chronic circulatory and/or 
respiratory insufficiency, mitochondrial ATP levels were only one-half of the levels found in normal patients ${ }^{18}$. Magnesium plays a critical role in key enzymatic reactions for both the aerobic and anaerobic glycolysis ${ }^{19,20}$. It has been known since the discovery of the $\mathrm{Na}^{+}, \mathrm{K}^{+}$pump that magnesium is required for enzymatic activity $^{21}$. The uptake and accumulation of magnesium by the mitochrondria is associated with enhanced uptake of phosphate and proton extrusion ${ }^{22}$. Also, most enzymes involved in the biochemistry of nucleic acids require a divalent metal ion cofactor to promote activity, and magnesium is with rare exceptions the metal ion of choice $^{23}$.

\section{I/R injury}

$\mathrm{I} / \mathrm{R}$ injury is recognized as a serious problem that occurs in a variety of medical procedures including thrombolytic therapy, organ transplantation, vascular bypass surgery, trauma and reconstructive surgery ${ }^{5}$. I/R injury is a two step process. During ischemia, depletion of cellular energy storage, loss of cellular homeostasis and accumulation of metabolites lead to cell damage that can be reversible depending on the duration of the ischemia. ${ }^{3}$ During reperfusion, further damage is produced though the production of reactive oxygen species, inflammatory mediators and chemotactic factors. ${ }^{4-7}$ Figure 3 summarizes the most typical events during I/R injury. 
Figure 1. Anaerobic Glycolysis

Glucose gets broken down to pyruvate. Then pyruvate is converted to lactate through the Cory cycle (Lactic acid fermentation). Through this pathway glucose is not completely broken down and it does not release all its stored energy. It only produces 2 moles of ATP per mole of glucose. Copyright Pearson Education, Inc.

Available at:

http://scidiv.bcc.ctc.edu/gb/Biol\%20130/Lectures/Metabolism.htm 


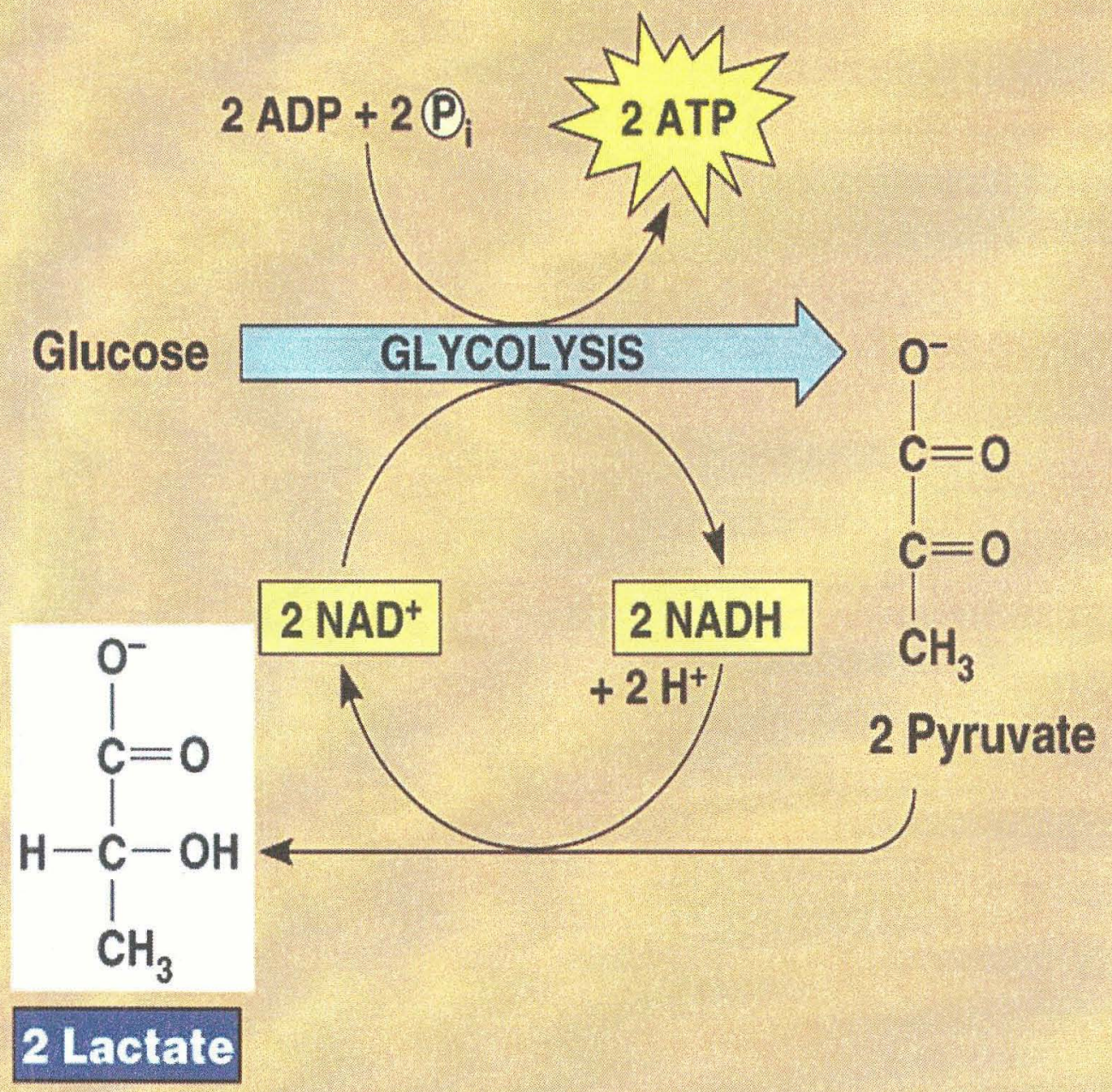


Figure 2. Cellular Respiration

Pyruvate is converted to AcylCoA, which then goes through the Krebs cycle producing NADH and $\mathrm{FADH}_{2}$. These two compounds then go through the electron transport chain which releases their energy to produce ATP. Though this pathway up to 38 moles of ATP can be produced for every mole of glucose.

Copyright Pearson Education, Inc. Available at:

http://scidiv.bcc.ctc.edu/gb/Biol\%20130/Lectures/Metabolism.htm 


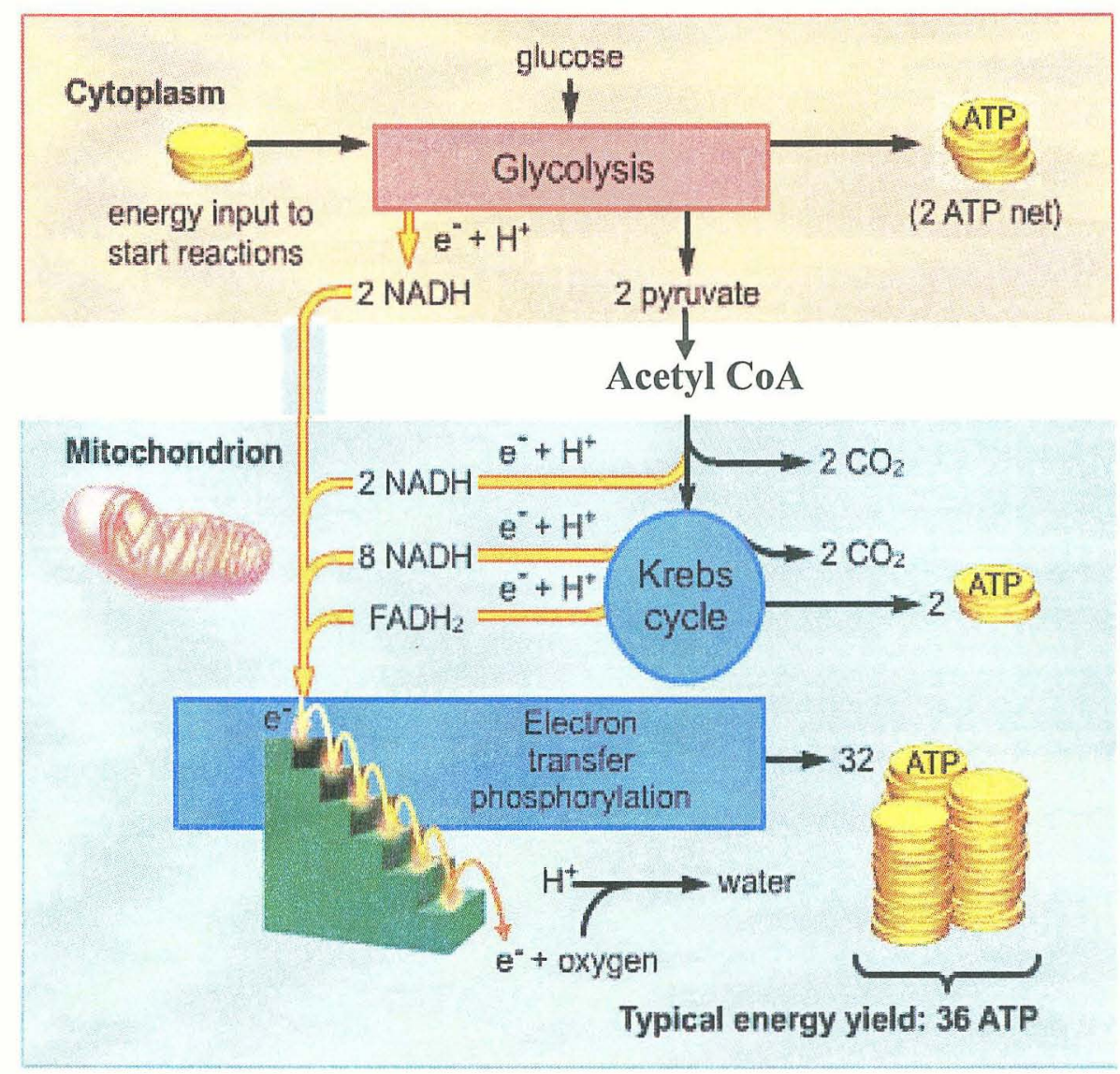




\section{Changes occurring during ischemia}

Ischemia is an absolute or relative shortage of the blood supply to an organ. Insufficient blood supply causes tissue to become hypoxic, or, if no oxygen is supplied at all, anoxic. Prolonged hypoxia or anoxia results in multiple cellular metabolic and structural changes (Table 1). Although the tolerance to ischemia varies with tissue types and adaptive mechanisms, cell damage inevitably occurs after extended periods of anoxia. Decrease in cellular oxidative phosphorylation results in a failure to resynthesize energy rich-phosphates including ATP. Such energy depletion leads to an alteration of the function of membrane ATP-dependent ionic pumps, which favor the efflux of potassium and influx of sodium, calcium and water into the cell provoking cell swelling, cytoskeletal disorganization and further membrane rupture and necrotic cell death ${ }^{3}$ (Figure 4). Adenine nucleotide catabolism during ischemia results in the accumulation of hypoxanthine which can be further converted into reactive oxygen species (ROS) when oxygen is reintroduced upon reperfusion ${ }^{7}$. Within the endothelium, the production of certain bioactive agents (prostacyclin, nitric oxide) will be diminished, while the production of others (endothelin, thromboxane $A_{2}$ ) will be augmented ${ }^{6}$. Also, in endothelial cells, certain genes such as adhesion molecules P-selectin and ICAM-1 are induced, while others like cNOS and thrombomodulin are suppressed. Upon reperfusion, many of these changes are exacerbated by reoxygenation and more severe damage occurs. 
Figure 3. The sequence of events occurring during ischemia and reperfusion. Khalil et al Plast. Reconstr. Surg. 117: 1024, 2006. ${ }^{4}$ 


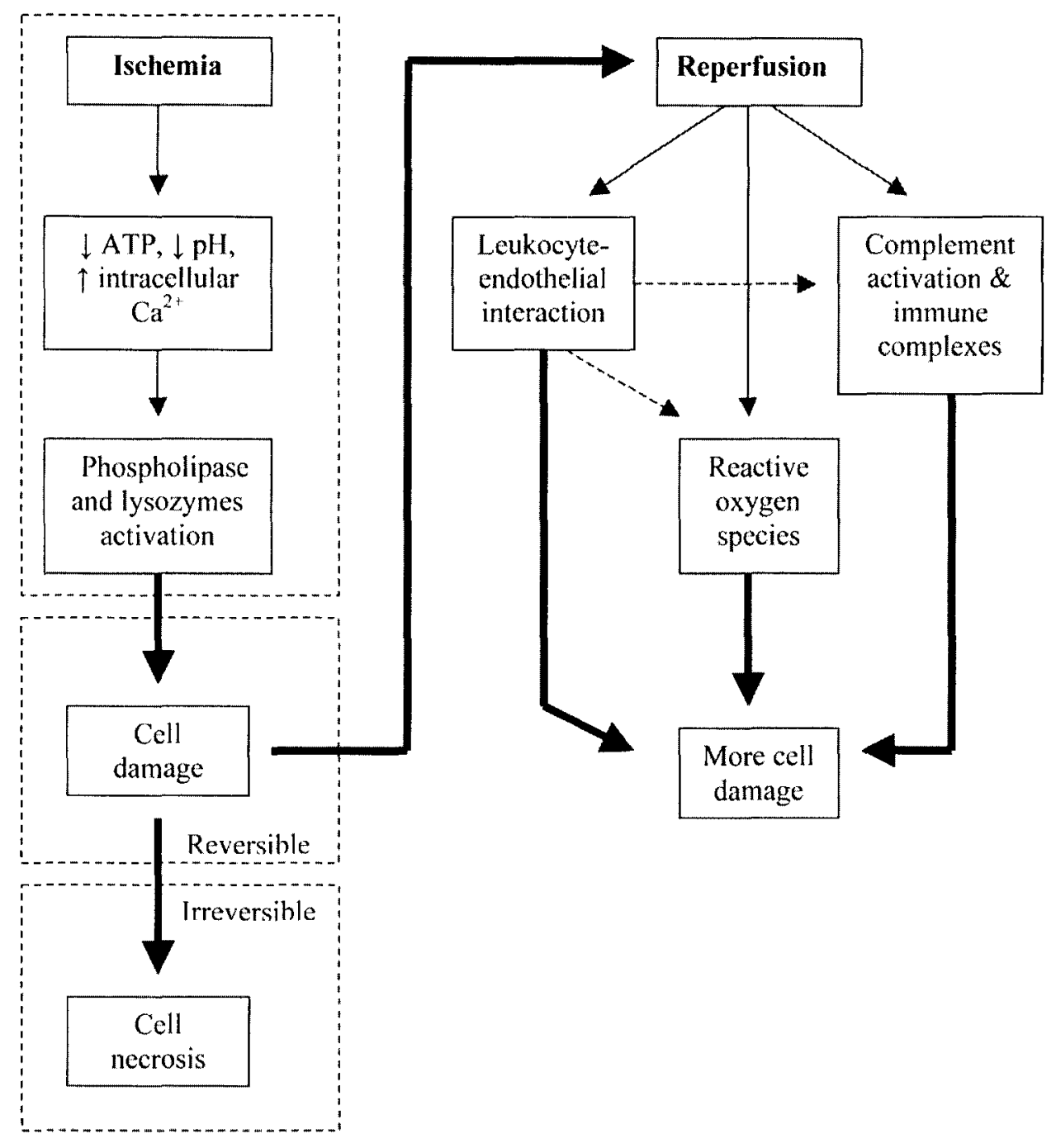


Table 1. Summary of the multiple cellular metabolic and structural changes that occur during ischemia or hypoxia. 


\section{Effects of Ischemia or Hypoxia on Cells}

Cellular acidosis

Altered membrane potential

Altered ion distribution (increased intracellular $\mathrm{Ca}^{++} / \mathrm{Na}^{+}$ratio)

Cellular swelling

Cytoskeleton disorganization

Increased hypoxanthine

Decreased ATP

Decreased phosphocreatine

Decreased glutathione

Stabilization and nuclear translocation of hypoxia-inducible factor 1 (HIF-1)

Increased leukocyte adhesion molecule expression 
Figure 4. ATP turnover of cells as a function of time exposure to anoxia or hypothermia. When the balance between ATP supply and ATP demand is lost, a cascade of events is triggered that leads to cell death by necrosis. Boutilier, R. G. J Exp Biol 2001;204:3171-3181 ${ }^{3}$ 


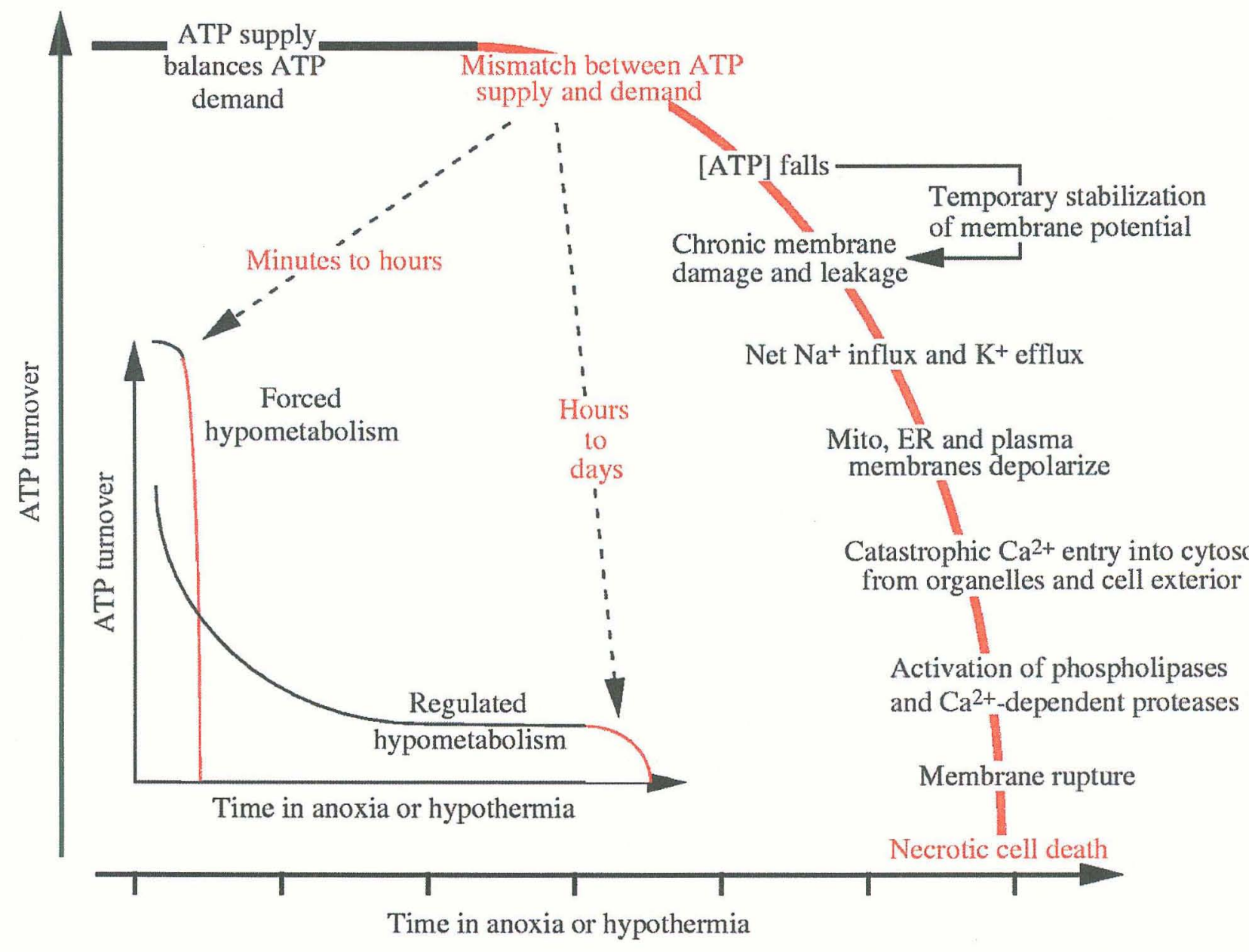




\section{Alteration of ionic transport systems}

The concentration of $\mathrm{Na}^{+}$is typically 10-20 times higher outside cells than inside, whereas the reverse is true for $\mathrm{K}^{+}$. The maintenance of this differential concentration has several biological implications. The $\mathrm{Na}^{+}$gradient provides an energy source for a set of $\mathrm{Na}^{+}$-linked transporters (ie: $\mathrm{Na}^{+} \mathrm{Cl}^{-}$cotranporter, $\mathrm{Na}^{+} \mathrm{Ca}^{2+}$ exchanger $)^{24}$ and is involved in several homeostatic functions including the regulation of cell volume, intracellular $\mathrm{pH}$ and intracellular $\mathrm{Ca}^{2+}$ concentration ${ }^{24,25}$. It is well known that the $\mathrm{Na}^{+}, \mathrm{K}^{+}$-ATPase pump is responsible for the maintenance of the $\mathrm{Na}^{+}$gradient by the coupled movement of $\mathrm{K}^{+}$and $\mathrm{Na}^{+}$into and out of the cell respectively. The pump expels $3 \mathrm{Na}^{+}$in exchange for $2 \mathrm{~K}^{+}$generating an electrochemical gradient with the intracellular space being low in $\mathrm{Na}^{+}$and electronegative. This electrochemical gradient creates a "sodium-motive force", which drives $\mathrm{Na}^{+}$back into the cell ${ }^{22,26}$. The pump activity requires ATP. It has been estimated that the $\mathrm{Na}^{+}, \mathrm{K}^{+}$-ATPase pumps consume $\sim 33 \%$ of the total energy (ATP) used by a typical animal cell. Blockade of the pump with ouabain inhibits its activity and prevents cells from maintaining their $\mathrm{Na}^{+} / \mathrm{K}^{+}$balance, which will disrupt cell homeostasis $^{22}$. Similarly, when cells are deprived from oxygen for oxidative phosphorylation, intracellular levels of ATP gradually dwindle, and cause a decrease in ATPase activity, which also disrupts cell $\mathrm{Na}^{+} / \mathrm{K}^{+}$balance and membrane potential. Imahashi et al. ${ }^{27}$ showed in the rat heart that intracellular $\mathrm{Na}^{+}$accumulated during ischemia and that the amount of accumulated $\mathrm{Na}^{+}$at the end of ischemia was correlated with the duration of the ischemia. They also showed that the 
accumulation of $\mathrm{Na}^{+}$during ischemia is a major determinant of the severity of the $\mathrm{I} / \mathrm{R}$ injury. In another study using a potassium cyanide $(\mathrm{KCN})$ poisoned rat heart, Kupriyanov et al., ${ }^{28}$ showed that $\mathrm{KCN}$ infusion caused a decrease in phosphocreatinine and ATP and an increase in phosphatidylinositol (PI) and $\mathrm{Na}^{+}$. This suggests that inhibition of $\mathrm{Na}^{+}, \mathrm{K}^{+}$-ATPase pump by $\mathrm{PI}$ is responsible for intracellular $\mathrm{Na}^{+}$accumulation, whereas loss of $\mathrm{K}^{+}$is associated with inhibition of the $\mathrm{Na}^{+}, \mathrm{K}^{+}$-ATPase pump as well as an activation of ATP-sensitive $\mathrm{K}^{+}$channels and the $\mathrm{K}^{+}$-lactate cotransporter. $\mathrm{Na}^{+}$accumulation during ischemia induces contractile dysfunction, has a deleterious effect on energy metabolism ${ }^{29,30}$ and results in $\mathrm{Ca}^{2+}$ overload during the initial phase of reperfusion ${ }^{31-33}$.

\section{Cell Death and I/R Injury}

There are two ways in which cells die, either by injurious agents or by suicide (program cell death). When injury occurs from mechanical or toxic chemical exposure, cells and their organelles loose their ability to control passage of ions and water. This process is called cell necrosis. As cells die, the cellular content starts to leak out and promote an inflammatory response in surrounding tissues. To the contrary, when cells are induced to undergo apoptosis, they shrink, the mitochondria break down and release cytochrome c. The cells develop bubble-like blebs on the surface, and the DNA degrades, breaking into small membrane-wrapped fragments. The intracellular machinery responsible for apoptosis depends on a family of proteases called caspases. Caspases have a cysteine at their active site and cleave their target at specific aspartic acids. ${ }^{22}$ During this process, the phospholipid phosphatidylserine on the membrane of fragments binds to receptors on phagocytic 
cells, which engulf and digest the cellular debris. Phagocytic cells also inhibit the inflammatory response by secreting anti-inflammatory cytokines ${ }^{34,35}$.

In skeletal muscle, evidence of DNA fragmentation using propidium iodide has been sparse and controversial ${ }^{36-46}$. In a rat hind limb model of I/R injury, recent studies have reported that skeletal muscle is resistant to reactive oxygen species (ROS) induced apoptosis. ${ }^{36,44}$ Furthermore, skeletal muscle appears to possess an inherent resistance to apoptosis but this is still a subject of discussion. ${ }^{47-50}$ Some have found that the caspase inhibitors FLICE/caspase- 8 inhibitory protein (FLIP) ${ }^{48}$ and apoptosis repressor with card (ARC) $)^{49}$ are highly expressed in skeletal muscle relative to other tissues, providing it with certain resistance to apoptosis. Moreover, caspase- 3 protein has been reported to be absent in skeletal muscle, ${ }^{50}$ and evidence that human skeletal muscle cytosol lacks Apaf $-1,{ }^{47}$ suggests that skeletal muscle is resistant to apoptosis. On the other hand, recent reports indicate that certain situations like denervation, ${ }^{39}$ aging, ${ }^{40}$ dystrophy, ${ }^{43}$ and mechanical ventilation ${ }^{51}$ induced disuse are associated with a loss of muscle nuclei through an apoptosis-like process..$^{37,41,42}$ This "myonuclear apoptosis" can occur without complete cell death in multinucleated cells $s^{38,41,52}$ and it seems to be a strategy to maintain the nuclei/fiber area ratio constant. ${ }^{41}$ Conversely, satellite cells are known to undergo apoptosis, ${ }^{50,53,54}$ and in some muscle studies, apoptotic satellite cells may have been mistakenly identified as apoptotic mature myocytes.

Cell death in I/R injury is usually associated with the generation of ROS during reperfusion, and the release of cytochrome $c$ into the cytoplasm ${ }^{55,56}$. ROS have been reported to directly damage the mitochondrial membrane causing what is 
known as mitochondrial permeability transition (MPT). MPT can occur temporarily but can rapidly become irreversible resulting in loss of mitochondrial homeostasis and producing dangerous mitochondrial swelling ${ }^{57}$. Another mechanism that has been implicated in ROS induced cytochrome c release involves the action of the proapoptotic protein Bax (of the $\mathrm{Bcl}-2$ family). It has been reported that Bax under oxidative stress conditions is overexpressed and is translocated from the cytosol to the mitochondrial membrane inducing cytochrome $c$ release into the cytosol ${ }^{58-60}$. Once cytochrome $\mathrm{c}$ is released into the cytosol (by MPT or Bax translocation), it aggregates with apoptotic protease-activating factor-1 (Apaf-1), procaspase-9, and ATP. The resulting complex (apoptosome) activates caspase-9, which in turn activates a series of caspases ultimately activating caspase-3. As ROS are generated during reperfusion and cytochrome c leaks out into the cytoplasm, the capacity of the electron transport system to generate ATP in the mitochondria is compromised. If the process is not quickly reversed, the cell's energy resources dwindle, and cell death by necrosis occurs ${ }^{61-65}$. Figure 5 summarizes mitochondrial factor-mediated apoptosis and necrosis induced by oxidative stress.

\section{I/R Injury and the Microcirculation}

The molecular and biochemical changes that occur in the microvascular bed following I/R injury are typical of an inflammatory response. This response is comprised of a series of complex reactions that occur in the endothelium and adjacent tissues. The most severe acute inflammatory response induced by $\mathrm{I} / \mathrm{R}$ injury is triggered by the reintroduction of blood and oxygen to ischemic tissues ${ }^{5,66,67}$ 
Figure 5. Apoptotic and necrotic pathways after oxidative stress of mitochondria. Release of cytochrome $\mathrm{c}$ from the mitochondria leads to decreased production of ATP, and in skeletal muscle cells primarily undergo the necrotic pathway only. (ROS= reactive oxygen species; AIF= apoptosis-inducing factor; MPT= mitochondrial permeability transition; Apaf-1=apoptotic protease-activating factor-1). 


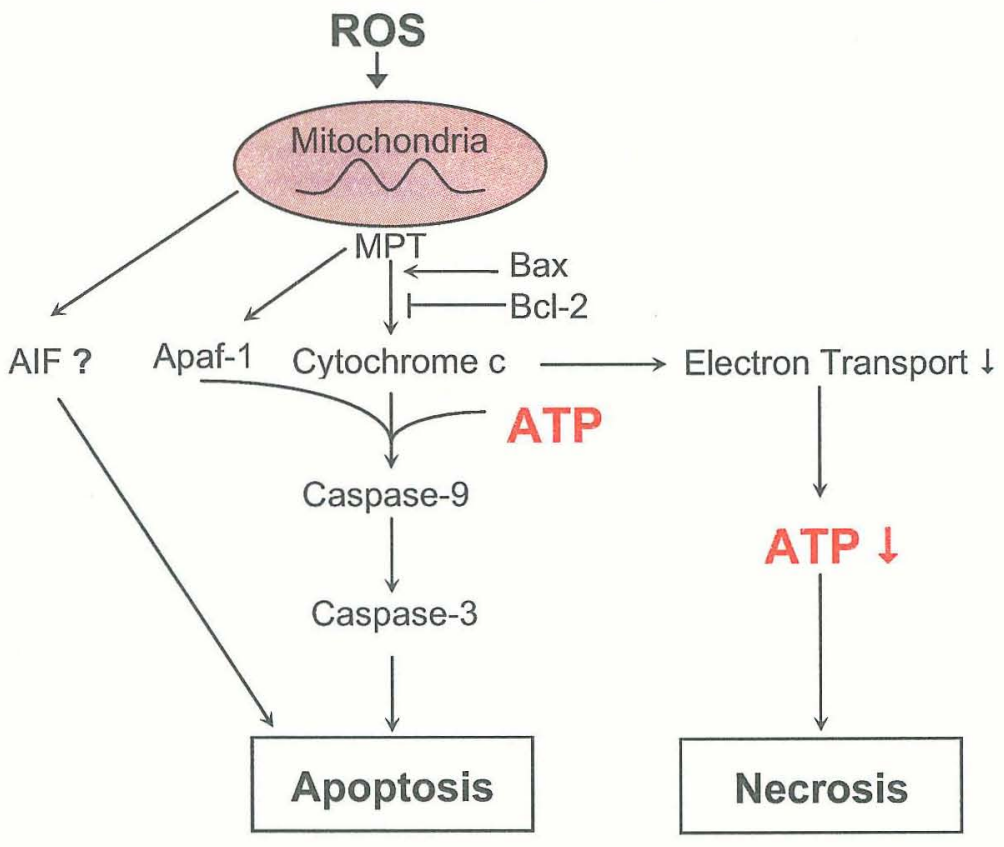


During reperfusion, reoxygenation leads to over production of ROS. The major sources of ROS are the xanthine oxidase system and the nicotinamide adenine dinucleotide phosphate (NADPH) system ${ }^{4}$ (Figure 6). ROS can induce cell death by disrupting cellular integrity and initiating apoptosis ${ }^{68-72}$.

Leukocyte recruitment and migration into the tissue are key to the development of I/R injury. Leukocytes marginate and adhere to the endothelium. Mast cell histamine release facilitates leukocyte migration into the perivascular space through gaps opened between venular endothelial cells or by migrating through endothelial cells $s^{73,74}$. Once leukocytes have migrated into the tissue, they can cause further damage by secreting proteolitic enzymes or production of free radicals. ${ }^{5}$

Microcirculation studies in skeletal muscle of humans and animals that examined ultrastructure changes of microvessels during and following 3 hours of ischemia were remarkably similar ${ }^{75}$. The first noticeable changes observed occurred in capillary endothelial cells. The endothelial cell membranes developed finger-like protrusions into the capillary lumen and invaginations into the cytosol. As the ischemia progressed, there was complete disjunction of adjacent endothelial cells resulting in extremely broad gaps in the endothelium. Edema of endothelial cells gradually progressed in some but not all cells creating an uneven surface. Leukocytes and platelets were rare. The primary finding consisted of erythrocytes tightly wedged in the capillary lumen. In animal studies only, after more than 4 hours of ischemia, cellular interactions became apparent and these were erythrocytic, thrombotic and leukocytic ${ }^{75}$. The capillaries and venules were filled with tightly 
wedged erythrocytes so as to appear fused. During early reperfusion the erythrocytes were compacted into rouleau that appeared to deform and rupture the endothelial surface. Large inter-endothelial gaps resulted from focal disintegration of the endothelial cytoplasm. Thrombotic interactions became particularly prominent and were characterized by the occurrence of intraluminal masses of platelets in post-capillary venules. The endothelium of such vessels was lost over long distances, with intertwining platelets closing the defects. Leukocyte interactions were observed in larger venules and small veins with increased white cell adherence to the endothelial surface and migration to the extravascular space. In capillaries, they observed leukocytes, lymphocytes and monocytes plugging the lumena. ${ }^{75}$

\section{Pathophysiology of I/R injury in Skeletal Muscle}

The re-establishment of blood flow to ischemic muscle produces what is known as the reperfusion syndrome. It was first established in patients in whom blood flow had been restored to ischemic extremities, but also has been reported following heart surgery, organ transplantation and revascularization of ischemic intestine ${ }^{76}$. The syndrome has a local component that results in an increase of the regional damage, and a systemic component that can result in the secondary failure of organs and tissues remote from the ischemic area. The tolerance of tissues for ischemia varies with the nature of the tissue. In extremities, muscle appears to be tolerant for up to 4 hours, nerve changes remain reversible up to 8 hours, fat up to 13 hours, skin up to 24 hours and bone up to 4 days $^{77}$. 
Figure 6. Sources and fate of superoxide radicals.

Khalil et al Plast. Reconstr. Surg. 117: 1024, 2006. ${ }^{4}$ 


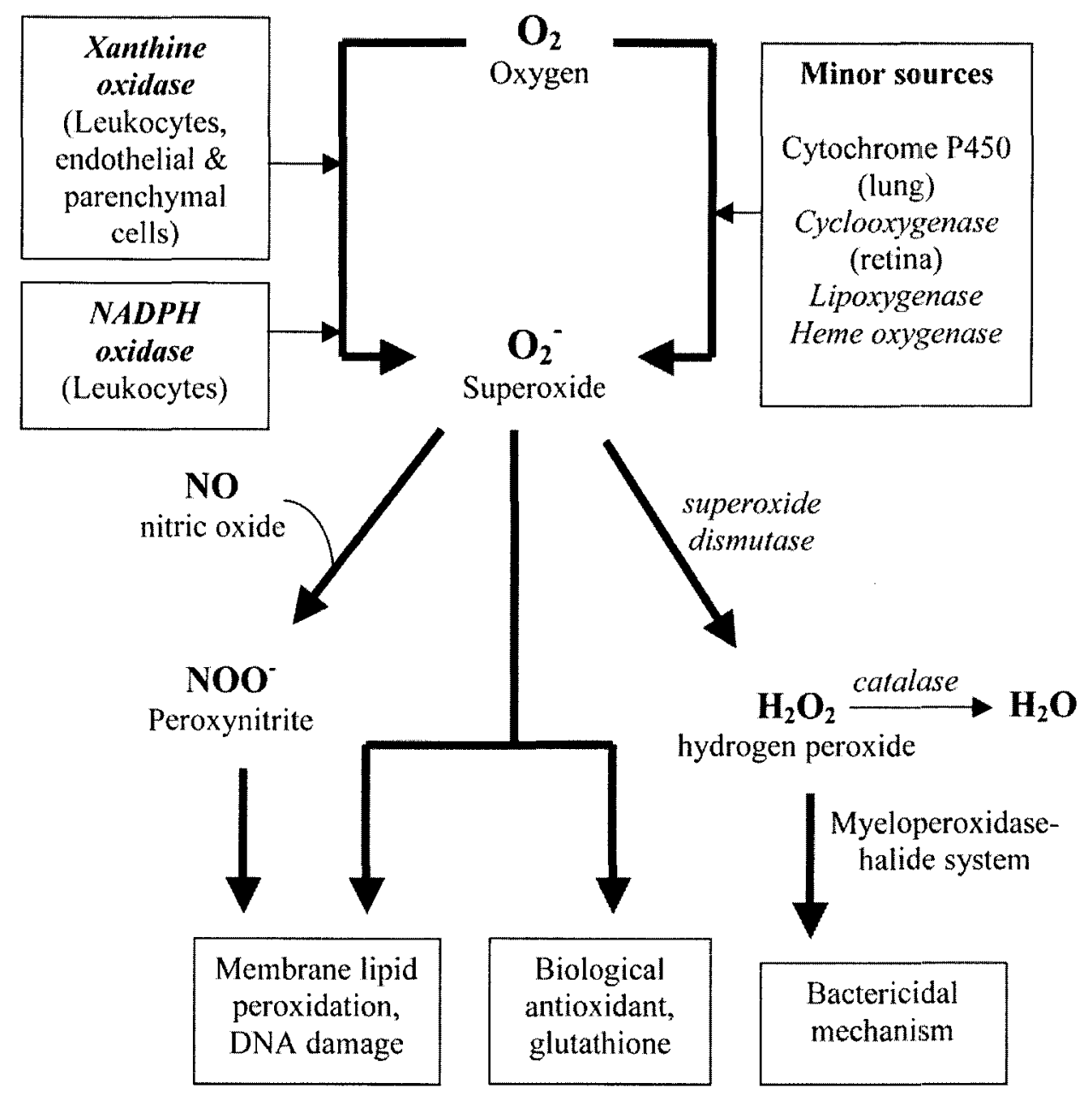


It is widely accepted that the duration of ischemia correlates directly with the severity of the injury. However, it has been difficult in muscle to distinguish when musicle cells die because gross and microscopic changes are minimal for many hours following muscle death. Using a tourniquet ischemia limb model and a spectrophotometric technique to analyze muscle damage, Belkin et al. ${ }^{31}$ determined that significant muscle injury occurred after 3 hours of ischemia and that after 4, 5 and 6 hours, the injury was severe.

Studies in ischemic muscle have demonstrated a close correlation between myonecrosis and depletion of ATP. Hayes et al. ${ }^{78}$ reported that during ischemia, myocyte glycogen and creatine phosphate are preferentially depleted over ATP, and that until ATP was depleted, little muscle necrosis occurred. In a similar study, Labbe et al. ${ }^{79}$ reported that the extent of necrosis in muscle after 3,4 and 5 hours of warm ischemia was 2,30 , and $90 \%$, respectively.

\section{Microvascular Dysfunction after I/R}

It is now well established that $I / R$ results in severe dysfunction of the affected endothelium ${ }^{5}$. This is the result of a combination of factors, which appear to be centered around a reduction in nitric oxide (NO) release ${ }^{80}$ and an increased expression of vascular adhesion factors. NO is a diatomic free radical, which is synthesized from L-arginine by a family of enzymes, termed NO synthases. The presence of NO in tissues has both direct and indirect effects. Direct effects are mediated by the direct interaction of NO with specific biological molecules. In contrast, indirect effects are mediated by reactive nitrogen oxide species formed from the reaction of $\mathrm{NO}$ either with oxygen to form dinitrogen trioxide $\left(\mathrm{N}_{2} \mathrm{O}_{3}\right)$ or 
superoxide radical to form peroxynitrite $\left(\mathrm{ONOO}^{-}\right)^{5,81}$. Nitric oxide can act in a tissueprotective manner through the physiological regulation of vascular tone, inhibition of platelet aggregation, attenuation of leukocyte adherence to the endothelium, scavenging oxygen-free radicals, maintenance of normal vascular permeability, inhibition of smooth muscle proliferation, immune defenses, and stimulation of endothelial cell regeneration ${ }^{5,82-84}$. The mechanisms responsible for the inhibition of NO production are still unclear. One of the mechanisms postulated is a physiological imbalance that favors $\mathrm{O}_{2}{ }^{-}$accumulation over $\mathrm{NO}$ during the early phase of reperfusion. Oxygen radical accumulation is the result of a variety of factors, including a substrate-initiated burst in xanthine oxidase activity and an inhibition of endogenous superoxide dismutase (SOD) and catalase activity. Consequently, the accumulation of NO will be limited and its beneficial actions, including vasodilation, prevented ${ }^{85-88}$. This will lead to dysfunction of the endothelium manifested as a lack of vasodilation contributing to a "no-reflow phenomenon" and a strong tendency for leukocytes to adhere to vascular endothelium. ${ }^{18,89,90}$ and for platelets to aggregate ${ }^{82}$. Furthermore, in the absence of $\mathrm{NO}, \mathrm{O}_{2}{ }^{-}$undergoes spontaneous dismutation to form $\mathrm{H}_{2} \mathrm{O}_{2}$, which can promote activation of phospholipase $\mathrm{A} 2$, result in the generation of inflammatory mediators and activate NF-kB, a primary regulator of cytokine and adhesion molecule gene expression ${ }^{5}$. Another mechanism to explain the inhibition of NO production is offered by recent in vitro reports that suggest that NADPH levels fall during ischemia ${ }^{91}$. NADPH is the reduced form of $\mathrm{NADP}^{+}$and is produced inside the mitochondria in the so-called "forward reaction" $"$. A lack of NADPH will inhibit NO 
synthesis by depriving NO synthase of energy. It has been well-established in vitro that NADPH levels can be increased by artificially supplementing ATP to cells and thus reduce mitochondrial pyridine nucleotides in a process called reversed electron transport ${ }^{93,94}$. In addition to this effect, the reduction of mitochondrial pyridine nucleotides could prevent mitochondria-mediated apoptosis by keeping the structural integrity of mitochondria intact. ${ }^{95-99}$

Finally, NADPH could participate directly in preventing I/R injury by eliminating hydroperoxides through the glutathione peroxidase/glutathione reductase and thioredoxin peroxidase/thioredoxin reductase enzyme systems ${ }^{95,96,100,101}$.

\section{Exogenous ATP as an Energy Source}

Numerous methods have been tried in the past to avert the grave consequence of energy depletion with limited success ${ }^{31,102-108}$. Although a few other molecules can serve as a source of energy in the cell, such as creatine phosphate and other nucleotide phosphates (e.g., GTP, CTP, and UTP), their production is also ultimately dependent on the supply of ATP ${ }^{109-111}$. Direct infusion of ATP or its precursors into tissues or organs is a logical approach that would provide an immediate energy supply. However, this approach has never yielded noteworthy results with in vivo experiments because the unique structure of the cell membrane prevents free diffusion of many substances including ATP. By serving as a selective barrier to the passage of molecules, the cell membrane determines the composition of the cytoplasm and the identity of the cell. The basic structure of the membrane is the phospholipid bilayer, which is permeable only to gases, small hydrophobic molecules, and to small polar uncharged molecules such as ethanol. Even water 
has a low permeability to many lipid bilayer structures. Most cells have aquaporins (protein channels) imbedded in the cell membrane to allow water to move in and out of cells ${ }^{112}$. Larger polar molecules (such as glucose) and charged molecules (such as $\mathrm{H}^{+}, \mathrm{Na}^{+}, \mathrm{Cl}^{-}, \mathrm{Ca}^{++}$, and amino acids) are not permeable unless they have channels or transporters. The highly charged high-energy phosphates like ATP or its many precursors do not pass through the cell membrane and therefore, extracellular sources of ATP cannot be used for cell metabolism.

\section{Multilammellar Vesicles (Liposomes) as Drug Delivery Vehicles}

The use of liposomes to deliver drugs such as antibiotics and anticancer agents has been in practice for years ${ }^{113-119}$. Liposomes can be filled with a variety of agents and, because of their similarity to cell membranes, are not toxic. They also protect their loads from being diluted or degraded in the blood. As a result, when the liposomes reach diseased tissues, they deliver concentrated doses of the agent they carry. Liposomes are made of phospholipids (amphipathic molecules) that form closed, fluid-filled spheres when mixed in water. As a liposome forms, any watersoluble molecules that are in the solution are encapsulated in the aqueous space in the interior of the sphere, whereas any lipid-soluble molecules present in the solution are incorporated into the lipid bilayer.

The interactions between liposomes and cell membranes have several forms (Figure 7). ${ }^{2}$ Liposomes can adsorb to almost any cell type. Once they have adsorbed, the spheres may be endocytosed by some cells. Adsorbed liposomes can also exchange lipids with cell membranes and may at times be able to fuse with cells. When fusion takes place, the liposomal membrane is integrated into the cell 
membrane and the aqueous contents of the liposome merge with the fluid in the cytosol. Because individual liposomes were shown to be capable of carrying thousands of drug molecules, this delivery technique becomes very efficient for some impermeable substances such as ATP. ATP delivery to tissues using liposomes has been tried in a small number of studies ${ }^{85,120-129}$. In a set of studies that used isolated perfused rat livers, Neveux et al. ${ }^{120,127}$ studied the effects of preserving livers with liposomally entrapped ATP in University of Wisconsin (UW) solution. They found that rat livers preserved in this cocktail for 18 hours at $4^{\circ} \mathrm{C}$ attenuated a decrease in hepatic ATP content, and during reperfusion, proteolysis was decreased and was associated with an increase in cell volume. The authors concluded that liposomally entrapped ATP represents an effective means to improve liver graft energy state and function. Also in a liver study that used a hypovolemic shock rat model, Konno et al. ${ }^{126}$ studied the effect of liposomally entrapped ATP on the liver during shock and reperfusion. They found that administration of liposomally entrapped ATP significantly improved hepatic blood flow, reduced hepatic enzyme release, and produced the fastest hepatic ATP recovery. The authors concluded that hepatic blood flow during and after hypovolemic shock was enhanced by the improved energy level and metabolism of hepatocytes. In a third study, Puisieux et al. ${ }^{128}$ using intra-carotid administration of ATP-entrapped liposomes reported a significant increase in the number of brain ischemic events tolerated by rats before the first irreversible electro-corticogram (ECoG) silence occurred and before death. The authors also studied the ability of their liposomes (loaded with carboxyfluorescein) to cross the blood-brain barrier in rat brain slices. 
Figure 7. Liposomes interact with cells in four distinct ways: a) absorption, b) endocytosis, c) lipid exchange, d) fusion. Ostro et al. Scientific American, 256:102-111, $1987^{2}$ 


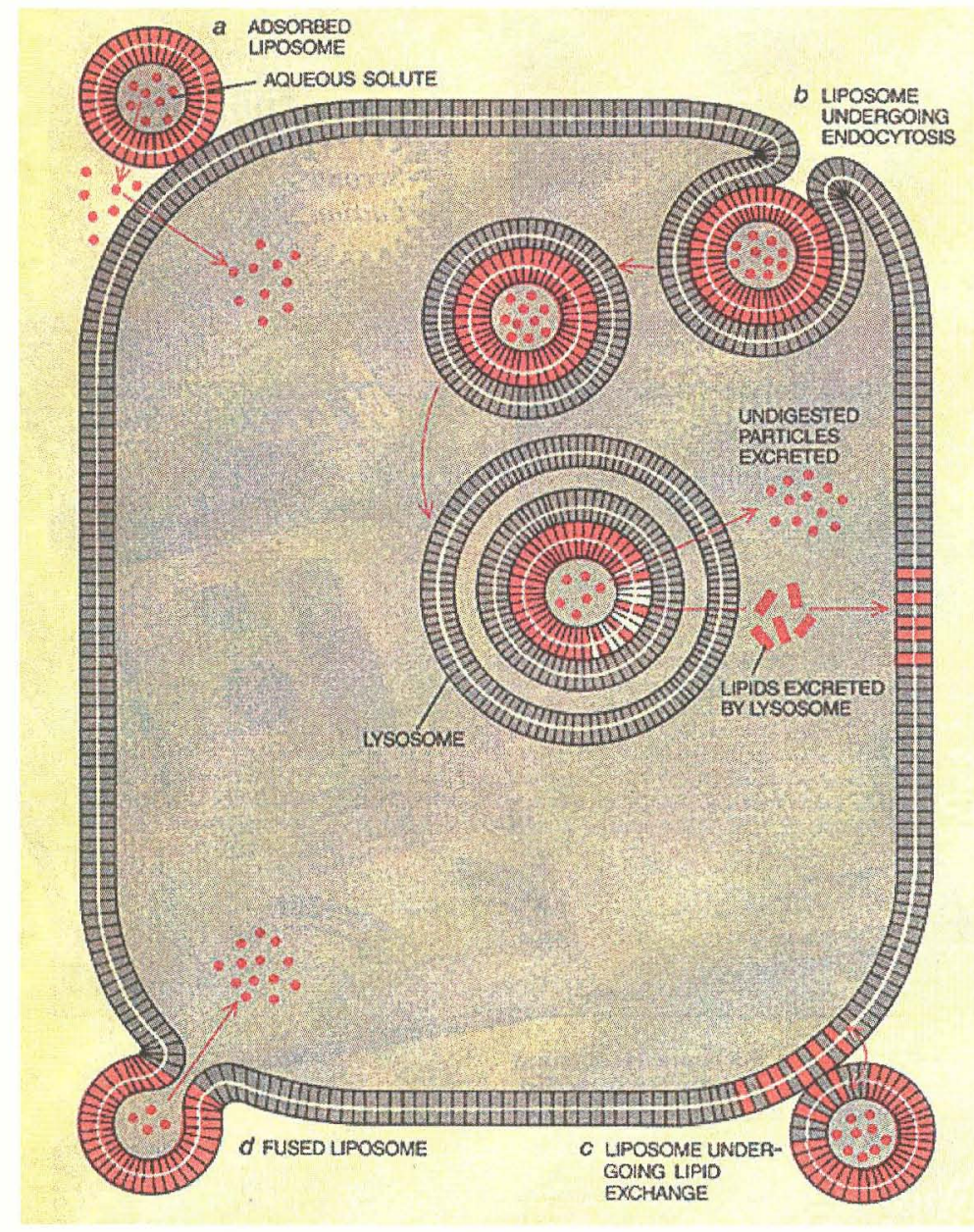


They found areas of punctuated fluorescence in the parenchyma and concluded that under hypoxic conditions tight junctions were opened and allowed liposomes to pass. Verma et $a^{123-125,129}$, in a set of myocardial ischemia studies, showed a reduction in the irreversible damaged area $^{123}$ and a substantially improved functional recovery ${ }^{124,125}$ after 30 min of total ischemia and 3 hours of reperfusion by perfusing the hearts with ATP-loaded liposomes before the ischemic insult. They also showed that the liposomes can cross the wall of myocardial capillaries ${ }^{125}$ and that they can be targeted by attaching monoclonal anti-bodies against the target tissue to their surface. ${ }^{124}$ Using a sepsis model, Han et al. ${ }^{122}$ showed that endothelial cells can be protected from energy failure when treated with liposome encapsulated ATP. In the above studies, none of the authors presented data that would indicate that their liposomes were very fusogenic. Therefore, it is not clear how their liposomes would exert a beneficial effect. In a study by Arakawa et al. ${ }^{85}$, ATP-entrapped liposomes were tested in vitro and were proposed to be used as a slow release system to rescue the ischemic retina. Though, no animal experiments were performed, the authors did report the slow rate of release (35\% of entrapped drug within 90 hours) of their liposomes. A similar in vitro study using ATP-entrapped liposomes was performed by Xu et al. ${ }^{129}$ In this study the authors reported that liposomal release of ATP was a mere $10 \%$ after 50 days.

The two most significant problems with all of the above studies are that the authors did not attempt to modify the phospholipid formulation of liposomes to increase fusogenicity to cell membranes, and that the diameter of liposomes used were too large to escape the vasculature. Therefore, it is not clear how their 
liposomes could deliver significant amounts of ATP to meet metabolic demand of cells in the vasculature as well as in the parenchyma. As reported by some of the studies above, liposome release of ATP was very slow, and if adsorption by the cell membrane does occur, ATP delivery to the cytosol will not be automatic.

Unencapsulated drugs typically diffuse through pores in the microvasculature, but standard liposomes are too large to pass through the endothelial barrier of most tissues, and therefore, small liposomes would need to be engineered to escape the intravascular space to reach cells in the parenchyma.

\section{Small Fusogenic Lipid Vesicles (FLVs) as Drug Delivery Vehicles}

Lipid vesicles can be made in a variety of layers and sizes (Figure. 8). Multilamellar vesicles have multiple layers of lipid and water, whereas large unilamellar vesicles and small unilamellar vesicles have a single phospholipid bilayer. To engineer small FLVs that effectively deliver agents, the vesicles must not fuse readily with each other and must not be so unstable as to leak their internal content. To enhance vesicle membrane fusion, the charge of the phospholipid head group can be manipulated to create dissimilar regions in the lipid layer and the vesicle's radius of curvature can be adjusted to provide different levels of stored kinetic energy. Liposomes or multilamellar vesicles are not readily fusogenic, mainly because the stored energy of the vesicle's radius of curvature is minimal. However, small unilamellar vesicles, which have a very tight radius of curvature, are very fusogenic. It has been reported that changes in lipid composition can dramatically alter vesicle-cell membrane fusion rates. Also by tightening the vesicle's radius of curvature the fusion rate can be further increased. ${ }^{130}$ 
Figure 8. Different types of lipid vesicles. Lipid vesicles can be made into multilamellar vesicles, small unilamellar vesicles (SUV), or large unilamellar vesicles (LUV). From Avanti Lipids, Inc.

Available at: http://www.avantilipids.com/PreparationOfLiposomes.htmI 


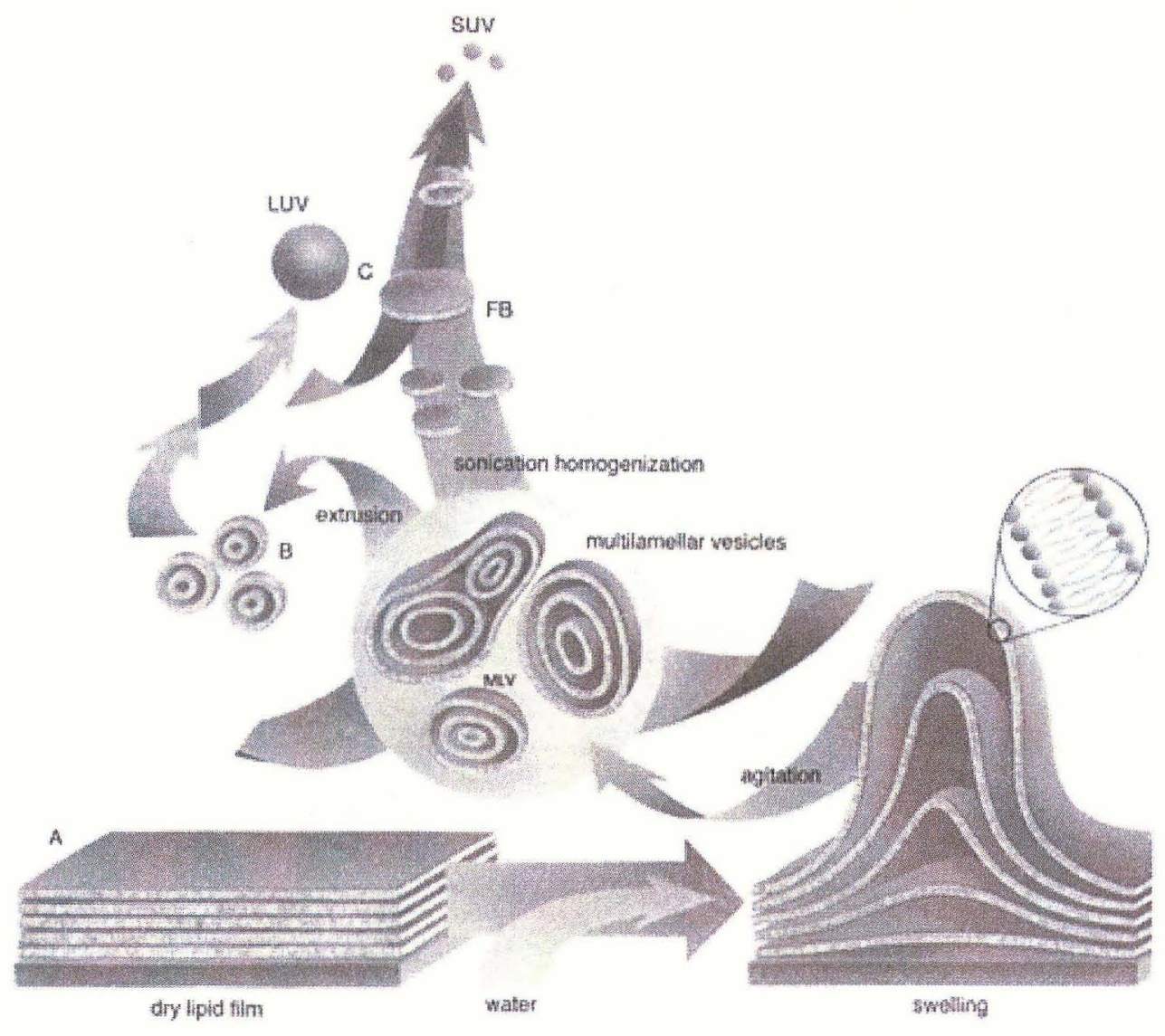




\section{FUNDAMENTAL QUESTIONS}

\section{Phenomenon:}

$\mathrm{I} / \mathrm{R}$ injury is recognized as a serious problem that occurs in a variety of medical procedures including, cardiovascular surgery, vascular bypass surgery transplantation, and reconstructive surgery. During ischemia, intracellular ATP levels decline leading to loss of cell homeostasis and cell death. This can be prevented by delivering Mg-ATP directly into the cells with the aid of FLVs.

\section{Questions:}

This dissertation addresses two questions:

1. Can the $\mathrm{Na}^{+}, \mathrm{K}^{+}$-ATPase pump activity be maintained by supplementing hypoxic human endothelial cells with direct delivery of exogenous Mg-ATP?

2. Can the vascular endothelium of ischemic skeletal muscle in rat hind limbs be preserved by direct delivery of exogenous Mg-ATP?

\section{Hypothesis \# 1}

Delivery of exogenous Mg-ATP using FLVs can preserve endothelial cell viability during chemical hypoxia.

To test hypothesis \#1, we designed two in vitro experiments that used $\mathrm{K}^{+}$ cyanide $(\mathrm{KCN})$ to induce chemical hypoxia. Experiment 1 determined the optimal dose of Mg-ATP that preserves HUVEC viability after 4 hours of chemical hypoxia. 
Experiment 2 determined the effect of varying FLV numbers on HUVEC viability after 4 hours of chemical hypoxia when the Mg-ATP levels were held constant.

\section{Hypothesis \# 2}

Direct delivery of exogenous Mg-ATP maintains $\mathrm{Na}^{+}, \mathrm{K}^{+}$-ATPase pump function following chemical hypoxia

To test hypothesis \#2, experiment \#3 was designed to determined the ability of Mg-ATP-loaded FLVs to maintain $\mathrm{Na}^{+}, \mathrm{K}^{+}$-ATPase pump function during chemical hypoxia. Cell uptake of radioactive ribidium $\left({ }^{86} \mathrm{Rb}^{+}\right)$was used to determine indirectly the $\mathrm{Na}^{+}, \mathrm{K}^{+}$-ATPase pump function.

\section{Hypothesis \#3}

Direct delivery of exogenous Mg-ATP preserves vascular endothelium viability in skeletal muscle during prolonged periods of warm ischemia, and this protection permits the reestablishment of normal blood flow during reperfusion allowing injured muscle to regenerate.

To test hypothesis \#3, a rat hind limb transplantation model was used. Five groups were included in this experiment. Using a modified Euro-Collins organ preservation solution (EC) in which dextrose was substituted with FLVs loaded with $10 \mathrm{mM}$ of Mg-ATP, we perfused isolated limbs from Wistar Furth rats every 4 hours for a total ischemic period of either 13 or $21 \mathrm{~h}$. Amputated donor limbs were incubated at room temperature $\left(23^{\circ} \mathrm{C}\right)$ in $\mathrm{EC}$ without dextrose $(13 \mathrm{~h}), \mathrm{EC}$ with empty FLVs (13 h), EC with free Mg-ATP without FLVs (13 h), and EC with Mg-ATP loaded 
FLVs (13 and $21 \mathrm{~h}$ ). After ischemic incubation, we transplanted the limbs to syngeneic recipients to avoid an immune response and rejection, and followed the animals for up to 8 days. Skin and limb viability were assessed visually. Extensor Digitorum Longus (EDL) and soleus (SOL) muscles were harvested at the end of the study and histologically scored using the MALPH-3 index. 


\section{CHAPTER 2}

\section{DELIVERY OF EXOGENOUS Mg-ATP PRESERVES NA ${ }^{+} \mathbf{K}^{+}$- ATPase PUMP FUNCTION DURING CHEMICAL HYPOXIA}

\section{Introduction}

$\mathrm{I} / \mathrm{R}$ injury is recognized as a serious problem that occurs in a variety of medical procedures including thrombolytic therapy, organ transplantation, vascular bypass surgery, trauma and reconstructive surgery ${ }^{5,67}$. l/R injury leads to post operative graft dysfunction and can contribute to delayed organ rejection. Endothelial cells have been shown to be a critical target of I/R injury. ${ }^{131-133}$

$\mathrm{I} / \mathrm{R}$ injury is a two step process. ${ }^{5}$ During ischemia, depletion of cellular energy storage, loss of cellular homeostasis and accumulation of metabolites lead to cell damage. ${ }^{3}$ This cellular damage can be further enhanced upon reperfusion by the production of oxygen radicals and chemotactic and inflammatory factors. ${ }^{4-7}$

The maintenance of ionic homeostasis throughout active transport of ions across the cell membrane is crucial for the normal functioning and survival of the cells. As cells become hypoxic, energy storages become depleted and ionic homeostasis is lost. ${ }^{6}$ It is well known that the $\mathrm{Na}^{+}, \mathrm{K}^{+}$ATPase is responsible for the maintenance of the $\mathrm{Na}^{+}$gradient by the coupled movement of $\mathrm{K}^{+}$and $\mathrm{Na}^{+}$in and out of the cell, respectively. When cells are deprived from oxygen for oxidative 
phosphorylation, intracellular levels of ATP gradually dwindle, and cause a decrease in ATPase activity, which also disrupts cell $\mathrm{Na}^{+} / \mathrm{K}^{+}$balance and membrane potential. Maintenance of the $\mathrm{Na}^{+}, \mathrm{K}^{+}$-ATPase pump activity during ischemia is crucial to the prevention of cell injury.

Providing the cell with Mg-ATP as an exogenous source of energy during anoxia would be a rational approach to maintain $\mathrm{Na}^{+}, \mathrm{K}^{+}$-ATPase pump function and potentially prevent cell death. However, the problem with this apparently simple solution is that ATP does not readily diffuse across the cell membrane due to its hydrophilic characteristics. Nevertheless, investigators have tried using exogenous ATP in conjunction with organ preservation solutions with controversial results ${ }^{102,105,108}$ and the concept has not gained widespread acceptance because adequate quantities of exogenous ATP will not diffuse into cells. To overcome this limitation, our group recently developed FLVs that rapidly deliver Mg-ATP into cells.

Thus we hypothesized that by delivering Mg-ATP directly into endothelial cells, cell viability and $\mathrm{Na}^{+}, \mathrm{K}^{+}$-ATPase pump function would be maintained when the cells are exposed to chemical hypoxia.

In this work, dose response studies were performed to optimize Mg-ATP delivery to HUVECs, and the efficacy of Mg-ATP delivery was determined by quantifying cell viability and ouabain-sensitive $\mathrm{Na}^{+}, \mathrm{K}^{+}$-ATPase pump function following chemical hypoxia. Chemical hypoxia was induced using $\mathrm{KCN}$, and cells were incubated in media devoid of any metabolically functional sugars to minimize endogenous production of ATP. The uptake of radioactive rubidium $\left({ }^{86} \mathrm{Rb}^{+}\right)$, a K $\mathrm{K}^{+}$ion 
substitute, was used to measure $\mathrm{Na}^{+}, \mathrm{K}^{+}$-ATPase pump function. Cell viability was assessed using a dye exclusion technique.

\section{Material and methods}

All experiments were conducted in cultured Human Umbilical Vein Endothelial Cells (HUVECs) and hypoxia was induced chemically by exposing the cells to KCN for 4 hours. Prior to the hypoxia experiments we determined the $\mathrm{KCN}$ concentration required to achieve complete loss of viability of cultured HUCECs after 4 hours of incubation. This experiment provided us with a standardized model of chemical hypoxia that was used in the cell viability studies.

In a 24-well plate, HUVECs were seeded at a concentration of $5 \times 10^{3}$ cells $/ \mathrm{cm}^{2}$. Cells were allowed to reach $30-40 \%$ confluence (3-4 days) and the plate was divided in 4 groups of 6 wells each. The control group was treated with $1.5 \mathrm{ml}$ of Krebs solution (without glucose) alone (no $\mathrm{KCN}$ ). The remaining 3 groups were treated with $1.5 \mathrm{ml}$ of Krebs solution containing $\mathrm{KCN}$ at one of the following concentrations:

$2.5,5.0$ and $10 \mathrm{mM}$. The plate was then incubated at room temperature for 4 hours, washed three times with HBSS, labeled with SYTOX Green and SYTO 64 dyes and fixed with $4 \%$ glutaraldehyde. Cells were counted in 10 randomly selected observation fields to determine percent viability.

\section{Cell Culture}

Cryopreserved HUVECs were purchased from Cambrex Bio Science (Walkersville, MD). Cells were seeded at a density of $5000 \mathrm{cells} / \mathrm{cm}^{2}$ and incubated at $37^{\circ} \mathrm{C}$ with Endothelial Basal Medium-2 growth media (Cambrex Bio Science) 
containing and the following supplements: Hydrocortisone, hFGF-B, VEGF, R1-IGF1, Ascorbic Acid, Heparin, FBS, hEGF, GA-1000 (Gentamcin, Amphotericin-B). Media was replaced the day after seeding and every other day there after. Dose response experiments were performed when cells reached 30 to $40 \%$ confluence (24 days), and ${ }^{86} \mathrm{Rb}^{+}$uptake experiments were performed when cells reached $100 \%$ confluence (5-9 days).

\section{FLV Preparation}

FLVs were prepared using a modification of the dry film method ${ }^{134,135}$. Briefly, 1,2-Dioleyol-sn-Glycero-3-Phosphocholine (DOPC), and 1-palmitoyl-2-oleyol-snGlycero-3-phosphate (POPA) were mixed together in chloroform at a ratio of 50:1 $(\mathrm{mol} / \mathrm{mol})$. The chloroform was then removed from the lipid material by exposure to a tream nitrogen gas. The lipid film was vacuum pumped for a period of 12 hours to remove traces of chloroform. The lipid material was hydrated in Hanks Balanced Salt Solution (HBSS) to a concentration of $25 \mathrm{mg} / \mathrm{ml}$. Mg-ATP $(1 \mathrm{mM})$ was mixed the buffer and lipid. Then, this mixture was vortexed for a period of 1 min to create multilamellar vesicles and placed in a $37^{\circ} \mathrm{C}$ bath for 5 minutes. This was repeated 6 times. The multilamellar vesicles were placed in an ice bath and sonicated with a pulse sonication ( $40 \%$ duty cycle) for a period of $1 \mathrm{~min} / \mathrm{ml}$ to produce small FLVs. The FLV solution was briefly centrifuged to remove traces of titanium from the sonicator probe. The diameter of the vesicles was measured using a Proterion DynaPro LSD Particle Size Analyzer (Proterion Corp., Piscataway, NJ) to insure that vesicle size was uniform throughout the study. The diameter of FLVs used in this study ranged between 220 and $380 \mathrm{~nm}$. 


\section{Cell Viability Assay}

HUVEC viability was assessed using SYTOX (green) and SYTO 64 (red) Nucleic Acid Stains (Molecular Probes, Eugene, OR). A diluted mixture of both dyes was prepared as per manufacturer instructions. Briefly, culture media in wells was removed and replaced with an equal amount of HEPES- Buffered saline solution $(\mathrm{H}-$ BSS) containing: $135 \mathrm{mM} \mathrm{NaCl}, 5 \mathrm{mM} \mathrm{KCl}, 1 \mathrm{mM} \mathrm{MgSO}_{4}, 1.8 \mathrm{mM} \mathrm{CaCl}_{2}$ and $10 \mathrm{mM}$ HEPES (pH 7.4). Two $\mu$ L of each, SYTOX Green and SYTO 64 were added for every $1 \mathrm{ml}$ of H-BSS needed (1:500 dilution of each) and mixed thoroughly by vortexing. The H-BSS buffer was then removed and replaced with diluted dye mixture (350-500 $\mu \mathrm{L}$ per well). After incubation for $15 \mathrm{~min}$ in the dark at room temperature, the dye solution was removed and the cells washed three times with fresh $\mathrm{H}$-BSS. Freshly prepared $4 \%$ glutaraldehyde in $\mathrm{H}-\mathrm{BSS}$ was added and incubated for 1 hour. Cells were observed using fluorescent microscopy equipped with filter sets for viewing both green (488 Abs/520 Em) and red (599 Abs/619 Em) fluorescence. The total number of cells and the number of dead cells were counted in 10 randomly selected observation fields per well. For each field, red cells (all cells) were counted first. Then, green cells were counted to determine the amount of dead cells. The values for all ten fields were summed and percent viability per well was calculated as dead cells per well/total cells in well $\times 100$. Each well was considered $n=1$. Positive and negative control dishes were run simultaneously.

\section{Measurements of Ouabain-sensitive ${ }^{86} \mathrm{Rb}^{+}$Uptake in HUVECs}

$\mathrm{Na}^{+}, \mathrm{K}^{+}$-ATPase pump activity was measured in confluent HUVECs as ouabainsensitive ${ }^{86} \mathrm{Rb}^{+}$uptake, using a similar method as previously described by McKenna 
et al. ${ }^{136}$ Uptake was measured in Hank's balanced salt solution without glucose (HBSS) containing (mM): $\mathrm{NaCl} 140, \mathrm{KCl} 5, \mathrm{MgCl}_{2} 1, \mathrm{CaCl}_{2} 2$, and HEPES $10(\mathrm{pH}$ 7.4) at $37^{\circ} \mathrm{C}$. Cells were preincubated for a specified period in HBSS containing $\mathrm{KCN}$ and various doses of Mg-ATP-loaded FUVs. To determine the ouabainsensitive ${ }^{86} \mathrm{Rb}^{+}$uptake, cells were incubated for 10 min with $100 \mu \mathrm{M}$ ouabain, followed by $30 \mathrm{~min}$ of incubation with $\sim 0.5 \mu \mathrm{Ci} / \mathrm{mL}^{86} \mathrm{Rb}^{+}$. At the end of the uptake period, cells were washed six times in $1 \mathrm{ml}$ ice-cold wash buffer. The wash buffer consisted of HBSS containing $\mathrm{RbCl}$ instead of $\mathrm{KCl}$ in order to displace ${ }^{86} \mathrm{Rb}^{+}$from extracellular sites. Cells were solubilized in Lowry reagent and total cellular protein measured by the Lowry method (Sigma protein assay kit P5656). Radioactivity was measured by liquid scintillation counting. Ouabain-sensitive uptake was calculated as the difference in uptake in the presence and absence of ouabain.

\section{Statistical considerations}

All results are expressed as mean \pm standard error of the mean (SEM). Statistical analyses were performed using SPSS software (Statistical Package for the Social Sciences, version 14) and GraphPad Prism (version 4 for Windows). For comparison between groups, means were analyzed using univariate analysis of variance (ANOVA). Levene's Test for equality of variance was performed along with the ANOVA. A multiple comparisons (Games-Howell) test for unequal variances was selected as ANOVA post-hoc statistics. Unless otherwise specified, a probability level of $p<0.01$ was taken to indicate statistical significance. For experiment 3 , the positive control and experimental group were compared using an independent-sample T-Test at the 0.05 level. 


\section{Experimental Design}

Experiment 1. Optimal dose of Mg-ATP

This experiment was performed to determine the optimal dose of Mg-ATP that would maximize cell viability after chemical hypoxia. Cultured HUVECs were seeded in wells at a concentration of 5,000 cells $/ \mathrm{cm}^{2}$ and allowed to reach $30-40 \%$ confluence (3-4 days). In the experimental groups, HUVECs were incubated with $10 \mathrm{mM} \mathrm{KCN}$ and Mg-ATP-loaded FLVs $\left(3.08 \times 10^{13} \mathrm{FLVs} / \mathrm{mL}\right)$ containing $2.5,5$, or 10 $\mathrm{mM}$ of Mg-ATP. Two control groups were included. In the negative control group (maximum cell death), HUVECs were placed in Krebs solution (without glucose) at $23^{\circ} \mathrm{C}$ containing $10 \mathrm{mM} \mathrm{KCN}$ alone (no FLV). In the positive control group (minimum cell death), cells were maintained in their culture media during the incubation period (no KCN/no FLVs). Cells were labeled with SYTOX green and SYTO 64 as described above. Then, cells were counted in 10 randomly selected observation fields to determine percent viability.

\section{Experiment 2. Effects of Mg-ATP loaded FLVs}

This experiment was performed to compare the effects of Mg-ATP-loaded FLVs and control solutions composed of either Krebs only, Mg-ATP (without FLVs) or FLVs (without Mg-ATP). HUVECs were seeded in wells at a concentration of 5,000 cells $/ \mathrm{cm}^{2}$ and allowed to reach $30-40 \%$ confluence (3-4 days). HUVECs were then placed in Krebs solution (without glucose) at $23^{\circ} \mathrm{C}$ and incubated in $10 \mathrm{mM} \mathrm{KCN}$ with one of the following: 1) Krebs alone, 2) FLVs loaded with $10 \mathrm{mM} \mathrm{Mg-ATP} \mathrm{at}$ $3.08 \times 10^{15} \mathrm{FLVs} / \mathrm{mL}$, 3) FLVs without Mg-ATP at $3.08 \times 10^{15} \mathrm{FLVs} / \mathrm{mL}$, or 4) HBSS with $10 \mathrm{mM} \mathrm{Mg-ATP.} \mathrm{A} \mathrm{positive} \mathrm{control} \mathrm{group} \mathrm{consisting} \mathrm{of} \mathrm{cells} \mathrm{incubated} \mathrm{in} \mathrm{Krebs}$ 
solution but without KCN was also included. Cells were labeled with SYTOX green and SYTO 64 dyes as previously described. Cells were counted in 10 randomly selected observation fields to determine percent viability.

\section{Experiment 3. Preservation of $\mathrm{Na}^{+}, \mathrm{K}^{+}$-ATPase function}

This experiment was performed to determine if the optimal concentration of exogenous Mg-ATP-FLVs observed to maintain cell viability in the previous experiments was able to preserve the rate of the $\mathrm{Na}^{+}, \mathrm{K}^{+}$-ATPase ion transporter during chemical hypoxia. HUVECs were seeded in wells at a concentration of 5,000 cells $/ \mathrm{cm}^{2}$ and allowed to incubate for 6-9 days until they reach confluence. HUVEC monolayers were then incubated at $23^{\circ} \mathrm{C}$ for 4 hours with Krebs solution or Krebs solution with one of the following: 1) $10 \mathrm{mM}$ Mg-ATP-loaded FLVs, 2) empty FLVs or 3) $10 \mathrm{mM}$ Mg-ATP. To measure ouabain-sensitive ${ }^{86} \mathrm{Rb}^{+}$uptake (as a substitute for $\mathrm{K}^{+}$), HUVECs were incubated for 10 min prior to the end of each experiment with or without ouabain $(100 \mu \mathrm{M})$ and followed by a $30 \mathrm{~min}$ incubation with ${ }^{86} \mathrm{Rb}^{+}(\sim 0.5$ $\mu \mathrm{Ci} / \mathrm{mL})$. At the end of the uptake period, cells were washed six times in $1 \mathrm{ml}$ icecold wash buffer. The wash buffer consisted of HBSS containing $\mathrm{RbCl}$ instead of $\mathrm{KCl}$ in order to displace ${ }^{86} \mathrm{Rb}^{+}$from extracellular sites. Cells were lysed with $0.5 \mathrm{M} \mathrm{NaOH}$ overnight at $4^{\circ} \mathrm{C}$ followed by standard colorimetric protein quantitation. A bicinchoninic acid (BCA) protein assay mixture (Pierce biotechnology, Rockford, IL) was prepared by combining reagents $A$ and $B$ (provided in kit) in a 50:1 ratio, respectively. $25-50 \mu \mathrm{L}$ of the cell lysate was added to $200 \mu \mathrm{L}$ of BCA mixture, followed by incubation at $37^{\circ} \mathrm{C}$ for $30 \mathrm{~min}$. Absorbance was read at $562 \mathrm{~nm}$. The levels of protein were then calculated from a standard curve generated with known 
quantities of protein. Radioactivity was measured by liquid scintillation counting. Ouabain-sensitive uptake was calculated as the difference in uptake in the presence and absence of ouabain.

\section{Results}

\section{Optimization of the Model}

To determine the concentration of $\mathrm{KCN}$ required to achieve complete loss of cell viability, 3 different concentrations $(2.5,5$ and $10 \mathrm{mM})$ of $\mathrm{KCN}$ were tested. Control wells (no KCN) were incubated with Krebs solution without glucose. In the control group, $95.26 \pm 1.27 \%$ of the cells were viable after 4 hours of incubation. On the groups treated with $\mathrm{KCN}$, a viability of $82.54 \% \pm 0.48 \%, 65.50 \pm 4.26 \%$ and $12.83 \pm 3.40 \%$ was observed for the wells treated with $2.5,5$ and $10 \mathrm{mM}$ of $\mathrm{KCN}$, respectively (Figure 9). The one-way ANOVA_yielded a "p" value $<0.0001$. On the post hoc multiple comparison, all groups showed a significant difference from controls $(p<0.01)$. From this experiment, the $10 \mathrm{mM}$ concentration of $\mathrm{KCN}$ was selected to perform all subsequent experiments since it resulted in more than $87 \%$ cell death after 4 hours of incubation.

\section{Experiment 1: Optimal Mg-ATP loading of FLVs}

To determine the ideal concentration of Mg-ATP that the vesicles needed to be loaded with to maintain cell viability after 4 hours of chemical hypoxia, three Mg-ATP concentrations $(2.5,5$ and $10 \mathrm{mM})$ were tested. The negative control group consisted of cells treated with Krebs solution (no FLVs). Only $16.2 \pm 2.64 \%$ were viable after 4 hours of chemical hypoxia. In the positive control group (no $\mathrm{KNC} / \mathrm{noFLV}), 92.4 \% \pm 1.25 \%$ were viable after 4 hours of incubation in culture media. 
A concentration dependent effect on viability was observed in the experimental groups, in which $20 \pm 1.24 \%, 83 \pm 1.16 \%$ and $97 \pm 0.67 \%$ of the cells were viable after chemical hypoxia when treated with FLVs loaded with 2.5, 5 and 10mM of Mg-ATP, respectively (Figure 10). The one way ANOVA showed a statistically significant difference between groups with a "p" value $<0.0001$. A post hoc multiple comparison was performed to determine the difference between the experimental and control groups. When compared to the negative control, the $2.5 \mathrm{mM}$ Mg-ATP group showed a non-significant difference $(p=0.678)$ while the 5 and $10 \mathrm{mM} \mathrm{Mg-ATP}$ groups were significantly different from controls $(p<0.0001)$. The opposite was observed when the experimental groups were compared to the positive control. A "p" value $<0.0001$ was obtained for the two lower concentration groups (2.5 and $5 \mathrm{mM} \mathrm{Mg-ATP})$ while the $10 \mathrm{mM}$ Mg-ATP group was not different from the positive control with a "p" value of 0.026 . Since $10 \mathrm{mM} \mathrm{Mg-ATP}$ loaded FLVs showed the effect to maintain viability after 4 hours of chemical hypoxia to levels comparable to controls, this Mg-ATP concentration was chosen as the optimal loading concentration for FLVs for following experiments.

Experiment 2: Mg-ATP loaded FLVs vs. control solutions

This experiment was performed to test the efficacy of $10 \mathrm{mM}$ Mg-ATP loaded FLVs in preserving cell viability during exposure to 4 hours chemical hypoxia. The test solution was compared against Krebs only, 10mM Mg-ATP (without FLVs) or FLVs (without Mg-ATP). The positive control consisting of cells incubated with Krebs solution without $\mathrm{KCN}$ showed a cell survival of $95 \pm 1.12 \%$. Ninety seven percent $\pm 0.67 \%$ of the cells incubated with $10 \mathrm{mM} \mathrm{Mg-ATP} \mathrm{FLVs} \mathrm{were} \mathrm{viable} \mathrm{after} 4$ 
hour of chemical hypoxia. For the control solution, the survival rates were $19.82 \pm 3.19 \%, 10.50 \pm 8.78 \%$ and $0.81 \pm 0.37 \%$ for Krebs solution, Mg-ATP only and FLVs only, respectively (Figure 11). A one way ANOVA showed a statistically significant difference between groups with a " $p$ " value $<0.0001$. A post hoc multiple comparison was performed to determine the difference between the experimental and control groups. A significance level of 0.01 was used. When compared to the positive control group, the $10 \mathrm{mM}$ Mg-ATP-FLV group showed a non significant statistical difference with a "p" value of 0.615 . All three control groups showed statistically significant differences when compared to both the positive control and the $10 \mathrm{Mm}$ Mg-ATP FLVs group, yielding "p" values $<0.01$. These results demonstrate that delivery of Mg-ATP using FLVs can maintain cell viability at levels comparable to non-hypoxic cells when treated cells are exposed to up to 4 hours of chemical hypoxia .

\section{Experiment 3: Mainteinance of $\mathrm{Na}^{+}, \mathrm{K}^{+}$pump activity}

This experiment was designed to determine whether the delivery of Mg-ATP to HUVECs using FLVs could maintain the ouabain sensitive $\mathrm{Na}^{+}, \mathrm{K}^{+}$-ATPase pump activity after 4 hours of chemical hypoxia. ${ }^{86} \mathrm{Rb}^{+}$uptake was used as an indicator of pump activity and is expressed as $\mathrm{mmol} / \mathrm{mg}$ protein/min. As in the viability experiments, the test solution, $10 \mathrm{mM}$ Mg-ATP loaded FLVs, was compared against Krebs solution without glucose, 10mM Mg-ATP (no FLVs) and FLVs only (no MgATP). A positive control consisting of Krebs solution with glucose was also included for comparison purposes. The rate of ${ }^{86} \mathrm{Rb}^{+}$uptake in the $10 \mathrm{mM}$ Mg-ATP FLV group of $5.46 \pm 1.34 \mathrm{mmol} / \mathrm{mg}$ prot $/ \mathrm{min}$ was not significantly different $(p=0.807)$ from that of 
the positive control of $4.8 \pm 2.58 \mathrm{mmol} / \mathrm{mg}$ prot $/ \mathrm{min}$ when compared using Student's ttest (Figure 12). The rate of ${ }^{86} \mathrm{Rb}^{+}$uptake of $4.8 \mathrm{mmol} / \mathrm{mg} \mathrm{prot} / \mathrm{min}$ obtained in our positive controls is very similar to that obtained by Kawai et al in rat brain capillary endothelial cells of $4.6 \mathrm{mmol} / \mathrm{mg} \mathrm{prot} / \mathrm{min}$. ${ }^{137}$ We were unable to measure the rate of ${ }^{86} \mathrm{Rb}^{+}$uptake in the group treated with FVLs due to loss of cell adherence to plate bottoms which caused cells to be lost during required experimental washes. Therefore, the data that was generated from this group was not reliable and it was not included in the statistical analysis. The rates of ${ }^{86} \mathrm{Rb}^{+}$uptake for the two remaining control groups were $1.31 \pm 0.41$ and $1.11 \pm 0.40 \mathrm{mmol} / \mathrm{mg} \mathrm{prot} / \mathrm{min}$ for the Krebs only and Mg-ATP only groups respectively (Figure 12). A one-way ANOVA including the $10 \mathrm{mM}$ Mg-ATP FLVs, Krebs only and Mg-ATP only groups showed a statistically significant difference between groups with a "p" value of 0.011 . The Games-Howell post hoc test showed that both control groups were different from 10mM Mg-ATP FLVs $(p<0.05)$ 
Figure 9. Percent viability of HUVECs in response to increasing doses of $\mathrm{KCN}$ for 4 hours. ${ }^{*} 0 \mathrm{mM} \mathrm{KCN}$ vs other $\mathrm{KCN}$ concentrations $p<0.01$ 


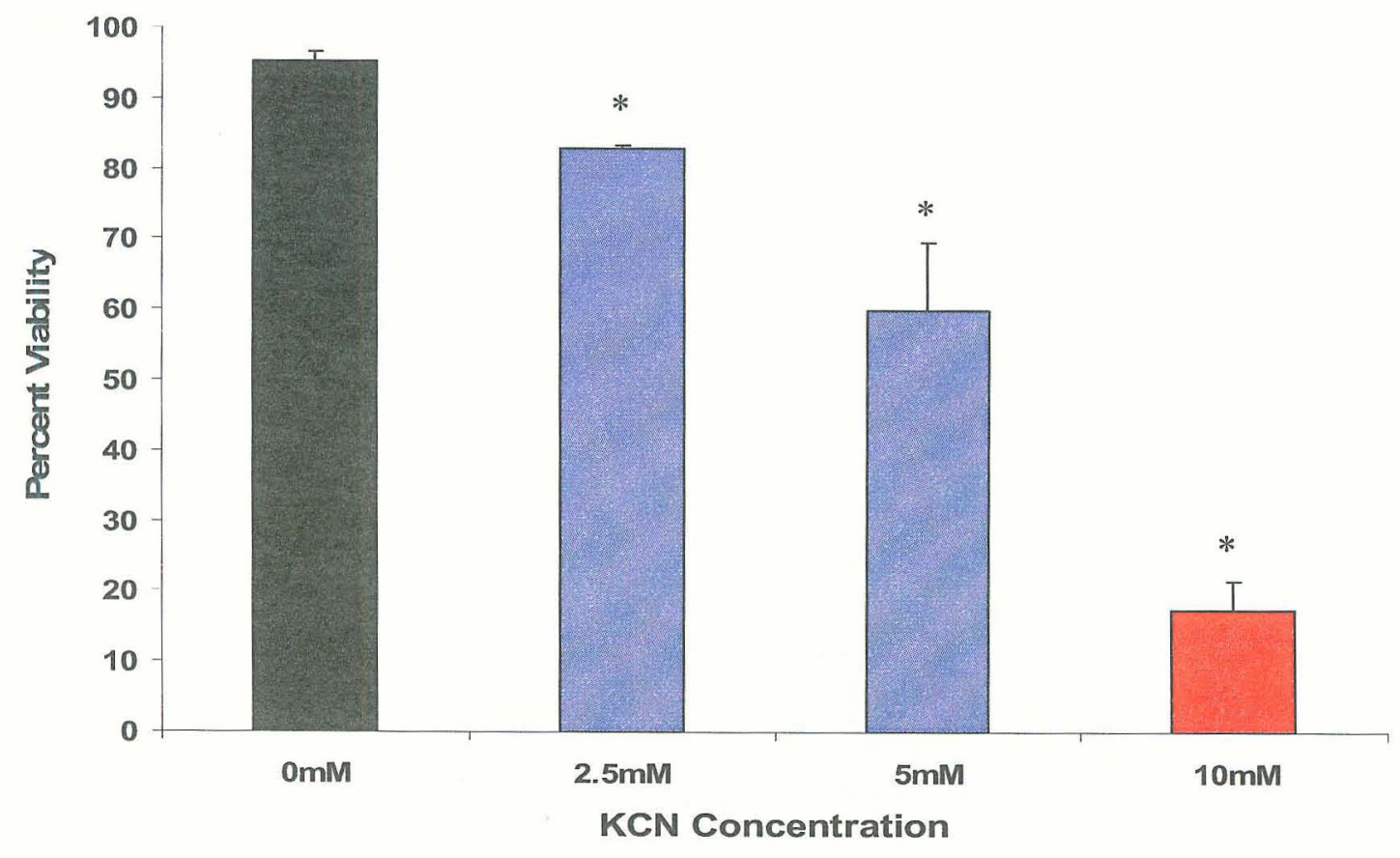


Figure 10. Percent viability of HUVECs after 4 hours of KCN treatment. Response to increasing doses of exogenous Mg-ATPvesicles. ${ }^{*}$ Control vs Mg-ATP-vesicles $p<0.0001$. 


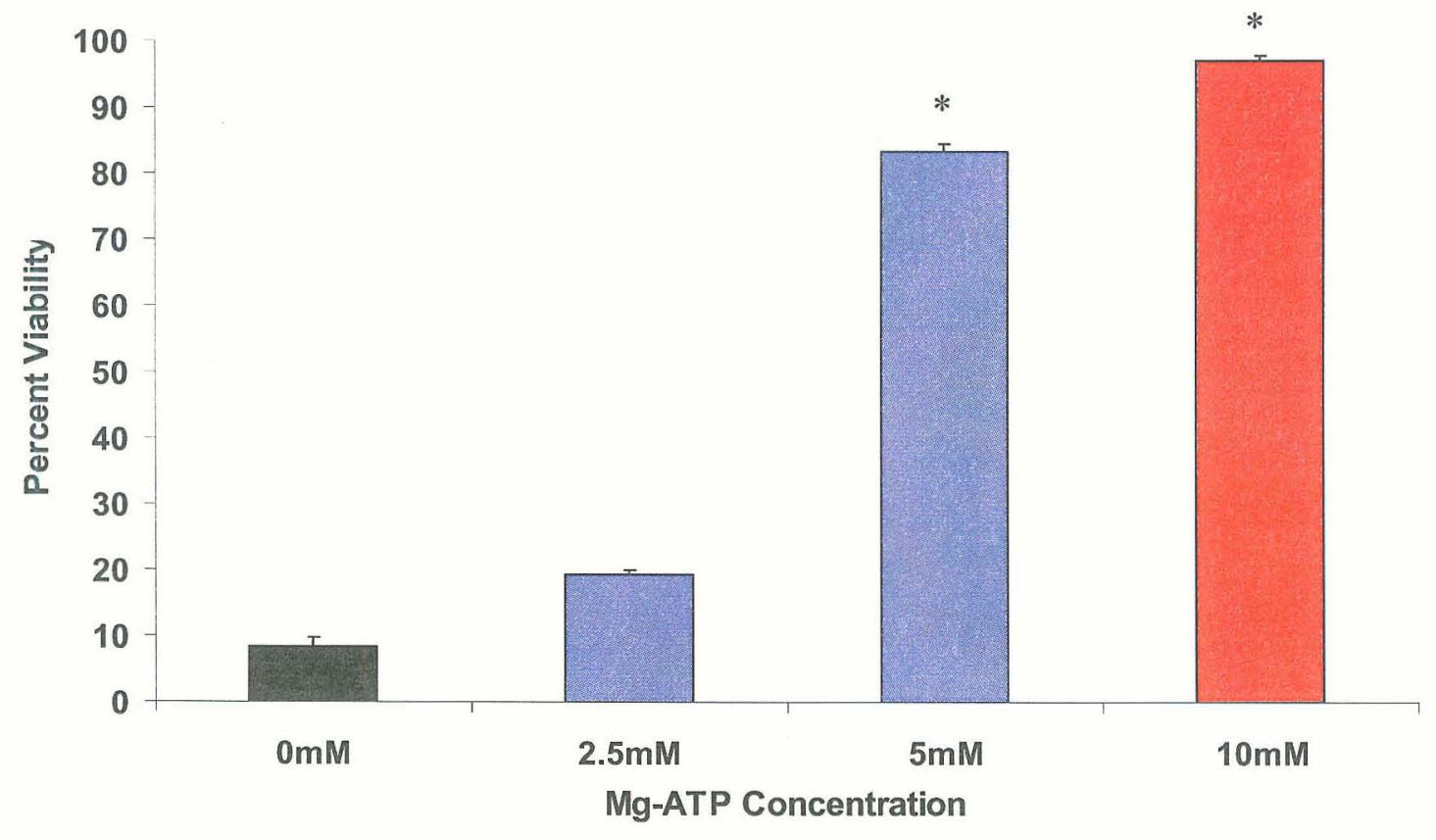


Figure 11. Percent viability of HUVECs incubated with Krebs, free MgATP, vesicles only and Mg-ATP-vesicles and subjected to 4 hours of $\mathrm{KCN}$ treatment. ${ }^{*} \mathrm{Mg}$-ATP-vesicles vs $\mathrm{KCN}$ treated controls (blue bars) $p<0.01$. ${ }^{\#}$ Mg-ATP-vesicles vs Normal controls (black bar) $p=0.615$ 


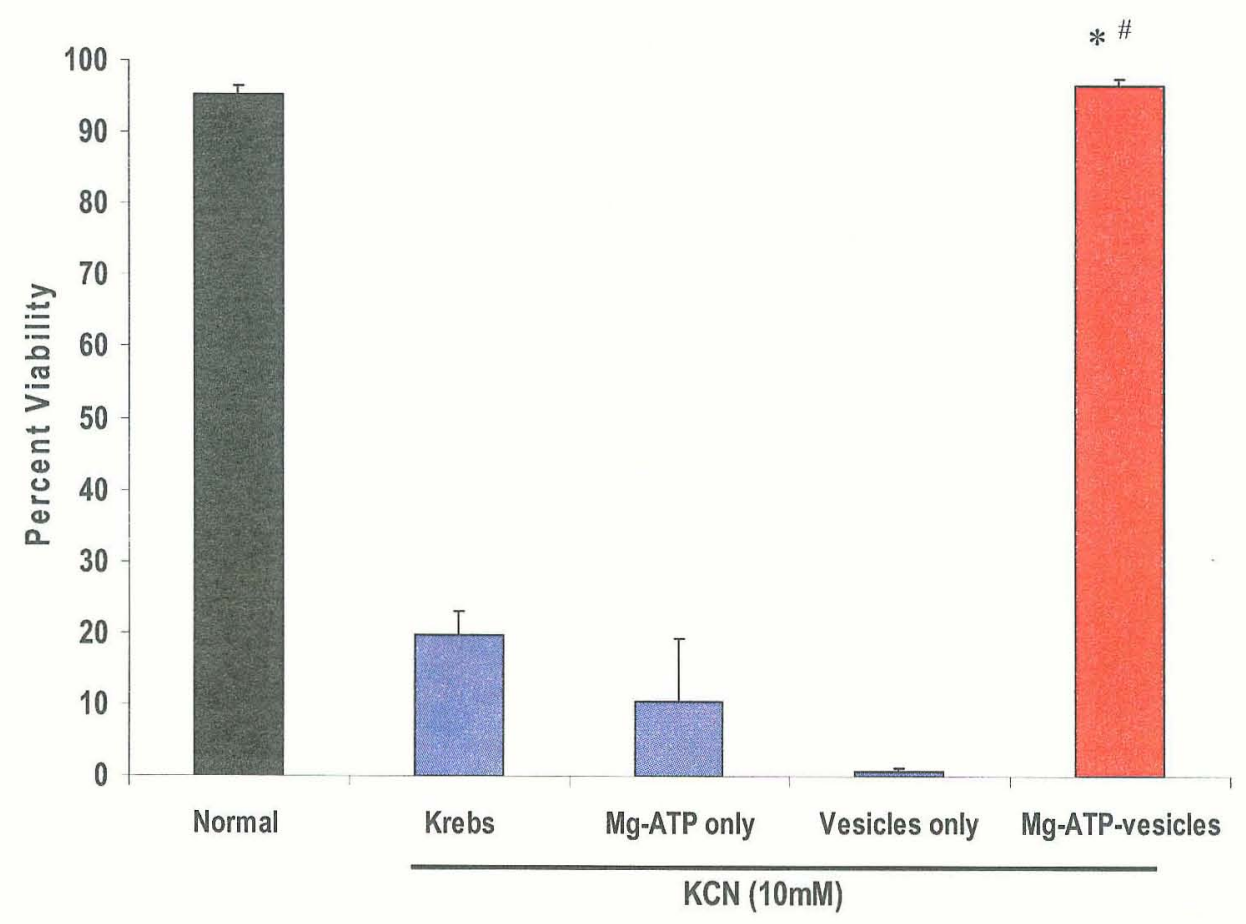


Figure 12. Results of ${ }^{86} \mathrm{Rb}^{+}$uptake experiments in HUVECs incubated in Krebs, free Mg-ATP and Mg-ATP-vesicles (10mM) and subjected to $4 \mathrm{~h}$ of KCN. * Mg-ATP-vesicles vs KCN treated controls (blue bars) $p<0.05$. ${ }^{\#}$ Mg-ATP-vesicles vs Normal controls (black bar) $p=0.807$. 


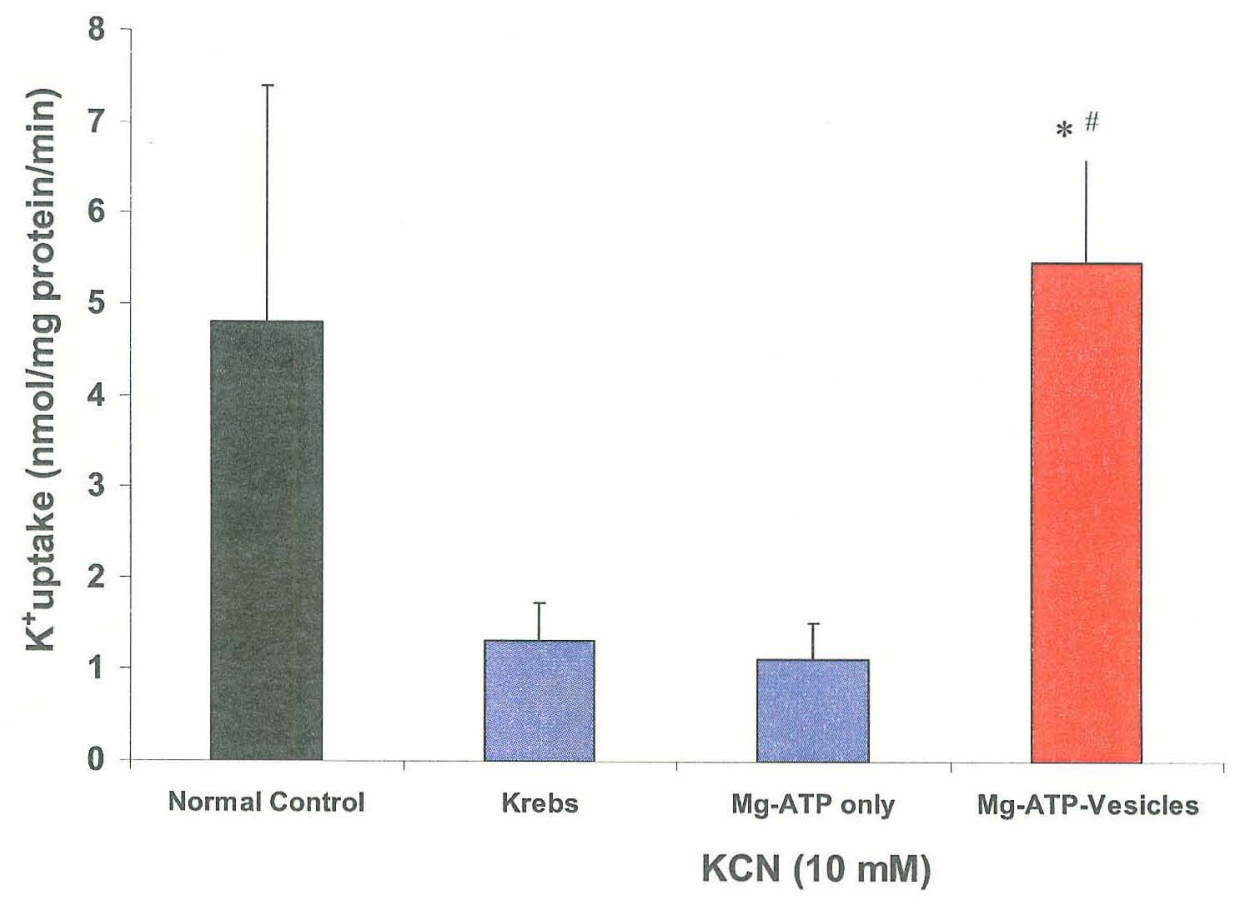




\section{Discussion}

This study performed herein examined the effects of direct delivery of Mg-ATP to endothelial cells using FLVs. It was demonstrated that Mg-ATP-FLVs are effective in maintaining cell viability and the functionality of the $\mathrm{Na}^{+}, \mathrm{K}^{+}$-ATPase pump when cells are exposed to chemical hypoxia. Potassium cyanide irreversibly inhibits the electron transport chain in the mitochondria by binding the iron atom of the enzyme cytochrome c oxidase. ${ }^{138,139}$ After cell respiration has been inhibited, ATP can still be produced from glucose through anaerobic glycolisis. Further, it has been shown that in certain cell types, blockage of the electron transport chain can enhance glucose transport across the plasma membrane as a compensatory mechanism. ${ }^{140}$ To avoid this and to make sure that the only source of energy was the exogenous Mg-ATP, we removed all metabolically functional sugars from the culture media.

The recovery of the parenchymal cells after an ischemic insult greatly depends on a patent, functioning microvasculature to restore an adequate blood supply to the ischemic region. Depletion of ATP during ischemia leads to cell damage characterized by structural changes and alterations of ionic homeostasis which in turn leads to loss of normal cell function and cell viability. 6,141

Structural changes such as alterations on the cytoskeleton will lead to loss of endothelial barrier function and increase of transendothelial permeability. ${ }^{142}$

Disintegration of F-actin filaments and the subsequent alteration of the cytoskeletal structure which in turn leads to cell retraction, loss of cell-cell and cell-matrix 
interactions and increase in paracellular macromolecular mobility have been observed in the renal microvascular endothelium exposed to ischemia. ${ }^{143,144}$ Further, these cytoskeletal changes have been demonstrated to be directly related to the levels of ATP depletion in vitro. ${ }^{145,146}$.

Intracellular accumulation of $\mathrm{Na}^{+}$during ischemia is a major determinant of ischemia reperfusion injury. Imahashi et al. ${ }^{27}$ showed in the rat heart that intracellular $\mathrm{Na}^{+}$was accumulated during ischemia and that the accumulation at the end of ischemia was related with the length of ischemia. In another study of potassium cyanide $(\mathrm{KCN})$ poisoned rat heart, Kupriyanov et al., showed that $\mathrm{KCN}$ infusion caused a decrease is phosphocreatinine and ATP and an increase in phophatidylinositol $(\mathrm{Pi})$ and $\mathrm{Na}^{+}$. This suggests that inhibition of $\mathrm{Na}^{+}, \mathrm{K}^{+}-\mathrm{ATPase}$ by $\mathrm{Pi}$ is responsible for intracellular $\mathrm{Na}^{+}$accumulation, whereas loss of $\mathrm{K}^{+}$is associated with inhibition of the $\mathrm{Na}^{+}, \mathrm{K}^{+}$-ATPase as well as an activation of ATP-sensitive $\mathrm{K}^{+}$ channels and the $\mathrm{K}^{+}$-lactate cotransporter. In rat hepatocytes, Carini et al. showed that $\mathrm{Na}^{+}$overload is critical to the development of irreversible cell injury during ischemia because it leads to uncontrolled cell swelling. ${ }^{147}$ They also showed that $\mathrm{Na}^{+}$accumulation is due to an increased $\mathrm{Na}^{+}$influx caused by the activation of the $\mathrm{Na}^{+} / \mathrm{H}^{+}$exchanger and the $\mathrm{Na}^{+}-\mathrm{HCO}_{3}^{-}$secondary to intracellular acidification and a decrease in the $\mathrm{Na}^{+}, \mathrm{K}^{+}$-ATPase activity secondary to ATP depletion. ${ }^{148}$ Also, blockade of the pump with ouabain inhibits its ATPase activity and prevents cells from maintaining their $\mathrm{Na}^{+}, \mathrm{K}^{+}$balance, which will disrupt cell homeostasis. ${ }^{22} \mathrm{Na}^{+}$ accumulation during ischemia induces contractile dysfunction, has a deleterious effect on energy metabolism ${ }^{15,29,30}$ and results in $\mathrm{Ca}^{2+}$ overload during the initial 
phase of reperfusion. ${ }^{18,32,33} \mathrm{Ca}^{2+}$ overload along with oxygen metabolite mediated damage and alteration of the arachidonic acid metabolism have been identified as central players in the development of no reflow phenomenon. $\mathrm{Ca}^{2+}$ overload will contribute to alteration of the cytoskeleton ${ }^{11}$ and will abolish oxidative phophorylation and ATP production when taken by the mitochondria in an attempt to buffer the intracellular excess. ${ }^{149,150}$ Oxygen-radical production and arachidonic acid metabolism are also dependant on the intracellular concentration of $\mathrm{Ca}^{2+}$. Augmented concentration of intracellular calcium activates a protease that converts xanthine dehydrogenase to xanthine oxidase ${ }^{151}$ and, with the re-introduction of oxygen upon reperfusion, xanthine oxidase catalyzes the conversion of hypoxanthine to xanthine and uric acid producing a burst of superoxide radical formation. ${ }^{149}$ Phospholipase $A_{2}$ will also be activated by the increased calcium concentration. Then Phospholipase $\mathrm{A}_{2}$ cleaves membrane phospholipids releasing arachidonic acid, ${ }^{152}$ the precursor for prostaglandin and thromboxane production. ${ }^{149,152}$

Preservation of the endothelium during ischemia is crucial for minimizing further damage upon reperfusion. All the above suggests that preservation of the $\mathrm{Na}^{+}, \mathrm{K}^{+}$-ATPase activity is crucial for the maintenance of cell homeostasis during hypoxia.

Current tissue preservation therapies do not deliver energy to the cells during ischemia in order to maintain cell viability. Instead, they attempt to slow down cellular metabolism by lowering the temperature, shut down ion transport systems by altering the concentration of ions in the preservation solutions or to counteract the 
effects of reperfusion by administering free radical scavengers, antithrombotic agents or leukocytes and lipid peroxidation inhibitors before reperfusion. ${ }^{4}$ Hypothermia extends viability of amputated $\operatorname{limbs}^{153}$ and has been shown to improve survival of replanted limbs in human ${ }^{154}$ and several animal models. ${ }^{155,156}$ However, muscle tissue is susceptible to cold ischemia reperfusion injury and this can be prevented by prior perfusion with a tissue preservation solution such as University of Wisconsin (UW) solution. ${ }^{157}$ Intra-arterial flushing with an organ preservation solution such as Euro-Collins and UW solutions is another treatment widely used for tissue preservation. ${ }^{4}$ UW solution has been reported to provide good endothelial protection for free flaps in humans. ${ }^{158}$ Although these therapies have been proven successful, they still pose the limitation of cold storage that is not always available.

In our study we demonstrated that, by directly delivering Mg-ATP into endothelial cells, their viability can be maintained after chemical hypoxia to levels comparable to those of normal controls. We also showed that, by delivering MgATP using FLVs to endothelial cells exposed to chemical hypoxia, the $\mathrm{Na}^{+}, \mathrm{K}^{+}-$ ATPase activity is sustained thus preventing loss of cell homeostasis.

In conclusion, the experiments described in this chapter successfully tested the concept that direct intracellular energy delivery using fusogenic lipid vesicles sustains hypoxic cells. Although further development is needed to optimize the solution for in vivo use, the foundation is set for a new approach in the tissue preservation field. 


\section{CHAPTER 3}

\section{PRESERVATION OF SKELETAL MUSCLE AT ROOM \\ TEMPERATURE USING A DIRECT INTRACELLULAR MG-ATP \\ DELIVERY SYSTEM}

\section{Introduction}

The desire to reattach dismembered body parts or to transplant limbs to make people whole again has been recorded throughout the ages in holy legends. Saint Hippolytus was reported to have replanted the leg of an oxcart driver who had suffered the misfortune of losing his limb after a lightning strike. The $13^{\text {th }}$ century legend of Saints Cosmas and Damian describes the transplantation of a leg from an unfortunate Moor to the stump site of a maimed Christian ${ }^{77}$. Although these ancient surgical feats were considered miracles and warranted sainthood, in today's medical practice, limb replantation is routinely performed and composite tissue transplantation (ie. hand and face transplantation) is gaining worldwide acceptance ${ }^{159,160}$. In the United States, the need for grafts by people suffering from amputation secondary to any cause is currently estimated to be $1,285,000$ per year.

The National Center for Health Statistics has reported that 43,000 major limb amputations per year are performed in the United States alone. When limbs are traumatically severed, autologous tissue or prosthetic materials are used to 
reconstruct the defect. Certainly, the best outcomes are achieved when native tissues are salvaged and supplemented with autologous tissue flaps transferred from adjacent or remote areas of the body. One of the challenges of salvaging amputated extremities is the mixture of tissues (skin, muscle, bone, nerves, etc) that comprise them and the differences in inherent tolerance to ischemia that each tissue type has. Skeletal muscle appears to be tolerant to ischemia for up to 4 hours, nerve changes remain reversible up to 8 hours, fat up to 13 hours, skin up to 24 hours and bone up to 4 days ${ }^{77}$. It is widely accepted that the duration of ischemia correlates directly with the severity of the injury. However, it has been difficult in muscle to distinguish when muscle cells die because gross and microscopic changes are minimal for many hours following muscle death.

When traumatic limb amputation only involves composite tissues that primarily contain skin, connective tissue, bone, and cartilage (e.g. hand digits), the "safe" warm ischemia window for re-attachment can be as long as 12 hours. However, when the amputation involves a large mass of skeletal muscle, depending on the duration of ischemia and ambient temperature, the patient is at risk of developing local compartment syndrome or systemic post-ischemia syndrome that can be lethal. Clinical cases have shown a correlation between the duration of limb ischemia and the incidence of severe systemic complications that are also associated with increased mortality ${ }^{52}$.

In the absence of oxygen during ischemia, the ATP needed to maintain cellular homeostasis is generated via anaerobic oxidation of glucose, which is highly inefficient and leads to lactic acid accumulation in skeletal muscle ${ }^{161}$. When 
ischemic limbs are replanted or reperfused after more than 4 hours of ischemia the "declamping phenomenon" is often observed systemically and is characterized by a large drop in blood pressure accompanied by a decline in total peripheral resistance. A compensatory increase in heart and respiratory rates follow, and as plasma continues to be sequestered within the ischemia damaged limb, severe hemoconcentration occurs throughout the body ${ }^{77}$. These events are also accompanied by a significant washout of potassium $\left(\mathrm{K}^{+}\right)$and acidic metabolites ${ }^{161}$ that circulate systemically. The resulting hyperkalemia, hemoconcentration, and acidosis can lead to shock syndrome in which cardiac output is reduced, cardiac arrhythmias are observed and eventually death may occur from ventricular fibrillation. ${ }^{161}$

Studies in ischemic muscle have demonstrated a close correlation between myonecrosis and depletion of ATP. Hayes et al. ${ }^{78}$ reported that during ischemia, myocyte glycogen and creatine phosphate are preferentially depleted over ATP, and that until ATP was depleted little muscle necrosis occurred. In a similar study, Labbe et al. ${ }^{79}$ reported that the extent of necrosis in muscle after 3,4 and 5 hours of warm ischemia was 2,30 , and $90 \%$, respectively. Several preservation studies have shown that endothelial cells are a critical target of ischemia and their preservation is crucial in preventing I/R. ${ }^{131-133}$ Here we hypothesize that direct delivery of exogenous Mg-ATP can preserve vascular endothelium viability in skeletal muscle during prolonged periods of warm ischemia, and this protection permits the reestablishment of normal blood flow during reperfusion allowing injured muscle to regenerate. 


\section{Materials and Methods}

\section{Experimental groups}

Syngeneic Wistar Furth rats were used in the study as limb donors and recipients to avoid antigenic interference. Five groups were included in this experiment. Groups 1 to 3 ( $n=5, n=6$ and $n=5$, respectively) were control groups and limbs were incubated for 13 hours at room temperature and perfused every 4 hours with a modified Euro-Collins (EC) containing free $1 \mathrm{mM}$ of Mg-ATP (EC-Mg-ATP), EC only or EC with unloaded FLVs (EC-FLVs), respectively. Limbs from the experimental groups 4 and 5 ( $n=7$ per group) were incubated at room temperature for 13 and 21 hours, respectively, and were perfused every 4 hours with EC containing $1 \mathrm{mM}$ of Mg-ATP-loaded FLVs (Mg-ATP-FLVs). For composition of solutions see Table 2.

\section{Preparation of FLVs}

To create FLVs containing Mg-ATP (Mg-ATP-FLV), the two phospholipids components, 1,2-Dioleyol-sn-Glycero-3-Phosphocholine (DOPC) and 1-Palmitoyl-2Oleyol-sn-Glycero-3-Phosphate (POPA) were mixed together in chloroform at a ratio of $50: 1(\mathrm{~mol} / \mathrm{mol})$. The chloroform was removed from the lipid material by exposure to nitrogen gas. The lipid film was vacuum pumped for a period of 12 hours to remove traces of choloroform. The lipid material was hydrated in EC solution (Baxter Health Corporation, Deerfield, IL) containing $1 \mathrm{mM}$ of Mg-ATP to a concentration of $25 \mathrm{mg} / \mathrm{ml}$. The buffer and lipid was vortexed for a period of 1 minute to create multilamellar vesicles and placed in a $37^{\circ} \mathrm{C}$ bath for 5 minutes, and repeated 6 times. The multilamellar vesicles were placed in an ice bath and were 
pulse sonicated ( $40 \%$ duty cycle) for a period of 5 minutes. The resultant small, fusogenic lipid vesicles were briefly centrifuged to remove traces of titanium from the sonicator probe. To create vesicles without Mg-ATP (EC-FLVs) the lipid material was hydrated with only EC and then processed as described above. For both solutions containing vesicles, a sample was taken after their preparation to measure the average hydrodynamic radius of the vesicles using a Proterion DynaPro LSD Particle Size Analyzer (Proterion Corp., Piscataway, NJ) to insure that vesicle size was uniform throughout the study. The diameter of FLVs used in this study ranged between 220 and $380 \mathrm{~nm}$. Euro Collins (EC only) solution was perfused "as is" and $1 \mathrm{mM}$ Mg-ATP was added before the perfusion to the EC-Mg-ATP solution.

Penicillin (Gibco, Invitrogen, MD) and Streptomicin (Gibco, Invitrogen, MD) at final concentrations of $200 \mathrm{U} / \mathrm{mL}$ and $200 \mu \mathrm{g} / \mathrm{mL}$, respectively, were added to all solutions after they were prepared.

\section{Hind-limb preservation and transplantation model}

Syngeneic Wistar Furth rats were used in the study as limb donors and recipients. Rats were housed in the animal research facility at the University of Louisville where they were kept in a controlled environment (humidity, temperature, 12-hour light cycle, and air flow) and had unrestricted access to food and water. All procedures were conducted under inhalation anesthesia using $2-5 \%$ isoflourane $(60 \mathrm{mg} / \mathrm{kg} \mathrm{ip})$ mixed with oxygen. Animals were shaved and their skin was prepped for surgery with betadine and ethanol. Digital thermometers and adjustable heating pads were used during operations to maintain core body temperature between $36-$ $37^{\circ} \mathrm{C}$. 
Table 2. Composition of experimental solution used in the study. 
Formulations

\begin{tabular}{|c|c|c|c|}
\hline & Components & Qty & Units \\
\hline Euro-Collins & Potassium & 115 & $\mathrm{mEq} / \mathrm{L}$ \\
\hline \multirow{5}{*}{ Solution } & Sodium & 10 & $\mathrm{mEq} / \mathrm{L}$ \\
\hline & (as HPO4=) & 85 & $\mathrm{mEq} / \mathrm{L}$ \\
\hline & (as HPO4-) & 15 & $\mathrm{mEq} / \mathrm{L}$ \\
\hline & Cholride & 15 & $\mathrm{mEq} / \mathrm{L}$ \\
\hline & Bicarbonate & 10 & $\mathrm{mEq} / \mathrm{L}$ \\
\hline \multirow[t]{2}{*}{ Antibiotics } & Penicillin & 200 & $\mathrm{U} / \mathrm{mL}$ \\
\hline & Streptomycin & 200 & $\mathrm{mg} / \mathrm{mL}$ \\
\hline ATP salt & ATP-Magnesium chloride & 1 & $\mathrm{mM}$ \\
\hline \multirow[t]{2}{*}{ Phospholipids } & $\begin{array}{l}\text { 1,2-Dioleyol-sn-Glycero-3-Phosphocholine } \\
\text { (DOPC) }\end{array}$ & 25 & $\mathrm{mg} / \mathrm{ml}$ \\
\hline & $\begin{array}{l}\text { 1-palmitoyl-2-oleoyl-sn-glycerol-3- } \\
\text { phosphate (POPA) }\end{array}$ & 0.1 & $\mathrm{mg} / \mathrm{ml}$ \\
\hline
\end{tabular}


Rats were euthanized with a lethal dose of sodium pentobarbital upon completion of the experimental protocol. All procedures in this study were performed in accordance with guidelines provided by the Animal Care and Use Committee of the University of Louisville School of Medicine, which conforms to the Guide for Care and Use of Laboratory Animals (Department of Health and Human Services, Publication No. [NIH] 86-23).

\section{Limb isolation procedure.}

A circumferential skin incision was made just proximal to the mid-thigh area. The femoral artery, vein and nerve were dissected and individual muscle groups of the hind limb were identified and divided as proximally as possible to their tendinous origins. Care was taken to not injure the profunda femoris vein. The sciatic nerve was identified, marked with a stay suture and sharply divided. The femur was exposed and divided transversely at the mid-shaft using a handle saw. Rats were anticoagulated with Heparin (50-100 U) injected intravenously into the contralateral femoral vein. After $5 \mathrm{~min}$, the femoral artery was clamped as proximally as possible, divided and cannulated with a 24-gauge catheter. The femoral vein was also divided, as proximally as possible and cannulated (Figure 13).

\section{Limb perfusion procedure.}

After limbs were isolated, blood was flushed out by perfusing $40 \mathrm{ml}$ of EC solution at a rate of $1 \mathrm{~mL} / \mathrm{min}$ using a syringe infusion pump. At the end of 1 hour of ischemia, limbs were perfused with $10 \mathrm{~mL}$ of either Mg-ATP-FLVs or one of the three control solutions (EC only or EC-Mg-ATP or EC-FLVs) at a rate of $1 \mathrm{~mL} / \mathrm{min}$. Isolated limbs were then placed in a sterile beaker containing the corresponding 
perfusion solution. The limbs were placed inside an aseptic glass chamber, where the perfusion system had been set up, to protect it from contamination (Figure 14). Subsequent perfusions of $10 \mathrm{~mL}$ of the corresponding solution were performed every 4 hours and the total number of perfusions depended on the total time of incubation. Limbs incubated for 13 hours were perfused a total of 3 times while limbs incubated for 21 hours were perfused a total of 5 times.

\section{Limb transplantation procedure.}

The operative procedure to remove the native host limb was similar to the isolation procedure described above except that the recipient was not anticoagulated and all neurovascular structures were cut as distally as possible to allow for maximum length during the anastomosis of the transplanted limb. The femoral bone was fixed using a $2 \mathrm{~mm}$ Kirschner wire inserted intramedularly. Muscles and tendons were approximated using interrupted suture (5-0 Nylon). The femoral vessels and nerves were anastomosed using microsurgical technique (10-0 Nylon) and limbs were reperfused by releasing the arterial microsurgical clamps (Figure 15). Skin was closed in layers using absorbable suture (5-0 Monocryl) and interrupted stitches. Recipients were returned to their cages where they were allowed to recover from anesthesia. For analgesia, ketoprofen (3-5 mg/kg: i.m.) was administered once a day over the first three days, and thereafter, as needed if animals displayed signs of distress. A solution (Butler® bitter safe mist, Columbus, $\mathrm{OH}$ ) was sprayed on transplanted limbs to prevent automutilation (chewing) of insensate limbs. 
Figure 13. Limb isolation procedure. After the skin and muscle are cut, the femoral vein is divided as proximally as possible and cannulated (arrow) 


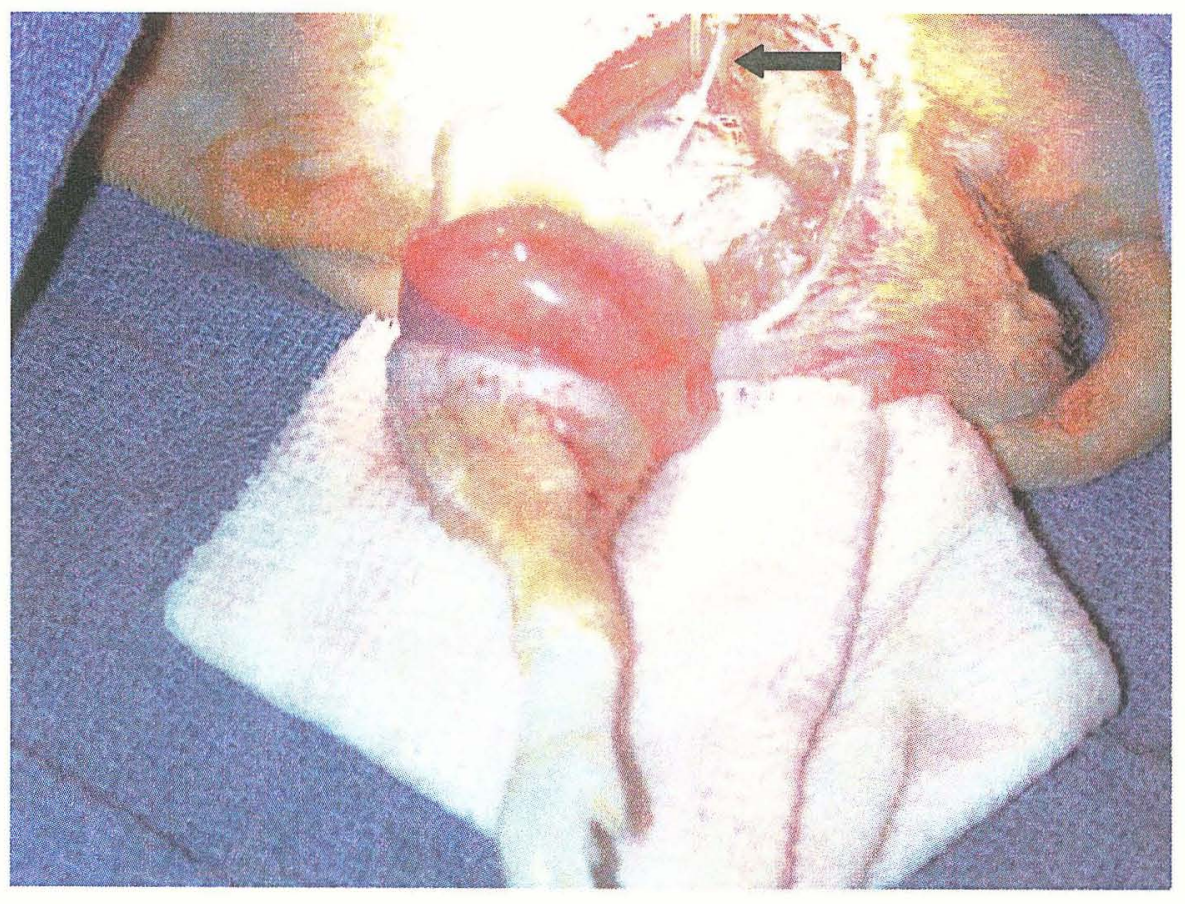


Figure 14. Aseptic glass chamber used to protect the limbs from contamination during incubation and the perfusion system set up. 


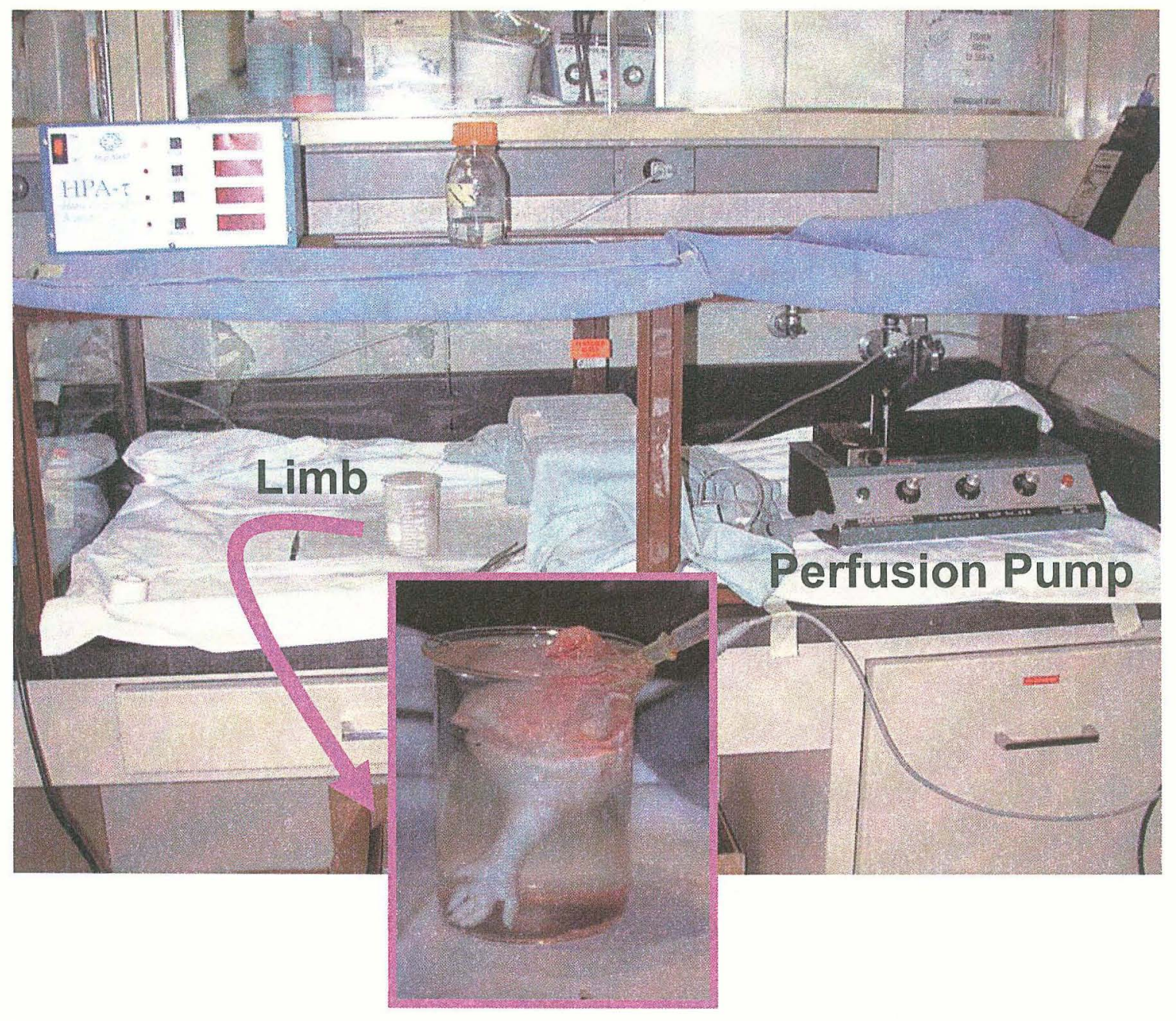


Figure 15. Anastomosis of vessels and limb reperfusion after clamp release. 
Vessel Anastomosis

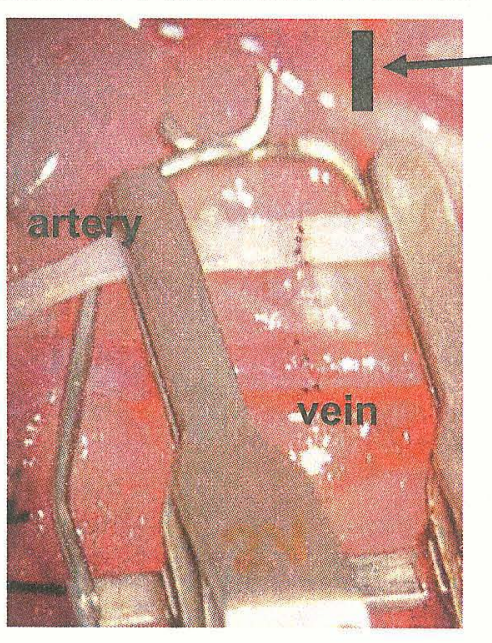

Limb Reperfusion $1 \mathrm{~mm}$

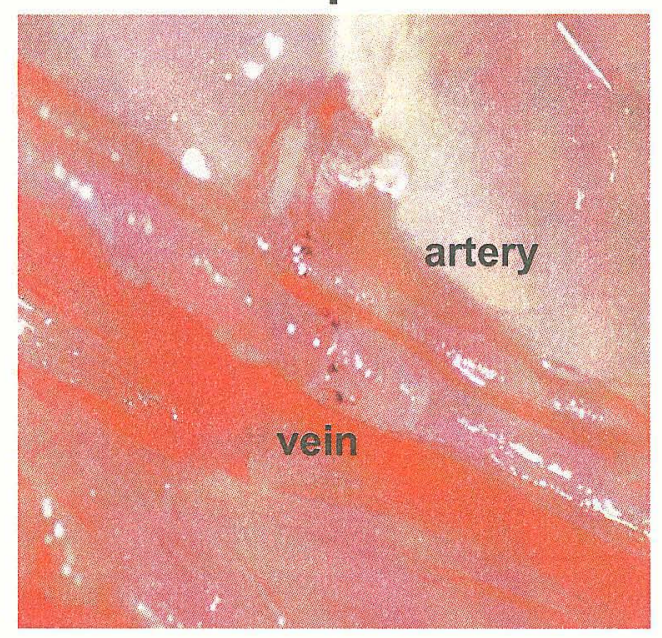




\section{Assessment of limb viability}

From immediately after reperfusion until the animals were euthanized, limbs were observed for macroscopic signs of reperfusion and animals were monitored for signs and symptoms of post-ischemia syndrome. Although, no standard criteria was generated to assess reperfusion and/or post-ischemia syndrome, a clinical assessment was made every time based on clinical observations. Signs of reperfusion (or lack thereof) included arterial and venous blood flow and muscle bleeding during limb reattachment, appearance of hyperemia or cyanosis of the skin, capillary perfusion in the nail beds, limb temperature, and swelling of limbs. To assess post-ischemia syndrome and the appearance of shock, the general health state of the animals (color of the skin, body temperature, heart and respiratory rates, responsiveness, etc) was closely monitored.

As per the experimental design, animals were to be sacrificed 8 days after limb transplantation. In some cases, animals were euthanized before the stipulated 8 days because the transplanted limb had become necrotic. The date of termination was recorded as the date of limb death which was used in the Kaplan-Meier survival analysis.

\section{Histological Analysis}

After animals were euthanized, the soleus and extensor digitorum longus $(E D L)$ muscles were isolated and harvested for histological analysis. Muscles were fixed in $10 \%$ formalin and prepared for longitudinal and transverse sections stained with hematoxin and eosin (H\&E). A pathologist in a blinded fashion scored muscle sections using the MALPH- 3 system $^{1}$ (Table 3 ). In this scoring system the 
watershed value [what was more normal than abnormal (above) and what was more abnormal than normal (below)] is 6.50 . The maximum upper score is 10.0 and the minimum score is 0.5 .

\section{Statistical considerations}

Statistical analyses were performed using SPSS software (Statistical Package for the Social Sciences, version 14) and GraphPad Prism (version 4 for Windows). Survival fractions were calculated using the product limit (Kaplan-Meier) method. Comparison of the survival curves was done using the Mantel-Cox (Log-rank) test. Histological scoring results are expressed as means \pm standard error of the mean (SEM) where $n=$ number of muscles per group. For comparison of different muscle types within each group, means were analyzed using an independent-sample TTest. For comparison between groups, means were analyzed using univariate analysis of variance (ANOVA). Levene's Test for equality of variance was performed along with the T-Test and ANOVA. A multiple comparisons (GamesHowell) test for unequal variances was selected as ANOVA post-hoc statistics. Goodman and Kruskal tau correlation was used to test the correlation between the different solutions and each individual histological parameter from the nominal by nominal crosstabs. A probability level of $p<0.05$ was selected to indicate statistical significance. 
Table 3. MALPH 3 Index ${ }^{1}$ 


\begin{tabular}{|c|c|c|c|}
\hline \multirow[t]{2}{*}{ Criteria } & \multicolumn{3}{|c|}{ Values } \\
\hline & $\mathbf{0}$ & 1 & 2 \\
\hline U2 $=$ White cell infiltration & No infiltration & Some infiltration & $\begin{array}{l}\text { Throughout the } \\
\text { slide }\end{array}$ \\
\hline $\begin{aligned} \text { U3 }= & \text { Localization of the white cell } \\
& \text { infiltration }\end{aligned}$ & No infiltration & $\begin{array}{l}\text { Periphery of } \\
\text { vessels }\end{array}$ & $\begin{array}{l}\text { Not limited to } \\
\text { periphery }\end{array}$ \\
\hline U4 = Edema & No edema & Some edema & Much edema \\
\hline $\begin{array}{l}\text { U5 = Absence of muscle fiber } \\
\text { nuclei }\end{array}$ & No absence & Some absence & $\begin{array}{c}\text { Complete areas } \\
\text { without }\end{array}$ \\
\hline U6 = Color aberrations & No aberrations & $\begin{array}{c}\text { Some } \\
\text { aberrations }\end{array}$ & $\begin{array}{c}\text { Many } \\
\text { aberrations }\end{array}$ \\
\hline $\begin{aligned} \text { U7 }= & \text { Fiber aberration and absent } \\
& \text { nuclei localization }\end{aligned}$ & $\begin{array}{l}\text { No } \\
\text { aberration/absence }\end{array}$ & $\begin{array}{l}\text { In well defined } \\
\text { areas }\end{array}$ & $\begin{array}{l}\text { Troughout the } \\
\text { slide }\end{array}$ \\
\hline $\begin{array}{l}\mathbf{U 8}^{*}=\text { There is muscle fibrosis } \\
\text { present }\end{array}$ & No Fibrosis & $\begin{array}{l}<25 \% \text { of the } \\
\text { section }\end{array}$ & $\begin{array}{l}>25 \% \text { of the } \\
\text { section }\end{array}$ \\
\hline U9 = Congestion/sludging & $\begin{array}{c}\text { No } \\
\text { congestion/sludging }\end{array}$ & Congestion & Sludging \\
\hline U10 = Endothelium aberrations & No aberrations & $\begin{array}{l}\text { At least one } \\
\text { observed }\end{array}$ & --- \\
\hline $\begin{array}{l}\text { U11 = Extravasation of } \\
\text { erythrocytes }\end{array}$ & No extravasation & Rare & $\begin{array}{l}\text { Frequent or } \\
\text { massive }\end{array}$ \\
\hline \multicolumn{4}{|c|}{ Formula } \\
\hline $\begin{array}{l}\text { M3 }=10-(1 / 3((4 \times U 2)+(0.5 \times U 3)+(1 \\
U 10+(1.5 \times U 11)))\end{array}$ & $x U 4)+(2.5 x U 5)+(1.5 x$ & )$+U 7+\left(U 8^{\star}+2\right.$ & )$+(0.5 \times \cup 9)+$ \\
\hline
\end{tabular}




\section{Results}

In this investigation, we sought to develop a preservation solution that would minimize $1 / R$ injury to ischemic extremities by minimizing energy expenditure while at the same time providing exogenous ATP to cells during the prolonged warm ischemia $\left(23^{\circ} \mathrm{C}\right)$. The effectiveness of the solution was tested in a rat hind limb transplantation model. Several analyses were used to determine the difference between limbs treated with our preservation solution for 13 or 21 hours and the control solutions. First, survival fractions for the different groups were calculated using Kaplan-Meier method and compared using the log-rank (Mantel-Cox) test; second, the histological MALPH-3 scores were compared by ANOVA and third, a more detailed analysis of the parameters used in the histological scoring was performed by cross tabulation of each parameter against all the solutions perfused.

\section{Survival}

The results showed that most control limbs became hyperemic, gradually turned cyanotic, and eventually lost viability within 4 days (Figure 16 A). In few instances, control limbs appeared viable at 8 days post-transplantation but the skeletal muscle was mostly necrotic. On the other hand, limbs treated with Mg-ATPFLVs appeared viable and well perfused at 8 days post-transplantation (Figure $16 \mathrm{~A}$ ) with the presence of areas of regeneration (Figure $16 \mathrm{~B}$ ). A survival analysis of all groups (Figure 17) showed that limbs that were ischemic for $13 \mathrm{~h}$ and treated with Mg-ATP-FLVs survived significantly longer than limbs treated with EC only $(p=0.0377)$ or $E C+$ free Mg-ATP $(p=0.0051)$. Limbs that were treated with Mg-ATP- 
FLVs for $21 \mathrm{~h}$ survived longer than limbs treated with EC-Mg-ATP $(p=0.02)$. Limbs treated with FLVs only survived significantly longer than limbs treated with EC+free Mg-ATP $(p=0.0143)$, indicating that FLVs alone appear to have some protective effect and that free Mg-ATP in EC is detrimental.

\section{Muscle Histology}

Soleus and extensor digitorum longus (EDL) were harvested from the limb at the time of death and scored by an independent pathologist in a blinded fashion using the MALPH-3 system. The number of muscles analyzed per group is smaller compared to the number of animals in each group because some muscles could not be recovered duo to either auto mutilation of limb by the animals or because the animals died overnight and were found the following morning. First, Soleus and EDL MALPH-3 scores (Table 4) were compared by t-test within each treatment group to investigate if there was a differential effect of the perfusion solutions on slow twitch and fast twitch muscle (Soleus and EDL respectively). No statistical difference was found between muscle types for any of the treatment groups $(p>0.05)$. Then, the scores for each group were compared by ANOVA within each muscle type. This showed no statistical difference between groups for either Soleus or EDL muscles ( $p$ $=0.69$ and 0.62 , respectively). Therefore, for each group the scores from both muscle types were pooled together for any further analysis (Table 5). No statistical difference was found between the combined scores for each group when compared by ANOVA $(p=0.83)$. Although, the statistical analysis of the scores shows no difference between the control limbs and the limbs treated with Mg-ATP-FLVs, the clinical and macroscopic outcome was clearly better in the latter groups. 
Figure 16. Clinical and pathological features of transplanted limbs preserved for 13 hours at $23{ }^{\circ} \mathrm{C}$. a. Limb preserved with EC only (left) and with EC-Mg-ATP-FLVs (right), after 12 hours post-transplantation, notice the cyanotic appearance of the limb not receiving EC-Mg-ATPFLVs. b. Representative longitudinal sections of soleus muscles ( $x 200)$ from a normal limb (top), and from transplanted limbs with either ECMg-ATP-FLVs (middle) or with EC only (bottom). At 8 days posttransplantation, muscle sections from viable limbs treated with EC-MgATP-FLVs had densely cellularized areas in which myocytes were markedly shrunken and were surrounded by proliferating satellite cells (middle). Muscles not receiving EC-Mg-ATP-FLVs were necrotic; notice the absence of nuclei in myocytes (bottom). c. EC-Mg-ATPFLVs treated muscle preserved for 13 hours and harvested at 8 days post-transplantation showed adjacent areas of necrosis and viable muscle undergoing regeneration. The magnified circles $(x 400)$ show a patent vessel in the area of regeneration (right) and a vessel with thrombus (left) in the area of necrosis. Notice the presence of viable endothelial cells in the patent vessel (arrow) and their complete absence in the vessel with thrombus (arrow). 


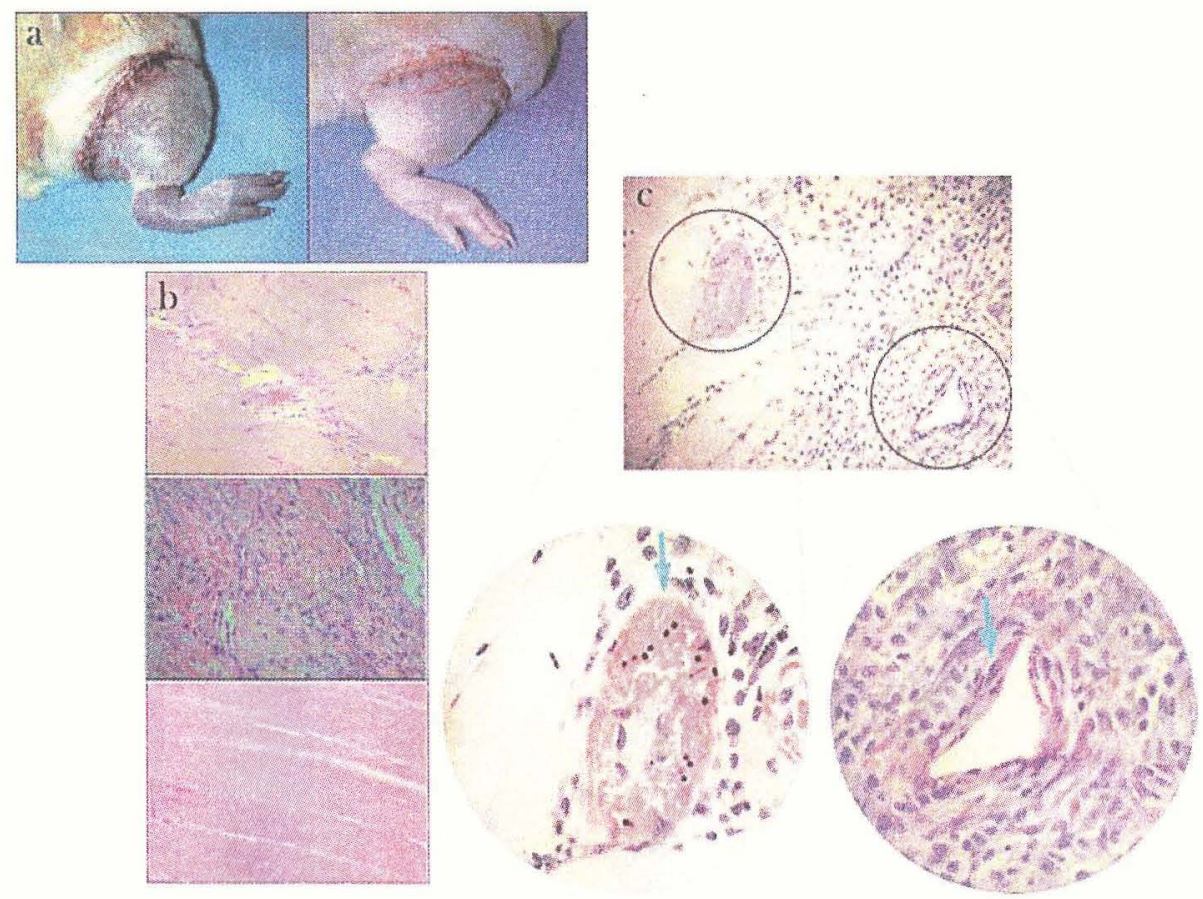


Figure 17. Kaplan-Meier survival curves of transplanted limbs preserved for 13 hours and 21 hours. Limbs treated with EC+Mg-ATPFLVs (13h) survived longer than limbs treated with EC $(p=0.0377)$ or with EC+free Mg-ATP ( $p=0.0051)$. However, limbs treated for $21 \mathrm{~h}$ were only significantly different from limbs treated with EC+free Mg-ATP $(D=0.02)$. 


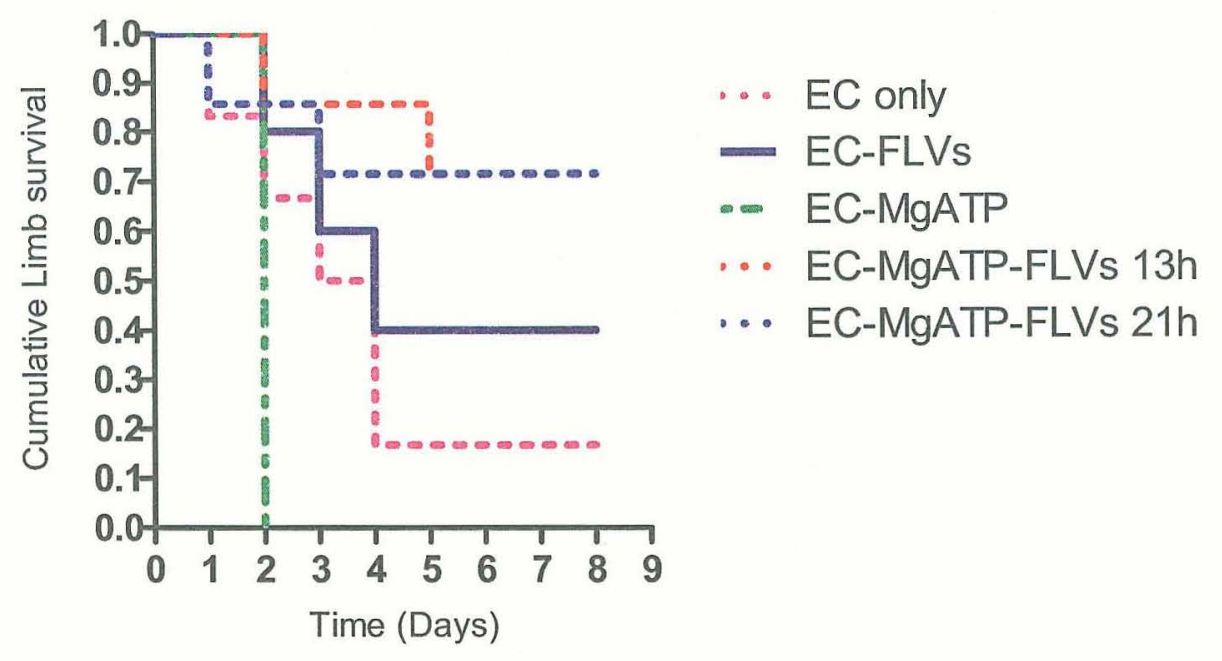


Table 4. MALPH-3 scores for Soleus (SOL) and Extersor Digitorius Longus (EDL) muscles by group. 
MALPH 3 score results

\begin{tabular}{llllll}
\hline \hline \multirow{2}{*}{ Group } & & \multicolumn{3}{c}{ M3 score } \\
\cline { 3 - 6 } & & & Mean & SEM & $\mathrm{N}$ \\
\cline { 2 - 5 } & \multirow{2}{*}{ EC only } & EDL & 5.604 & .805 & 5 \\
\cline { 2 - 5 } & SOL & 3.640 & .295 & 5 \\
\hline \multirow{2}{*}{ EC-MgATP } & EDL & 4.256 & .250 & 2 \\
\cline { 2 - 5 } & SOL & 5.505 & .000 & 2 \\
\hline \multirow{2}{*}{ EC--MgATP-FLVs-13 } & EDL & 6.115 & .364 & 3 \\
\cline { 2 - 5 } & SOL & 4.894 & 1.391 & 3 \\
\cline { 2 - 5 } & EDL & 5.375 & .669 & 6 \\
\cline { 2 - 5 } & SOL & 5.366 & .487 & 6 \\
\hline \hline
\end{tabular}

SEM $=$ Standard Error of the Mean 
Table 5. Combined (SOL and EDL) MALPH-3 scores for each treatment group. 
MALPH 3 score results

\begin{tabular}{lllll}
\hline \hline \multirow{4}{*}{ Group } & & \multicolumn{3}{c}{ M3 score } \\
\cline { 2 - 5 } & & Mean & SiEM & $\mathrm{N}$ \\
\cline { 2 - 5 } & EC-FLVs & 4.622 & .520 & 10 \\
\cline { 2 - 5 } & EC-MgATP & 4.880 & .375 & 4 \\
\cline { 2 - 5 } & EC--MgATP-FLVs-13 & 5.370 & .395 & 12 \\
\cline { 2 - 5 } & EC--MgATP-FLVs-21 & 4.805 & .862 & 10 \\
\hline \hline
\end{tabular}

$\mathrm{SEM}=\mathrm{Standard}$ Error of the Mean 


\section{Endothelium protection}

The question of why the observed clinical outcome of the experimental limbs was much better than the controls remained unanswered (although there were no statistical differences in the histology of the experimental and control groups). In order to elucidate this, a separate analysis of each variable used to obtain the MALPH-3 score was performed. The analysis consisted in the cross tabulation and correlation test between each variable and the solutions used to perfused the limbs. Of the 10 variables analyzed, only two showed statistical significance. First, the amount of cell infiltration was different between groups with a "p" value of 0.036 . In the control groups, absence of or rare infiltration was more common compared with the experimental groups in which widespread cell infiltration was observed in about $40 \%$ of the samples (Table 6). The second and most important variable that showed statistical significance was the presence of endothelium aberrations with $p=0.05$. Clearly, both of the experimental groups had less endothelium aberrations than the controls. At least one aberration was observed only on $25 \%$ and $40 \%$ of the slides when the muscles were perfused with EC-Mg-ATP-FLVs for 13 and 21 hours, respectively. This is clearly different from the $70 \%, 83.3 \%$ and $75 \%$ of slides when at least one aberration was observed for the CE only, CE Mg-ATP and CE-FLVs groups respectively (Table 7 ). This factor may very well explain the better clinical outcome observed in the two experimental groups. Also, these results suggest that Mg-ATP-loaded vesicles protected the vasculature to a greater extent than the muscle parenchyma itself. 
Table 6. Cross-tabulation showing the percentage of cell infiltration for all the solutions tested. 
Crosstab (Groups vs Cell Infiltration)

\begin{tabular}{|c|c|c|c|c|c|c|}
\hline & & & \multicolumn{3}{|c|}{ Cell infiltration } & \multirow[b]{2}{*}{ Total } \\
\hline & & & None & Rare & Widespread & \\
\hline \multirow[t]{10}{*}{ Group } & EC only & Count & 3 & 6 & 1 & 10 \\
\hline & & $\%$ within Group & $30.0 \%$ & $60.0 \%$ & $10.0 \%$ & $100.0 \%$ \\
\hline & EC-FLVS & Count & 0 & 4 & 0 & 4 \\
\hline & & $\%$ within Group & $.0 \%$ & $100.0 \%$ & $.0 \%$ & $100.0 \%$ \\
\hline & EC-MgATP & Count & 3 & 3 & 0 & 6 \\
\hline & & $\%$ within Group & $50.0 \%$ & $50.0 \%$ & $.0 \%$ & $100.0 \%$ \\
\hline & EC--MgATP-FLVs-13 & Count & 6 & 1 & 5 & 12 \\
\hline & & $\%$ within Group & $50.0 \%$ & $8.3 \%$ & $41.7 \%$ & $100.0 \%$ \\
\hline & EC--MgATP-FLVs-21 & Count & 4 & 2 & 4 & 10 \\
\hline & & $\%$ within Group & $40.0 \%$ & $20.0 \%$ & $40.0 \%$ & $100.0 \%$ \\
\hline \multirow[t]{2}{*}{ Total } & & Count & 16 & 16 & 10 & 42 \\
\hline & & $\%$ within Group & $38.1 \%$ & $38.1 \%$ & $23.8 \%$ & $100.0 \%$ \\
\hline
\end{tabular}


Table 7. Cross-tabulation showing the percentage of endothelium aberration for all the solutions tested. 
Crosstab (Groups vs Endothelium Aberrations)

\begin{tabular}{|c|c|c|c|c|c|}
\hline & & & \multicolumn{2}{|c|}{ Endotelium Aberrations } & \multirow[b]{2}{*}{ Total } \\
\hline & & & None & $\begin{array}{l}\text { At least } 1 \\
\text { observed }\end{array}$ & \\
\hline \multirow[t]{10}{*}{ Group } & EC only & Count & 3 & 7 & 10 \\
\hline & & $\%$ within Group & $30.0 \%$ & $70.0 \%$ & $100.0 \%$ \\
\hline & EC-FLVs & Count & 1 & 3 & 4 \\
\hline & & $\%$ within Group & $25.0 \%$ & $75.0 \%$ & $100.0 \%$ \\
\hline & EC-MgATP & Count & 1 & 5 & 6 \\
\hline & & $\%$ within Group & $16.7 \%$ & $83.3 \%$ & $100.0 \%$ \\
\hline & EC--MgATP-FLVs-13 & Count & 9 & 3 & 12 \\
\hline & & $\%$ within Group & $75.0 \%$ & $25.0 \%$ & $100.0 \%$ \\
\hline & EC--MgATP-FLVs-21 & Count & 6 & 4 & 10 \\
\hline & & $\%$ within Group & $60.0 \%$ & $40.0 \%$ & $100.0 \%$ \\
\hline \multirow[t]{2}{*}{ Total } & & Count & 20 & 22 & 42 \\
\hline & & $\%$ within Group & $47.6 \%$ & $52.4 \%$ & $100.0 \%$ \\
\hline
\end{tabular}




\section{Discussion}

In ancient holy scriptures, the reattachment of an amputated limb by Saint Hippolytus, ${ }^{77}$ was considered miraculous and warranted sainthood. Today, this ancient surgical feat is a routine procedure, the success dependant on reducing tissue injury due to ischemia and reperfusion. Reduction of the duration of ischemia is the single most important factor in prevention of reperfusion injury. However, reduction of the ischemia time is not always possible and other measures are necessary to diminish the degree of ischemia and reperfusion injury. Hypothermia prolongs the viability of amputated limbs ${ }^{153}$ and improves the survival of replanted limbs. ${ }^{154}$ Intra-arterial flushing with organ preservation solutions such as University of Wisconsin and the EC solutions have also been used to minimize ischemia and reperfusion injury. ${ }^{158}$ Also, radical scavengers, anti-inflammatory modulators and lipid peroxidation inhibitors have been added to the preservation solutions to help reduce reperfusion injury. ${ }^{162,163}$ In situations where reanastomosis is planned to be made beyond the ischemia tolerance time for the flap, intra-arterial flushing with tissue preservation solutions and local hypothermia improve flap viability significantly. ${ }^{157}$ However, in many situations such as traumatic amputation of limbs, refrigeration is not practical or is not available and these limbs only benefit from a modest ATP sparing effect brought about by the cooling of limbs to ambient temperature. This creates a need for tissue preservation solutions that do not require hypothermia to exert their tissue preservation ability. 
In this chapter, a rat limb transplantation model was used to test a method to reduce IR injury in amputated limbs when those limbs are kept a room temperature during the ischemia period. This method uses fusogenic lipid vesicles to directly deliver Mg-ATP inside the cell. This direct energy delivery method is a paradigm shift from current organ preservation strategies in which substrate is provided to cells for ATP synthesis and tissue temperature is lowered $\left(\sim 4^{\circ} \mathrm{C}\right)$ to decrease cellular metabolic rate and ATP usage. By directly providing Mg-ATP to cells in ischemic limbs, our method minimizes cellular utilization of glucose and oxygen and lessens the need for low temperature hypothermia.

Skeletal muscle was a focus of the study over other limb tissues because it has the highest metabolic rate which makes it the most susceptible to IR injury. ${ }^{77,79}$ After more than 4 hours of ischemia, muscle sustains considerable damage, and upon reperfusion, releases toxic metabolites into the systemic circulation, which can have lethal consequences. ${ }^{76,77,164}$ The results of our study showed that control limbs preserved without the benefit of intracellular delivery of Mg-ATP became hyperemic, gradually turned cyanotic and eventually lost viability after reperfusion. In a few instances, the skin of control limbs remained viable up to 8 days posttransplantation. However, the skeletal muscle of these limbs was completely necrotic. This result was not unexpected since skeletal muscle has the highest metabolic rate of all the limb tissues and is the most susceptible to ischemiareperfusion injury. ${ }^{76}$ At 8 days post-transplantation, skin and skeletal muscle were viable in $83 \%$ and $67 \%$ of the limbs perfused with Mg-ATP-FLVs for 13 and 21 hours, respectively. Survival of limbs to 13 hours of warm ischemia is more than 
double than what it was previously reported by Nishikawa et al. ${ }^{165}$ In their study, adipomusculocutaneous flaps exposed for 2 hours to warm ischemia survived. Flaps exposed to 4 hours partially survived but those exposed to more than 6 hours became completely necrotic.

It was interesting to find that some portions of some muscles were not viable in our study. Nevertheless, the areas of muscle that were viable were in an active state of regeneration, suggesting that the nourishing blood flow after reperfusion continued, and in fact aided the differentiation process of surviving skeletal muscle satellite cells. Viable endothelial cells in blood vessels were found in areas surrounded by regenerating skeletal muscle fibers, where as in areas where the muscle was necrotic, the endothelial cells of vessels were not viable. Also, the amount of endothelial aberrations in both Mg-ATP-FLVs groups was less than that in the controls.

In the EC only group, limbs were incubated and perfused with EC with no additives for 13 hours. After transplantation, these limbs were immediately hyperemic, gradually turned cyanotic and eventually blood flow in the nail beds was observed to stop (Fig $16 \mathrm{~A}$ ). After calculating the MALPH-3 scores for both muscles, the mean value for soleus was $3.69 \pm 0.29$ and for EDL was $5.60 \pm 0.80$ and were not statistically different $(p=0.07)$. These scores reflect a moderate degree of histological abnormality consistent with the presence of thrombus or congestion in blood vessels and endothelial aberrations, and a marked absence of nuclei in myofibrils at a higher degree than in other groups (Fig 16 B). However, these results 
indicate that EC solution had the same effect on the predominantly slow-twitch fiber soleus muscle and the predominantly fast-twitch EDL muscle.

In the second group (EC-FLVs), limbs were incubated with EC and lipid vesicles without Mg-ATP for 13 hours. It was hypothesized that membrane pores formed during lipid vesicle fusion could hyperpolarize cells and protect energy reserves. However, the macroscopic outcome of these limbs was similar to the limbs receiving EC with no additives. The limbs during reperfusion were hyperemic, became cyanotic and ultimately blood flow stopped. The muscle histological analysis showed that the mean MALPH-3 index for the soleus was $5.50 \pm 0.2$ and for the EDL was $4.25 \pm 0.24(p=0.126)$. These scores also reflected a moderate level of histological abnormality similar to the muscles perfused with EC solution alone. The damage was similar between fast-twitch and slow-twitch muscle.

In the third group (EC-Mg-ATP), limbs were incubated with EC solution containing $1 \mathrm{mM}$ of Mg-ATP but no vesicles for 13 hours. This experiment tested the ability of Mg-ATP to diffuse inside cells of limb tissues and provide ATP-derived energy during ischemia. The macroscopic outcome of limbs was similar to the two experimental groups above. The muscle histological analysis showed that the mean MALPH-3 index for the soleus was $4.89 \pm 1.39$, and for the EDL was $6.11 \pm 0.36$ $(p=0.47)$. These scores also reflected a moderate degree of histological abnormality similar to the muscles perfused with EC alone. The damage was similar between fast-twitch and slow-twitch muscle.

In the fourth group (EC-Mg-ATP-FLVs 13), limbs were incubated with EC solution containing vesicles loaded with $1 \mathrm{mM}$ of Mg-ATP for 13 hours. It was 
hypothesized that Mg-ATP-loaded vesicles would deliver Mg-ATP into the cytosol of cells in limb tissues, prevent the complete depletion of intracellular Mg-ATP levels, and maintain muscle cell homeostasis. The macroscopic outcome of these limbs was very different from the three control groups above. Only in one of seven transplanted limbs were venous thrombus observed and blood flow eventually stopped within an hour of reperfusion. However, in the six successful limbs, there were no signs of excessive hyperemia during early reperfusion, limbs were pinkish in color, they were well perfused and circulation of blood in exposed muscle and nail beds was apparent (Fig $16 \mathrm{~A}$ ). Histological analysis of skeletal muscle showed that the mean MALPH-3 index for the soleus was $5.36 \pm 0.48$, and for the EDL was 5.37 $\pm 0.66(p=0.991)$. Although, these scores are close to the scores for controls and it reflects a moderate degree of histological abnormality, the clinical outcome of the limbs in this group was particularly different and much better. Most blood vessels appeared normal and viable, the endothelium had few aberrations, and there was no evidence of thrombus or congestion in 5 out of the 6 successful limbs. As reflected by the mean MALPH-3 scores, the soleus and EDL muscles were viable. However, there were necrotic fibers present surrounded by considerable muscle fiber regeneration. The EC-Mg-ATP-FLVs solution appeared to protect equally fast-twitch and slow-twitch muscles.

In a fifth set of experiments, to test the preservation ability of EC-Mg-ATP-FLVs solution, the incubation period of limbs was extended to 21 hours. Similarly to the 13-hour group, the macroscopic outcome of these limbs was very different from the control groups. Even after 21 hours of warm ischemia, in the majority of these limbs, 
there were no signs of excessive hyperemia during early reperfusion, limbs were pinkish in color, they looked well perfused and circulation of blood in exposed muscle and nail beds was apparent. The mean MALPH-3 index for the soleus was $5.03 \pm 1.59$, and for the EDL was $4.57 \pm 0.88(p=0.804)$. In the same way as with the 13-hour group, the scores are close to those of controls, reflecting a moderate degree of histological abnormality. However, in this group the clinical outcome was particularly different and most blood vessels appeared normal and viable, with the histological sections showing less endothelial aberrations (Table 7). Also, the limbs treated with Mg-ATP-FLVs showed an increased amount of cell infiltration (Figure 16 $B$ and Table 6). This may be explained by the fact that there was a patent circulation in these limbs allowing good blood flow that, although it lead to increased cell infiltration, it also helped the muscle to regenerate.

These results indicate that EC solution, lipid vesicles alone or EC-Mg-ATP do not provide a protective effect to skeletal muscle and blood vessels after prolonged ischemia and reperfusion. On the other hand, EC-Mg-ATP-FLVs solution appeared to protect the limbs for up to 21 hours of warm ischemia.

In conclusion, the fusogenic lipid vesicles used in this study were effective in delivering Mg-ATP into cells in warm ischemic limbs. Endothelial cells of skeletal muscle vessels appeared to be protected along with skeletal muscle satellite cells in the parenchyma. Satellite cells appeared to be stimulated to regenerate new muscle tissue. Further optimization of ATP-FLVs for limb preservation is needed. This direct ATP delivery technique has the potential to be used in many clinical situations to combat ischemia. 


\section{CHAPTER 4}

\section{CONCLUDING REMARKS}

This dissertation presents new information regarding the direct delivery of MgATP to ischemic muscle using small fusogenic lipid vesicles. The results presented here show evidence that direct intracellular delivery of energy in the form of Mg-ATP is feasible and provides the basis for further development of this technology.

In our first set of experiments we demonstrated in vitro that by delivering MgATP to cultured HUVECS, that viability and $\mathrm{Na}^{+} \mathrm{K}^{+}$-ATPase pump funtion can be maintained when these cells are exposed to chemical hypoxia. For these experiments the lipid vesicles and Mg-ATP concentration were optimized to provide protection against chemical hypoxia for up to 4 hours. Although, no attemps were made here to extend the protection beyond 4 hours, this could potentially be achieved by modifying the vesicles' lipid composition and Mg-ATP content. Engineering of vesicles to deliver Mg-ATP for extended periods of time may be possible. This could be solved by using mixed formulations of fast and slow fusogenic lipid vesicles.

Technical limitations prevented us from characterizing the effects of exogenous Mg-ATP on intracellular pathways and structures. Further investigation of the effects 
of Mg-ATP on cellular organelles, intracellular trafficking and on the cytoskeleton as well as the effect of vesicle fusion on the cellular membrane is needed. This knowledge will be crucial for further engineering and development of this technology.

In our last series of experiments we showed that limbs subject to 13 and 21 hours of warm ischemia survived longer when perfused with Mg-ATP FLVs than when perfused with control preservation solutions. Although, we failed to demostratate statistical significant difference in the histological score, muscles perfused with Mg-ATP FLVs had clearly less endothelial aberrations than controls. Also, muscles perfused with Mg-ATP FLVs showed signs of regeneration and increased cell infiltration suggesting that blood vessels were protected during ischemia, allowing good blood flow upon reperfusion.

Preservation solutions used routinely in clinical practice have proven to be effective in preserving ischemic tissues for prolonged periods of time. One caviat is the need for cold storage to maximize their effect. In many clinical situations, rapid access to refrigeration, let alone more complex organ cooling devices, is very limited. In these situations a preservation solution that does not need cooling, such as Mg-ATP FLVs would be extremely useful.

There is, indeed, much work to be done to optimize this technology. Although challenging, the lipid vesicles should be engineered to deliver Mg-ATP for longer periods of time to avoid the need for repeated perfusions. The mechanism involved in vesicle fusion and delivery of Mg-ATP should be further studied and a better understanding of the effects of direct energy delivery to tissues is crucial. 


\section{REFERENCES}

1. Werker,P.M.N. Free Flap Preservation: An Experimental Study on Cold Ischaemic Tolerance in Rats. Chapter 8: Latissimus Dorsi Flaps: A Survival and Morphology Study after Cold Preservation. 183-206. 1992. Ref Type: Thesis/Dissertation

2. Ostro,M.J. Liposomes. Sci. Am. 256, 102-111 (1987).

3. Boutilier,R.G. Mechanisms of cell survival in hypoxia and hypothermia. J. Exp. Biol. 204, 3171-3181 (2001).

4. Khalil,A.A., Aziz,F.A. \& Hall,J.C. Reperfusion injury. Plast. Reconstr. Surg. $117,1024-1033$ (2006).

5. Anaya-Prado,R., Toledo-Pereyra,L.H., Lentsch,A.B. \& Ward,P.A. Ischemia/reperfusion injury. J. Surg. Res. 105, 248-258 (2002).

6. Carden,D.L. \& Granger,D.N. Pathophysiology of ischaemia-reperfusion injury. J. Pathol. 190, 255-266 (2000).

7. Kaminski,K.A., Bonda,T.A., Korecki,J. \& Musial,W.J. Oxidative stress and neutrophil activation--the two keystones of ischemia/reperfusion injury. Int. J. Cardiol. 86, 41-59 (2002).

8. Gerlach,E. \& Zimmer,H.G. Alterations of myocardial adenine nucleotide metabolism. Recent Adv. Stud. Cardiac. Struct. Metab 7, 121-130 (1975).

9. Guyton,A.C. Physiology of the human body. Saunders, Philadelphia (1979).

10. Marzi,I., Zhi,Z.N., Zimmermann,F.A., Lemasters,J.J. \& Thurman,R.G. Xanthine and hypoxanthine accumulation during storage may contribute to reperfusion injury following liver transplantation in the rat. Transplant. Proc. 21, 1319-1320 (1989).

11. Kristensen,S.R. Mechanisms of cell damage and enzyme release. Dan. Med. Bull. 41, 423-433 (1994).

12. Grum,C.M. Zelenock,G.B. (ed.), pp. 47-62 (Mosby, St. Louis,1990). 
13. Opie,L.H. Opie,L.H. (ed.), pp. 136-153 (Grune \& Stratton, London,1984).

14. Ozawa,K. Energy metabolism. Cowley,R.A. \& Trump,B.F. (eds.), pp. 7483 (Williams \& Wilkins, Baltimore,1982).

15. Baracos,V., Rodemann,H.P., Dinarello,C.A. \& Goldberg,A.L. Stimulation of muscle protein degradation and prostaglandin E2 release by leukocytic pyrogen (interleukin-1). A mechanism for the increased degradation of muscle proteins during fever. N. Engl. J. Med. 308, 553-558 (1983).

16. Kristensen,S.R. A critical appraisal of the association between energy charge and cell damage. Biochim. Biophys. Acta 1012, 272-278 (1989).

17. Meisenberg,G. \& Simmons,W.H. (eds.), pp. 75-84 (Mosby, St Louis, 1998).

18. Bergstrom,J., Bostrom,H., Furst,P., Hultman,E. \& Vinnars,E. Preliminary studies of energy-rich phosphagens in muscle from severely ill patients. Crit Care Med. 4, 197-204 (1976).

19. Garfinkel,L. \& Garfinkel,D. Magnesium regulation of the glycolytic pathway and the enzymes involved. Magnesium 4, 60-72 (1985).

20. Heaton FW. Metal lons In Biologic Systems. Siegel H. (ed.), pp. 119 (Marcel Dekker, New York,1990).

21. SKOU,J.C. The influence of some cations on an adenosine triphosphatase from peripheral nerves. Biochim. Biophys. Acta 23, 394-401 (1957).

22. Alberts B. Molecular Biology of the Cell. Garland Science, Taylor and Francis Group, New York, NY (2006).

23. Cowan,J.A. Metal Activation of Enzymes in Nucleic Acid Biochemistry. Chem. Rev. 98, 1067-1088 (1998).

24. Boron,W.F. \& Boulpaep,E.L. Medical physiology a cellular and molecular approach. W.B. Saunders, Philadelphia, PA (2003).

25. Jansen,M.A., Shen,H., Zhang,L., Wolkowicz,P.E. \& Balschi,J.A. Energy requirements for the $\mathrm{Na}+$ gradient in the oxygenated isolated heart: effect of changing the free energy of ATP hydrolysis. Am. J. Physiol Heart Circ. Physiol 285, H2437-H2445 (2003).

26. Harold FM. The Vital Force: A Study of Bioenergetics. New York: Freeman (1986). 
27. Imahashi,K. et al. Intracellular sodium accumulation during ischemia as the substrate for reperfusion injury. Circ. Res. 84, 1401-1406 (1999).

28. Kupriyanov,V.V., Yang,L. \& Deslauriers,R. Cytoplasmic phosphates in $\mathrm{Na}(+)-\mathrm{K}+$ balance in $\mathrm{KCN}$-poisoned rat heart: a 87Rb-, 23Na-, and 31PNMR study. Am. J. Physiol 270, H1303-H1311 (1996).

29. Hendrikx,M. et al. New $\mathrm{Na}(+)-\mathrm{H}+$ exchange inhibitor $\mathrm{HOE} 694$ improves postischemic function and high-energy phosphate resynthesis and reduces $\mathrm{Ca} 2+$ overload in isolated perfused rabbit heart. Circulation $\mathbf{8 9}$, 2787-2798 (1994).

30. Pike,M.M. et al. NMR measurements of $\mathrm{Na}+$ and cellular energy in ischemic rat heart: role of $\mathrm{Na}(+)-\mathrm{H}+$ exchange. Am. J. Physiol 265, H2017H2026 (1993).

31. Belkin,M., Brown,R.D., Wright,J.G., LaMorte,W.W. \& Hobson,R.W. A new quantitative spectrophotometric assay of ischemia-reperfusion injury in skeletal muscle. Am. J. Surg. 156, 83-86 (1988).

32. Kusuoka,H. \& Marban,E. Cellular mechanisms of myocardial stunning. Annu. Rev. Physiol 54, 243-256 (1992).

33. Kusuoka,H., Camilion de Hurtado,M.C. \& Marban,E. Role of sodium/calcium exchange in the mechanism of myocardial stunning: protective effect of reperfusion with high sodium solution. J. Am. Coll. Cardiol. 21, 240-248 (1993).

34. Forman,H.J. \& Torres,M. Redox signaling in macrophages. Mol. Aspects Med. 22, 189-216 (2001).

35. Xaus,J. et al. Molecular mechanisms involved in macrophage survival, proliferation, activation or apoptosis. Immunobiology 204, 543-550 (2001).

36. Cowled,P.A., Leonardos,L., Millard,S.H. \& Fitridge,R.A. Apoptotic cell death makes a minor contribution to reperfusion injury in skeletal muscle in the rat. Eur. J. Vasc. Endovasc. Surg. 21, 28-34 (2001).

37. Allen,D.L. et al. Apoptosis: a mechanism contributing to remodeling of skeletal muscle in response to hindlimb unweighting. Am. J. Physiol 273, C579-C587 (1997).

38. Allen,D.L., Roy,R.R. \& Edgerton,V.R. Myonuclear domains in muscle adaptation and disease. Muscle Nerve 22, 1350-1360 (1999).

39. Borisov,A.B. \& Carlson,B.M. Cell death in denervated skeletal muscle is distinct from classical apoptosis. Anat. Rec. 258, 305-318 (2000). 
40. Dirks,A. \& Leeuwenburgh,C. Apoptosis in skeletal muscle with aging. Am. J. Physiol Regul. Integr. Comp Physiol 282, R519-R527 (2002).

41. Powers,S.K., Kavazis,A.N. \& McClung,J.M. Oxidative stress and disuse muscle atrophy. J. Appl. Physiol (2007).

42. Sandri,M. Apoptotic signaling in skeletal muscle fibers during atrophy. Curr. Opin. Clin. Nutr. Metab Care 5, 249-253 (2002).

43. Sandri,M. et al. Apoptosis, DNA damage and ubiquitin expression in normal and $\mathrm{mdx}$ muscle fibers after exercise. FEBS Lett. 373, 291-295 (1995).

44. Knight,K.R. et al. Muscle cells become necrotic rather than apoptotic during reperfusion of ischaemic skeletal muscle. Int. J. Exp. Pathol. 80, 169-175 (1999).

45. Primeau,A.J., Adhihetty,P.J. \& Hood,D.A. Apoptosis in heart and skeletal muscle. Can. J. Appl. Physiol 27, 349-395 (2002).

46. Suzuki,H., Poole,D.C., Zweifach,B.W. \& Schmid-Schonbein,G.W. Temporal correlation between maximum tetanic force and cell death in postischemic rat skeletal muscle. J. Clin. Invest 96, 2892-2897 (1995).

47. Burgess,D.H. et al. Human skeletal muscle cytosols are refractory to cytochrome c-dependent activation of type-II caspases and lack APAF-1. Cell Death. Differ. 6, 256-261 (1999).

48. Irmler,M. et al. Inhibition of death receptor signals by cellular FLIP. Nature 388, 190-195 (1997).

49. Koseki,T., Inohara,N., Chen,S. \& Nunez,G. ARC, an inhibitor of apoptosis expressed in skeletal muscle and heart that interacts selectively with caspases. Proc. Natl. Acad. Sci. U. S. A 95, 5156-5160 (1998).

50. Ruest,L.B., Khalyfa,A. \& Wang,E. Development-dependent disappearance of caspase-3 in skeletal muscle is post-transcriptionally regulated. J. Cell Biochem. 86, 21-28 (2002).

51. McClung,J.M. et al. Caspase-3 regulation of diaphragm myonuclear domain during mechanical ventilation-induced atrophy. Am. J. Respir. Crit Care Med. 175, 150-159 (2007).

52. Abbott,W.M., Maloney,R.D., McCabe,C.C., Lee,C.E. \& Wirthlin,L.S. Arterial embolism: a 44 year perspective. Am. J. Surg. 143, 460-464 (1982). 
53. Jejurikar,S.S., Marcelo,C.L. \& Kuzon,W.M., Jr. Skeletal muscle denervation increases satellite cell susceptibility to apoptosis. Plast. Reconstr. Surg. 110, 160-168 (2002).

54. Stangel,M. et al. $\mathrm{H} 2 \mathrm{O} 2$ and nitric oxide-mediated oxidative stress induce apoptosis in rat skeletal muscle myoblasts. J. Neuropathol. Exp. Neurol. 55, 36-43 (1996).

55. Fan,C., Zwacka,R.M. \& Engelhardt,J.F. Therapeutic approaches for ischemia/reperfusion injury in the liver. J. Mol. Med. 77, 577-592 (1999).

56. Zhou,W. et al. Subcellular site of superoxide dismutase expression differentially controls AP-1 activity and injury in mouse liver following ischemia/reperfusion. Hepatology 33, 902-914 (2001).

57. Kroemer,G., Zamzami,N. \& Susin,S.A. Mitochondrial control of apoptosis. Immunol. Today 18, 44-51 (1997).

58. Cook,S.A., Sugden,P.H. \& Clerk,A. Regulation of bcl-2 family proteins during development and in response to oxidative stress in cardiac myocytes: association with changes in mitochondrial membrane potential. Circ. Res. 85, 940-949 (1999).

59. Jurgensmeier,J.M. et al. Bax directly induces release of cytochrome c from isolated mitochondria. Proc Natl. Acad. Sci U. S. A 95, 4997-5002 (1998).

60. Misao,J. et al. Expression of bcl-2 protein, an inhibitor of apoptosis, and Bax, an accelerator of apoptosis, in ventricular myocytes of human hearts with myocardial infarction. Circulation 94, 1506-1512 (1996).

61. Katori,M. \& Berne,R.M. Release of adenosine from anoxic hearts. Relationship to coronary flow. Circ. Res. 19, 420-425 (1966).

62. Klein,H.H. et al. Loss of canine myocardial nicotinamide adenine dinucleotides determines the transition from reversible to irreversible ischemic damage of myocardial cells. Basic Res. Cardiol. 76, 612-621 (1981).

63. Reimer,K.A., Jennings,R.B. \& Hill,M.L. Total ischemia in dog hearts, in vitro 2. High energy phosphate depletion and associated defects in energy metabolism, cell volume regulation, and sarcolemmal integrity. Circ. Res. 49, 901-911 (1981).

64. Stringham,J.C., Southard,J.H., Anderson,G.M. \& Belzer,F.O. Mechanisms of ATP depletion in the cold-stored heart. Transplant. Proc 23, 2437-2438 (1991). 
65. Whitman,G. et al. The relationship between global myocardial ischemia, left ventricular function, myocardial redox state, and high energy phosphate profile. A phosphorous-31 nuclear magnetic resonance study. J. Surg. Res. 35, 332-339 (1983).

66. Gute,D.C., Ishida,T., Yarimizu,K. \& Korthuis,R.J. Inflammatory responses to ischemia and reperfusion in skeletal muscle. Mol. Cell Biochem. 179, 169-187 (1998).

67. Pirsch,J.D. ASTS Second Annual Winter Symposium 2002: Bench to Bedside, Ischemia and Reperfusion Injury in Clinical Transplantation. Medscape Transplantation 3, (2002).

68. Halliwell,B., Gutteridge,J.M. \& Cross,C.E. Free radicals, antioxidants, and human disease: where are we now? J. Lab Clin. Med. 119, 598-620 (1992).

69. Halliwell,B. \& Gutteridge,J.M. Biologically relevant metal ion-dependent hydroxyl radical generation. An update. FEBS Lett. 307, 108-112 (1992).

70. Halliwell,B., Clement,M.V., Ramalingam,J. \& Long,L.H. Hydrogen peroxide. Ubiquitous in cell culture and in vivo? IUBMB. Life 50, 251-257 (2000).

71. Halliwell,B., Clement,M.V. \& Long,L.H. Hydrogen peroxide in the human body. FEBS Lett. 486, 10-13 (2000).

72. Wink,D.A., Wink,C.B., Nims,R.W. \& Ford,P.C. Oxidizing intermediates generated in the Fenton reagent: kinetic arguments against the intermediacy of the hydroxyl radical. Environ. Health Perspect. 102 Suppl 3, 11-15 (1994).

73. Krishnaswamy,G. et al. The human mast cell: functions in physiology and disease. Front Biosci. 6, D1109-D1127 (2001).

74. Kvietys,P.R. \& Sandig,M. Neutrophil diapedesis: paracellular or transcellular? News Physiol Sci 16, 15-19 (2001).

75. Hammersen,F. The ultra structure of microvessels and their contents following ischemia on reperfusion. Prog Appl Microcirc 13, 1-26 (1989).

76. Blaisdell,F.W. The pathophysiology of skeletal muscle ischemia and the reperfusion syndrome: a review. Cardiovasc. Surg. 10, 620-630 (2002).

77. Steinau,H.U. Major limb replantation and post ischemia syndrome: Investigation of aute ischemia-induced myopathy and reperfusion injury. Springer Verlag, New York (1988). 
78. Hayes G, Liauw $S \&$ Romaschin AD. Separation of reperfusion injury from ischemia-induced necrosis. Surg Forum 39, 306-308 (1988).

79. Labbe,R., Lindsay,T. \& Walker,P.M. The extent and distribution of skeletal muscle necrosis after graded periods of complete ischemia. J. Vasc. Surg. 6, 152-157 (1987).

80. Wang,W.Z. et al. Lack of nitric oxide contributes to vasospasm during ischemia/reperfusion injury. Plast. Reconstr. Surg. 99, 1099-1108 (1997).

81. Wink,D.A. \& Mitchell,J.B. Chemical biology of nitric oxide: Insights into regulatory, cytotoxic, and cytoprotective mechanisms of nitric oxide. Free Radic. Biol. Med. 25, 434-456 (1998).

82. Grisham,M.B., Granger,D.N. \& Lefer,D.J. Modulation of leukocyteendothelial interactions by reactive metabolites of oxygen and nitrogen: relevance to ischemic heart disease. Free Radic. Biol. Med. 25, 404-433 (1998).

83. Guo,J.P., Murohara,T., Buerke,M., Scalia,R. \& Lefer,A.M. Direct measurement of nitric oxide release from vascular endothelial cells. $J$. Appl. Physiol 81, 774-779 (1996).

84. Lefer,A.M. \& Lefer,D.J. The role of nitric oxide and cell adhesion molecules on the microcirculation in ischaemia-reperfusion. Cardiovasc. Res. 32, 743-751 (1996).

85. Arakawa,A., Ishiguro,S., Ohki,K. \& Tamai,M. Preparation of liposomeencapsulating adenosine triphosphate. Tohoku J. Exp. Med. 184, 39-47 (1998).

86. Kugiyama,K. et al. Nitric oxide activity is deficient in spasm arteries of patients with coronary spastic angina. Circulation 94, 266-271 (1996).

87. Ma,X.L., Tsao,P.S., Viehman,G.E. \& Lefer,A.M. Neutrophil-mediated vasoconstriction and endothelial dysfunction in low-flow perfusionreperfused cat coronary artery. Circ. Res. 69, 95-106 (1991).

88. Ma,X.L., Weyrich,A.S., Lefer,D.J. \& Lefer,A.M. Diminished basal nitric oxide release after myocardial ischemia and reperfusion promotes neutrophil adherence to coronary endothelium. Circ. Res. 72, 403-412 (1993).

89. Gauthier,T.W., Davenpeck,K.L. \& Lefer,A.M. Nitric oxide attenuates leukocyte-endothelial interaction via P-selectin in splanchnic ischemiareperfusion. Am. J. Physiol 267, G562-G568 (1994). 
90. Kishimoto,T.K., Jutila,M.A., Berg,E.L. \& Butcher,E.C. Neutrophil Mac-1 and MEL-14 adhesion proteins inversely regulated by chemotactic factors. Science 245, 1238-1241 (1989).

91. Ceconi,C. et al. New insights on myocardial pyridine nucleotides and thiol redox state in ischemia and reperfusion damage. Cardiovasc. Res. 47, 586-594 (2000).

92. Peake,S.J., Venning,J.D. \& Jackson,J.B. A catalytically active complex formed from the recombinant dl protein of Rhodospirillum rubrum transhydrogenase, and the recombinant dIII protein of the human enzyme. Biochim. Biophys. Acta 1411, 159-169 (1999).

93. Freedman,J.A. \& Lemasters,J.J. Thermodynamics of reverse electron transfer across site 1: ATP/2e- is greater than one. Biochem. Biophys. Res. Commun. 125, 8-13 (1984).

94. Scholes,T.A. \& Hinkle,P.C. Energetics of ATP-driven reverse electron transfer from cytochrome $c$ to fumarate and from succinate to NAD in submitochondrial particles.PG -. Biochemistry 23, (1984).

95. Beatrice,M.C., Stiers,D.L. \& Pfeiffer,D.R. The role of glutathione in the retention of Ca2+ by liver mitochondria. J. Biol. Chem. 259, 1279-1287 (1984).

96. Kowaltowski,A.J., Castilho,R.F. \& Vercesi,A.E. Mitochondrial permeability transition and oxidative stress. FEBS Lett. 495, 12-15 (2001).

97. Lehninger,A.L., Vercesi,A. \& Bababunmi,E.A. Regulation of Ca2+ release from mitochondria by the oxidation-reduction state of pyridine nucleotides. Proc. Natl. Acad. Sci. U. S. A 75, 1690-1694 (1978).

98. Lemasters,J.J. et al. The mitochondrial permeability transition in cell death: a common mechanism in necrosis, apoptosis and autophagy. Biochim. Biophys. Acta 1366, 177-196 (1998).

99. Zoratti,M. \& Szabo,I. The mitochondrial permeability transition. Biochim. Biophys. Acta 1241, 139-176 (1995).

100. Lemeshko,V.V. Biphasic oxidation of mitochondrial NAD(P)H. Biochem. Biophys. Res. Commun. 291, 170-175 (2002).

101. Lotscher,H.R., Winterhalter,K.H., Carafoli,E. \& Richter,C. Hydroperoxides can modulate the redox state of pyridine nucleotides and the calcium balance in rat liver mitochondria. Proc. Natl. Acad. Sci. U. S. A 76, 43404344 (1979). 
102. Fedelesova,M., Ziegelhoffer,A., Krause,E.G. \& Wollenberger,A. Effect of exogenous adenosine triphosphate on the metabolic state of the excised hypothermic dog heart. Circ. Res. 24, 617-627 (1969).

103. Fremes,S.E., Zhang,J., Furukawa,R.D., Mickle,D.A. \& Weisel,R.D. Adenosine pretreatment for prolonged cardiac storage. An evaluation with St. Thomas' Hospital and University of Wisconsin solutions. J. Thorac. Cardiovasc. Surg. 110, 293-301 (1995).

104. Hirasawa, $\mathrm{H}$. et al. Effects of ATP-MgCl2 and ATP-Na2 administration on renal function and cellular metabolism following renal ischemia. Circ. Shock 16, 337-346 (1985).

105. McAllister,H.A., Jr. Histologic grading of cardiac allograft rejection: a quantitative approach. J. Heart Transplant. 9, 277-282 (1990).

106. Palombo,J.D. et al. Hepatic utilization of exogenous nucleotide precursors for restoration of ATP after cold ischemia in rats. Am. J. Clin. Nutr. 57, 420-427 (1993).

107. Siegel,N.J. et al. Enhanced recovery from acute renal failure by the postischemic infusin of adenine nucleotides and magnesium chloride in rats. Kidney Int. 17, 338-349 (1980).

108. Venkatachalam,M.A., Kreisberg,J.I., Stein,J.H. \& Lifschitz,M.D. Salvage of ischemic cells by impermeant solute and adenosinetriphosphate. Lab Invest 49, 1-3 (1983).

109. Geisbuhler,T. et al. Adenine nucleotide metabolism and compartmentalization in isolated adult rat heart cells. Circ. Res. 54, 536546 (1984).

110. Mayes,P.A. Harper's Biochemistry. Murray,R.K., Granner,D.K., Mayes,P.A. \& Rodwell,V.W. (eds.), pp. $93-99$ (Appleton \& Lange, Norwalk,1988).

111. Vogt,A.M. \& Kubler,W. Heart failure: is there an energy deficit contributing to contractile dysfunction? Basic Res. Cardiol. 93, 1-10 (1998).

112. Matsuzaki,T. et al. Aquaporins: a water channel family. Anat. Sci. Int. 77, 85-93 (2002).

113. Allen,T.M. Liposomes. Opportunities in drug delivery. Drugs $\mathbf{5 4}$ Suppl 4, 8-14 (1997).

114. Fraley,R., Straubinger,R.M., Rule,G., Springer,E.L. \& Papahadjopoulos,D. Liposome-mediated delivery of deoxyribonucleic acid to cells: enhanced 
efficiency of delivery related to lipid composition and incubation conditions. Biochemistry 20, 6978-6987 (1981).

115. Garrett,F.E., Goel,S., Yasul,J. \& Koch,R.A. Liposomes fuse with sperm cells and induce activation by delivery of impermeant agents. Biochim. Biophys. Acta 1417, 77-88 (1999).

116. Kozubek,A., Gubernator,J., Przeworska,E. \& Stasiuk,M. Liposomal drug delivery, a novel approach: PLARosomes. Acta Biochim. Pol. 47, 639-649 (2000).

117. Pagano,R.E. \& Weinstein,J.N. Interactions of liposomes with mammalian cells. Annu. Rev. Biophys. Bioeng. 7, 435-468 (1978).

118. Schiffelers,R., Storm,G. \& Bakker-Woudenberg,I. Liposome-encapsulated aminoglycosides in pre-clinical and clinical studies. J. Antimicrob.

Chemother. 48, 333-344 (2001).

119. Trigiante,G. \& Huestis,W.H. Selective virus-mediated intracellular delivery of membrane-impermeant compounds by means of plasma membrane vesicles. Antiviral Res. 45, 211-221 (2000).

120. Neveux,N., De Bandt,J.P., Chaumeil,J.C. \& Cynober,L. Hepatic preservation, liposomally entrapped adenosine triphosphate and nitric oxide production: a study of energy state and protein metabolism in the cold-stored rat liver. Scand. J. Gastroenterol. 37, 1057-1063 (2002).

121. Chapat,S. et al. Efficiency of liposomal ATP in cerebral ischemia: bioavailability features. Brain Res. Bull. 26, 339-342 (1991).

122. Han,Y.Y. et al. Liposomal atp or NAD+ protects human endothelial cells from energy failure in a cell culture model of sepsis. Res. Commun. Mol. Pathol. Pharmacol. 110, 107-116 (2001).

123. Verma,D.D., Hartner,W.C., Levchenko,T.S., Bernstein,E.A. \& Torchilin,V.P. ATP-loaded liposomes effectively protect the myocardium in rabbits with an acute experimental myocardial infarction. Pharm. Res. 22, 2115-2120 (2005).

124. Verma,D.D., Levchenko,T.S., Bernstein,E.A., Mongayt,D. \& Torchilin,V.P. ATP-loaded immunoliposomes specific for cardiac myosin provide improved protection of the mechanical functions of myocardium from global ischemia in an isolated rat heart model. J. Drug Target 14, 273-280 (2006).

125. Verma,D.D., Levchenko,T.S., Bernstein,E.A. \& Torchilin,V.P. ATP-loaded liposomes effectively protect mechanical functions of the myocardium from 
global ischemia in an isolated rat heart model. J. Control Release 108, 460-471 (2005).

126. Konno,H., Matin,A.F., Maruo,Y., Nakamura,S. \& Baba,S. Liposomal ATP protects the liver from injury during shock. Eur. Surg. Res. 28, 140-145 (1996).

127. Neveux,N. et al. Cold preservation injury in rat liver: effect of liposomallyentrapped adenosine triphosphate. Journal of Hepatology 33, 68-75 (2000).

128. Puisieux,F. et al. Liposomes, an interesting tool to deliver a bioenergetic substrate (ATP). in vitro and in vivo studies. J. Drug Target 2, 443-448 (1994).

129. Xu,G.X. et al. Adenosine triphosphate liposomes: encapsulation and distribution studies. Pharm. Res. 7, 553-557 (1990).

130. Ehringer,W., Belcher,D., Wassall,S.R. \& Stillwell,W. A comparison of the effects of linolenic (18:3 omega 3 ) and docosahexaenoic (22:6 omega 3 ) acids on phospholipid bilayers. Chem. Phys. Lipids 54, 79-88 (1990).

131. Caldwell-Kenkel,J.C., Thurman,R.G. \& Lemasters,J.J. Selective loss of nonparenchymal cell viability after cold ischemic storage of rat livers. Transplantation 45, 834-837 (1988).

132. McKeown,C.M. et al. Sinusoidal lining cell damage: the critical injury in cold preservation of liver allografts in the rat. Transplantation 46, 178-191 (1988).

133. Otto,G., Wolff,H. \& David,H. Preservation damage in liver transplantation: electron-microscopic findings. Transplant. Proc. 16, 1247-1248 (1984).

134. Montero,M.T., Carrera,I. \& Hernandez-Borrell,J. Encapsulation of a quinolone in liposomes. Location and effect on lipid bilayers. $J$. Microencapsul. 11, 423-430 (1994).

135. Sezer,A.D., Bas,A.L. \& Akbuga,J. Encapsulation of enrofloxacin in liposomes I: preparation and in vitro characterization of LUV. J. Liposome Res. 14, 77-86 (2004).

136. McKenna,M.J., Gissel,H. \& Clausen,T. Effects of electrical stimulation and insulin on $\mathrm{Na}+-\mathrm{K}+-A T P a s e([3 \mathrm{H}]$ ouabain binding) in rat skeletal muscle. $J$. Physiol 547, 567-580 (2003).

137. Kawai,N., McCarron,R.M. \& Spatz,M. Effect of hypoxia on $\mathrm{Na}(+)-\mathrm{K}(+)-\mathrm{Cl}-$ cotransport in cultured brain capillary endothelial cells of the rat. $J$. Neurochem. 66, 2572-2579 (1996). 
138. Ballantyne,B. \& Marrs,T.C. Clinical and experimental toxicology of cyanides. Wright, Bristol (1987).

139. Baud,F.J., Borron,S.W., Bavoux,E., Astier,A. \& Hoffman,J.R. Relation between plasma lactate and blood cyanide concentrations in acute cyanide poisoning. BMJ 312, 26-27 (1996).

140. Mercado,C.L., Loeb,J.N. \& Ismail-Beigi,F. Enhanced glucose transport in response to inhibition of respiration in Clone 9 cells. Am. J. Physiol 257, C19-C28 (1989).

141. Seal,J.B. \& Gewertz,B.L. Vascular dysfunction in ischemia-reperfusion injury. Ann. Vasc. Surg 19, 572-584 (2005).

142. Nishimura,Y., Romer,L.H. \& Lemasters,J.J. Mitochondrial dysfunction and cytoskeletal disruption during chemical hypoxia to cultured rat hepatic sinusoidal endothelial cells: the $\mathrm{pH}$ paradox and cytoprotection by glucose, acidotic pH, and glycine. Hepatology 27, 1039-1049 (1998).

143. Leemreis,J.R., Versteilen,A.M., Sipkema,P., Groeneveld,A.B. \& Musters,R.J. Digital image analysis of cytoskeletal F-actin disintegration in renal microvascular endothelium following ischemia/reperfusion. Cytometry A 69, 973-978 (2006).

144. Sutton,T.A. et al. Injury of the renal microvascular endothelium alters barrier function after ischemia. Am. J. Physiol Renal Physiol 285, F191F198 (2003).

145. Hinshaw,D.B. et al. ATP depletion induces an increase in the assembly of a labile pool of polymerized actin in endothelial cells. Am. J. Physiol 264, C1171-C1179 (1993).

146. Kuhne,W. et al. Disintegration of cytoskeletal structure of actin filaments in energy-depleted endothelial cells. Am. J. Physiol 264, H1599-H1608 (1993).

147. Carini,R., Autelli,R., Bellomo,G., Dianzani,M.U. \& Albano,E. Sodiummediated cell swelling is associated with irreversible damage in isolated hepatocytes exposed to hypoxia or mitochondrial toxins. Biochem. Biophys. Res. Commun. 206, 180-185 (1995).

148. Carini,R. et al. Alteration of $\mathrm{Na}$ + homeostasis as a critical step in the development of irreversible hepatocyte injury after adenosine triphosphate depletion. Hepatology 21, 1089-1098 (1995).

149. Allen,D.M., Chen,L.E., Seaber,A.V. \& Urbaniak,J.R. Pathophysiology and related studies of the no reflow phenomenon in skeletal muscle. Clin. Orthop. Relat Res. 122-133 (1995). 
150. Poole-Wilson,P.A., Harding,D.P., Bourdillon,P.D. \& Tones,M.A. Calcium out of control. J. Mol. Cell Cardiol. 16, 175-187 (1984).

151. Granger,D.N. Role of xanthine oxidase and granulocytes in ischemiareperfusion injury. Am. J. Physiol 255, H1269-H1275 (1988).

152. Boros,M., Bako,L. \& Nagy,S. Effect of antioxidant therapy on cyclooxygenase-derived eicosanoid release during intestinal ischemiareperfusion. Eur. Surg Res. 23, 141-150 (1991).

153. Sapega,A.A. et al. The bioenergetics of preservation of limbs before replantation. The rationale for intermediate hypothermia. J. Bone Joint Surg Am. 70, 1500-1513 (1988).

154. Usui,M., Ishii,S., Muramatsu,I. \& Takahata,N. An experimental study on "replantation toxemia". The effect of hypothermia on an amputated limb. $J$. Hand Surg [Am. ] 3, 589-596 (1978).

155. KIEHN,C.L. \& DESPREZ,J.D. Effects of local hypothermia on pedicle flap tissue. I. Enhancement of survival of experimental pedicles. Plast. Reconstr. Surg 25, 349-359 (1960).

156. Mowlavi,A. et al. Local hypothermia during early reperfusion protects skeletal muscle from ischemia-reperfusion injury. Plast. Reconstr. Surg 111, 242-250 (2003).

157. Wagh,M. et al. Cold storage of rat skeletal muscle free flaps and preischemic perfusion with modified UW solution. Microsurgery 20, 343-349 (2000).

158. Bschorer,R., Blake,F. \& Lisboa,B. Free flap transfer and the prevention of endothelial damage. Mund Kiefer Gesichtschir. 1, 235-238 (1997).

159. Barker,J.H., Francois,C.G., Frank,J.M. \& Maldonado,C. Composite tissue allotransplantation. Transplantation 73, 832-835 (2002).

160. Francois,C.G. et al. Hand transplantation: comparisons and observations of the first four clinical cases. Microsurgery 20, 360-371 (2000).

161. Grace PA \& Mathie RT. Ischemia-reperfusion Injury. Blackwell Science Ltd, Oxford (1999).

162. Aeba, R. et al. Lazaroid U74500A as an additive to University of Wisconsin solution for pulmonary grafts in the rat transplant model. J. Thorac.

Cardiovasc. Surg 104, 1333-1339 (1992).

163. Gu,X.P., Xu,F.T., Jiang,Y., Qiu,Y.D. \& Ding,Y.T. Pyrrolidine dithiocarbamate added to University of Wisconsin solution inhibits 
reperfusion injury after orthotopic liver transplantation in rats. Ann. Clin. Lab Sci. 34, 187-194 (2004).

164. Rose,S., Maier,B., Frank,J. \& Marzi,I. Neutrophil responses to replantation of large extremities. European journal of Trauma 29, 284-291 (2003).

165. Nishikawa,H., Manek,S., Barnett,S.S., Charlett,A. \& Green,C.J. Pathology of warm ischaemia and reperfusion injury in adipomusculocutaneous flaps. Int. J. Exp. Pathol. 74, 35-44 (1993). 


\section{CURRICULUM VITAE}

\section{FEDERICO V GROSSI, MD, MS}

\section{PERSONAL DATA}

Date of Birth:

June 13, 1974.

Place of Birth:

Villa del Rosario, Córdoba, Argentina.

Address:

10139 Spring Gate Dr, Louisville, KY 40241

Telephone: (502)291-6376

Email:

federicogrossi@hotmail.com

\section{EDUCATION}

2003-Present

Ph.D. (Candidate) in Physiology and Biophysics under the supervision of Dr. Gary Anderson at the University of Louisville.

2002-2004

M.S. in Physiology and Biophysics under the supervision of Dr. Gary Anderson at the University of Louisville.

1994-2000

M.D. obtained at the Universidad Nacional de Córdoba, Argentina. The school of medicine's 6-year study program consists of 3 years of Basic non-clinical studies and 3 years of clinical studies and hospital practice. 


\section{POSTGRADUATE EDUCATION}

2002-2004 Research Fellow, working under the supervision of Dr John H. Barker at the Division of Plastic \& Reconstructive Surgery, Department of Surgery, University of Louisville, Louisville, Kentucky, USA.

\section{POSITIONS AND HONORS}

2006-Current Clinical Research Director, Potentia Pharmaceuticals Inc., Louisville, KY.

2006

Research Associate Senior, Potentia Pharmaceuticals Inc., Louisville, KY.

2004-2006

Research Associate Senior, Department of Physiology, University of Louisville, KY.

2004-2005 Co-founder and Vice President of Research, EndoProtech Inc., Louisville, KY

2002-2004 Plastic Surgery Research Fellow, Department of Surgery, University of Louisville, $\mathrm{KY}$

\section{ACADEMIC APPOINTMENTS}

2004-Present Research Associate Senior, Department of Physiology and Biophysics, University of Louisville, Louisville, KY, USA. 


\section{RESEARCH EXPERIENCE}

2004-Present "Development of new treatments for age-related macular degeneration". Departments of Physiology and Biophysics, and Ophthalmology, University of Louisville, and Potentia Pharmaceuticals. Louisville, KY.

2004-Present "Development of ophthalmologic-drugs slow-release delivery systems". Departments of Physiology and Biophysics, and Ophthalmology, University of Louisville, and Potentia Pharmaceuticals. Louisville, KY.

2004- 2006 "New Anti-complement Therapy to Reduce Reperfusion Injury". Departments of Surgery, and Physiology and Biophysics, University of Louisville and EndoProtech. Inc., Louisville, KY.

2002-2005 "Risk Acceptance in composite tissue allotransplantation reconstructive procedures". Divisions of Plastic \& Reconstructive Surgery, University of Louisville, Louisville, KY.

2002-2005 "Development of a Direct Cellular Energy Delivery System." Departments of Surgery, and Physiology \& Biophysics, University of Louisville, Louisville, KY.

2002-2004 "Limb allotransplantation without immunosuppression". Departments of Surgery, and Physiology \& Biophysics, University of Louisville, Louisville, KY.

2002-2003 "Effect of the late window of ischemic preconditioning on postischemic function of skeletal muscle". Divisions of Plastic \& 
Reconstructive Surgery, University of Louisville, Louisville, KY.

2002

"Intensive Basic training in the Microsurgical techniques".

University of Louisville Microsurgery Teaching Laboratory.

Divisions of Plastic \& Reconstructive Surgery, University of Louisville, Louisville, KY.

2002

"Use of Chimerism Induce Tolerance for Composite Tissue Allotransplantation". Divisions of Plastic \& Reconstructive Surgery, and Institute for Cellular Therapeutics, University of Louisville, Louisville, KY.

\section{ACADEMIC AND PROFESSIONAL HONORS}

$20034^{\text {th }}$ Annual MD3 Conference, Louisville KY

Second Place Award

"Development of a Direct Cellular Energy Delivery System"

L Laurentin-Perez, WD Ehringer, C Maldonado, G Anderson, B Chiang, C Francois, G Perez-Abadia, F Grossi, and S Chien.

2003 Research! Louisville, Jewish Hospital Foundation. Louisville, KY. Nov 3-7. First Place: Most Promising Basic Science Research First Place: Potential for Major Clinical Applications "Accelerated wound healing using a newly developed adenosine triphosphate (ATP) delivery system."

W.D. Ehringer, C. Thomas, E. Essick, F.V. Grossi, G. Perez-Abadia, C. Maldonado, S. Chien.

2003 Research! Louisville, Jewish Hospital Foundation. Louisville, KY. Nov 3-7. Graduate Student Division: Honorable Mention 
"Non-hypothermic preservation of composite tissue grafts using a novel direct intracellular ATP delivery system"

F. V. Grossi, G. Perez-Abadia, C. Francois, W.D. Ehringer, G. Anderson, L. Laurentin-Perez, S. Chien, C. Maldonado.

2002 Research! Louisville, Jewish Hospital Foundation. Louisville, KY. Oct 28Nov 1.

Second Place: Scientific Importance

Second Place: Innovation in Biotechnology

"Development of a Direct Cellular Energy Delivery System."

WD Ehringer, C Maldonado, G Anderson, B Chiang, C Francois, G PerezAbadia, L Laurentin-Perez, F Grossi, and S Chien.

\section{MEETING PRESENTATIONS}

2007 Complement Inhibition: A New Therapeutic Approach to Macular Degeneration. Presented at the $9^{\text {th }}$ Michaelson Symposium, The Johns Hopkins University School of Medicine, Baltimore, MD. May 2-4, 2007.

\section{MEETING ABSTRACTS}

2006 Differential expression of inflammatory cytokines and chemokines genes by homocysteine in the human retinal pigmented epithelial cells. Singh M, Olson P, Grossi F, Zhang ZM, Tyagi N, Mosha KS, Tyagi SC. FASEB JOURNAL 20 (4): A719-A719 Part 1, MAR 6 2006. Presented at Experimental Biology, Washington D.C. April 2006.

2004 Non-hypothermic preservation of composite tissue grafts using a novel direct intracellular ATP delivery system". F.V. Grossi, G. Perez-Abadia, C. Francois, W.D. Ehringer, G. Anderson, L. Laurentin-Perez, S. Chien, C. 
Maldonado. Presented at the Research! Louisville. Jewish Hospital Foundation, Louisville, KY, Nov 3-7, 2003.

2004 Non-hypothermic preservation of composite tissue grafts using a novel direct intracellular ATP delivery system". F.V. Grossi, G. Perez-Abadia, C. Francois, W.D. Ehringer, G. Anderson, L. Laurentin-Perez, S. Chien, C. Maldonado. Presented at the Research! Louisville. Jewish Hospital Foundation, Louisville, KY, Nov 3-7, 2003.

2004 Accelerated wound healing using a newly developed adenosine triphosphate (ATP) delivery system. Ehringer WD, Thomas C, Essick E, Grossi F, Chien S. Biophysical Journal 86 (1): 518A-518A Part 2 Suppl. S, Jan 2004. Presented at the Annual Biophysical Society Meeting, Baltimore, February 2004.

2004 Direct delivery of ATP to skeltal muscle to combat hypoxia. Keith RJ, Grossi F, Chiang B, Su S, Maldonado C, Ehringer W. FASEB Journal 18 (4): A569-A570 Suppl. S, MAR 23 2004. Presented at Experimental Biology, Washington D.C. April 2004.

2004 Use of direct energy delivery system to accelerate wound healing. Thomas CM, Essick E, Grossi FV, Abadia-Perez G, Wolfe D, Chiang B, Rose B, Keith R, Su S, Ehringer WD FASEB Journal 18 (5): A941-A941 Suppl. S, Mar 242004 Presented at Experimental Biology, Washington D.C. April 2004.

2004 Hemodynamic effects of exogenous ATP delivery. Wolfe D, Grossi F, Perez G, Ehringer W.FASEB Journal 18 (5): A1279-A1279 Suppl. S, Mar 24 2004. Presented at Experimental Biology, Washington D.C. April 2004.

2003 Development of a Direct Cellular Energy Delivery System". L LaurentinPerez, WD Ehringer, C Maldonado, G Anderson, B Chiang, C Francois, G 
Perez-Abadia, F Grossi, and S Chien. Presented at the $4^{\text {th }}$ Annual MD3 Conference, Louisville, Oct 30, 2003.

2003 Accelerated wound healing using a newly developed adenosine triphosphate (ATP) delivery system". W.D. Ehringer, C. Thomas, E. Essick, F.V. Grossi, G. Perez-Abadia, C. Maldonado, S. Chien. Presented at the Research! Louisville. Jewish Hospital Foundation, Louisville, KY, Nov 37, 2003.

2002 Development of a Direct Cellular Energy Delivery System. WD Ehringer, C Maldonado, G Anderson, B Chiang, C Francois, G Perez-Abadia, L Laurentin-Perez, F Grossi, and S Chien. Presented at the Research! Louisville. Jewish Hospital Foundation, Louisville, KY, Oct 30, 2002

\section{PEER-REVIEWED PUBLICATIONS}

1. Barker JH, Furr A, Cunningham M, Grossi F, Vasilic D, Storey B, Wiggins O, Majzoub R, Vossen M, Brouha P, Maldonado C, Reynolds CC, Francois C, Perez-Abadia G, Frank JM, Kon M, Banis JC Jr. Investigation of risk acceptance in facial transplantation. Plast Reconstr Surg. 2006 Sep;118(3):66370 .

2. Cottrell BL, Perez-Abadia G, Onifer SM, Magnuson DS, Burke DA, Grossi FV, Francois CG, Barker JH, Maldonado C.: Neurodegeneration in Composite Tissue Allografts: Effect of Low Dose FK506 and Mycophenolate Maofetil Immunotherapy. Plast Reconstr Surg. 2006 Sep;118(3):615-23; discussion 624-5

3. Francois CG, Brouha PC, Laurentin-Perez LA, Perez-Abadia G, Grossi FV, Barker JH, Hewitt CW, Kon M, Ramsamooj R, Maldonado C.Vascularized lymph node transplantation induces graft-versus-host disease in chimeric hosts. Transplantation. 2006 May 27;81(10):1435-41. 
4. Brouha P, Naidu D, Cunningham M, Furr A, Majzoub R, Grossi FV, Francois CG, Maldonado C, Banis JC, Martinez S, Perez-Abadia G, Wiggins O, Kon M, Barker JH.. Risk Acceptance in Composite Tissue Allotransplantation reconstructive procedures. Microsurgery. 2006;26(3):144-9; discussion 149-50.

5. Majzoub RK, Cunningham M, Grossi F, Maldonado C, Banis JC, Barker JH. Investigation of Risk Acceptance in hand transplantation. J Hand Surg [Am]. 2006 Feb;31(2):295-302.

6. Thomas Harralson, M.S.; Federico V. Grossi, M.D.; Edwin E. Quan, M.D.; Taskin Tecimer, M.D.; Gustavo Perez-Abadia, M.D.; Gary Anderson, Ph.D.; John H. Barker, M.D., Ph.D., Claudio Maldonado, Ph.D.: Ischemic Preconditioning of Skeletal Muscle: Duration of Late-Phase Protection. $\underline{\text { Ann }}$ Plast Surg. 2005 Aug;55(2):216-222.

7. Cunningham M, Majzoub R, Brouha PCR, Laurentin-Perez LA, Naidu D, Maldonado C, Banis JC, Grossi F, Frank JM, Barker JH. Risk Acceptance in composite tissue allotransplantation reconstructive procedures: Instrument design and validation. European Journal of Trauma 2004, 30:12-6.

8. Quan EE, Ramirez S, Tecimer T, Grossi FV, Barker JH, Maldonado C. Late phase ischemic preconditioning in skeletal muscle: Is the phenomenon protective? Microsurgery 2004, 24 (2): 151-156.

9. Wiggins OP, Barker JH, Martinez S, Vossen M, Maldonado C, Grossi FV, Francois CG, Cunningham M, Perez-Abadia G, Kon M, Banis JC. On the ethics of facial transplantation research. American Journal Of Bioethics 2004, 4 (3): $1-12$.

10. Banis JC, Barker JH, Cunningham M, Francois CG, Furr A, Grossi F, Kon M, Maldonado C, Martinez S, Perez-Abadia G, Vossen M, Wiggins OP Response to selected commentaries on the AJOB target article "on the ethics of facial transplantation research. American Journal Of Bioethics 2004, 4 (3): W23-W31 


\section{FUNDING HISTORY}

2005 National Institute of Health

STTR Phase I. “New Anti-complement Therapy to Reduce Reperfusion Injury"

Principal Investigator: C Maldonado, PhD

Co-Investigators: GA Perez-Abadia, MD, FV Grossi, MD

Period of award: 2005-2006. Amount $\$ \underline{122,978}$

2005 Kentucky Science and Technology Corporation

R\&D Voucher. Project: "Anti-complement therapies in transplantation"

Principal Investigator: C Maldonado, $\mathrm{PhD}$

Co-Investigators: FV Grossi, MD, MS; GA Perez-Abadia, MD

Period of award: 2006-2008. Amount $\$ 200,000$ 